The Place of Play

Toys and Digital

Cultures
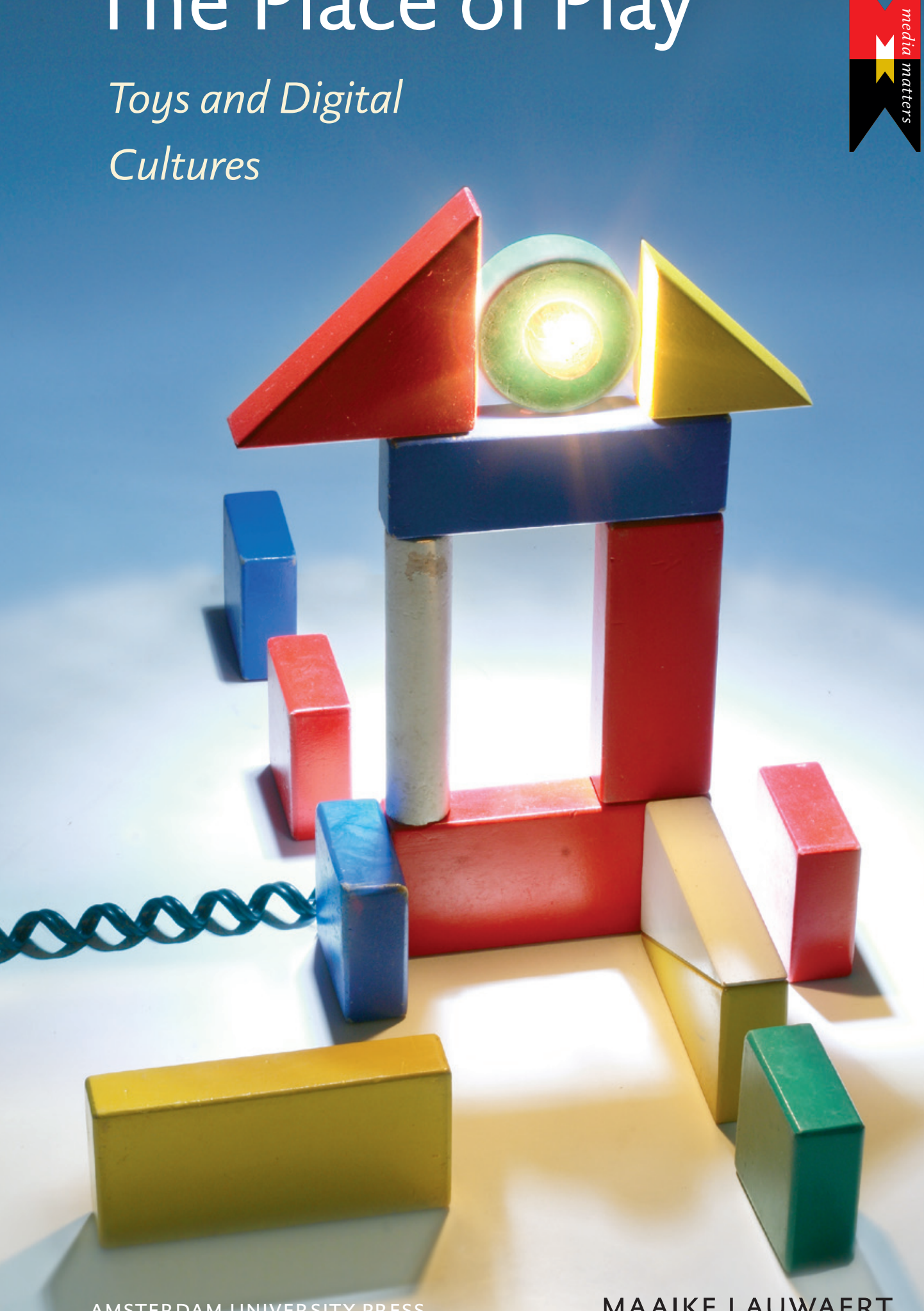
The Place of Play 



\section{The Place of Play \\ Toys and Digital Cultures}

Maaike Lauwaert 
MediaMatters is a new series published by Amsterdam University Press on current debates about media technology and practices. International scholars critically analyze and theorize the materiality and performativity, as well as spatial practices of screen media in contributions that engage with today's digital media culture. For more information about the series, please visit: www.aup.nl

The publication of this book is made possible by a grant from the Netherlands Organisation for Scientific Research (NWO).

Cover illustration: Goos Bronkhorst

Cover design: Suzan de Beijer, Weesp

Lay out: JAPES, Amsterdam

ISBN $\quad 9789089640802$

e-ISBN $\quad 9789048507962$

NUR $\quad 8 I$

(c) M. Lauwaert / Amsterdam University Press, Amsterdam, 2009

All rights reserved. Without limiting the rights under copyright reserved above, no part of this book may be reproduced, stored in or introduced into a retrieval system, or transmitted, in any form or by any means (electronic, mechanical, photocopying, recording or otherwise) without the written permission of both the copyright owner and the author of the book. 


\section{Table of contents}

\section{Introduction}

I. Changing Practices, Shifting Sites 7

2. Core and Periphery of Play 12

Part I: New Children, Different Toys 21

3. The Child as Consumer 26

4. Domesticating Play 30

5. The Child in the City 35

6. Toys as Containers, Mediators and Promoters 39

Part II: From Solitary to Networked Geographies of Play 45

7. LEGO Toys: from Wooden Blocks to Plastic Bricks 50

8. Brand Extension \& Product Differentiation 58

9. Bringing the Fans into the Company 62

Io. Many-to-Many Geographies of Play 66

Part III: Commercial Geographies of Play ו

II. Toy Towns and Simulated Cities 73

I2. A 2Ist-century Dollhouse: The Sims 83

13. Unwanted Play Practices in The Sims Online 94

I4. Commodified Geographies of Play 103

$\begin{array}{ll}\text { Part IV: Serious Geographies of Play } & 107\end{array}$

15. Participation Tools 111

I6. Participation Processes 119

I7. Purposeful Play 122

I8. Serious Geographies of Play 124

$\begin{array}{ll}\text { Conclusion } & 127\end{array}$

19. Changing Geographies of Play 127

20. Making Do 132

$\begin{array}{ll}\text { Notes } & 137\end{array}$

Bibliography 139

$\begin{array}{ll}\text { Index } & 153\end{array}$ 



\section{Introduction}

\section{Changing Practices, Shifting Sites}

Daniel Siskind (1970) received his first LEGOTM set in I975. His parents had brought it with them from a trip to Europe. Ever since, he has been 'hooked on playing with Lego building bricks' (Siskind, personal website). In 2000, Siskind started his personal website to sell his MOC (My Own Creation) LEGO sets. Siskind's favorite themes for MOC sets are castles, trains and war paraphernalia. Siskind ships his MOC sets in a box with a printed picture of the design on it, like a real set. A manual with building instructions accompanies the LEGO pieces. His Blacksmith Shop, designed in 1999, contained 637 pieces and sold for \$150. Some of the pieces for the Blacksmith Shop were taken out of production by LEGO and were thus hard to come by. All MOC sets are relatively expensive definitely more expensive than official LEGO sets - because designing and assembling the sets is a time consuming process and the seller has, of course, to buy all the items for the set him- or herself. Someone from the LEGO Direct division, who later approached Siskind with a licensing proposal, bought the Blacksmith Shop in 2000. Siskind agreed to the licensing proposal and sold his rights of the design to the LEGO Company for an undisclosed amount. By the end of $200 \mathrm{r}$ the set was on sale as an official LEGO set (item \#3739) for \$39.99 containing 622 pieces. Some minor changes were made to Siskind's design, both to the exterior and interior of the shop. The out-of-use bricks Siskind originally integrated in his design were not part of the official set. The set is at this time no longer on sale on the official LEGO website.

When the Blacksmith Shop was launched by the LEGO Company in 200I, it was promoted as the first in what was to become a series of official LEGO MOC sets. On the LEGO website news section, it read: 'The Master Builders search for designs that they like in places like personal home pages, Brickshelf, at LEGOrelated events, and - you guessed it! - in the LEGO Club!' (LEGO, Brick Street Journal). However, no second MOC set was released as an official LEGO set. So far, Siskind was thus granted a unique honor: to see his personal creation be turned into an official, commercial LEGO set. Most of the Lugnet (LEGO Users Group Network) users, an international group of LEGO fans, were overjoyed with Siskind's success, and they expressed hope that this move by the LEGO Company signaled a turn of events in their policy towards active LEGO users.

Although no second MOC set was released as an official LEGO set after the Blacksmith Shop, the LEGO Company increasingly cooperates with dedicated LEGO fans. Jake McKee from LEGO Community Development works hard to con- 
nect his LEGO colleagues with LEGO fans and thus 'bring the fans into the company' (McKee, 2005). The recently launched LEGO Factory - which includes both a digital design tool and an exchange platform - is exactly about this effort to bring LEGO fans into the company (LEGO Factory). In LEGO Factory, fans can design their own sets with the free software, share their designs with other fans and buy any of these custom sets directly from LEGO. The official LEGO online store sells some of these Factory custom sets created by Adult Fans of LEGO or AFOLs (LEGO, Factory Exclusives). LEGO Factory signals a change in how the LEGO Company puts so-called User-Generated Content (often abbreviated as UGC) to use. Instead of having headhunters browse user sites and visit LEGO events, everyone can now add their creations to the LEGO Factory Gallery.

Bringing the fans into the company marks a wider shift noticeable in many layers of society and culture, a shift based on the early philosophy of the Internet: the many-to-many approach rather than the one-to-many approach. As media theorists Jenkins and Thorburn write: 'Networked computing operates according to principles fundamentally different from those of broadcast media: access, participation, reciprocity, and many-to-many rather than one-to-many communication' (2003, p. 2). Instead of having LEGO designers work in secrecy behind closed doors on new LEGO sets, the LEGO Company will invite the fans, the users to 'sit at the table' with the designers and work together on future LEGO sets.

The many-to-many model originally stems from specific ways in which the Internet can be put to use and from certain software applications. In the one-to-one Internet paradigm, users communicate through e-mail or FTP (file transfer protocol) with one another on an individual basis. Websites have added to this the display of information for many visitors to access: what one could call a one-to-many paradigm. Technological innovations and new Internet applications such as file sharing (through $\mathrm{P}_{2} \mathrm{P}$ or peer-to-peer networks), blogging (maintaining a personal website that documents or comments), tagging (adding comments on blogs or websites) and Wiki sites (to which anyone who is registered can add information, make changes or create new entries) have created a situation that is referred to as 'participatory culture', 'many-to-many culture' or the 'Web 2.0 revolution'. Many a software application nowadays incorporates sharing and publishing options that encourage the social and participatory use of this software. The term 'prosumers' is often used to indicate the shift in the many-to-many culture towards consumers becoming producers of media content.

Increasingly, technology is at stake in toys, games and playing. With the immense popularity of computer games, questions concerning the role and function of technology in play have become more pressing. ${ }^{\text {I }}$ A key aspect of the increasing technologization and digitalization of both toys and play is the vagueness of borders between producers, consumers and players. In these so-called participatory cultures characterized by a many-to-many model, players do not play with a toy designed behind closed doors but become co-designers of their own toys. With 
this many-to-many approach, not only money is fed back into the circuit of capital that moves from production to commodity to consumption and back to production, but also the voluntary, unpaid labor of devoted fans. This tightens the bond between company, commodity and consumer considerably.

Participatory cultures are often hailed as a democratizing force, the ultimate means of consumer or user empowerment. After all, one can now take on a more active role as consumer or user, be it as designer or co-designer of new products or product updates, as reviewer of consumer goods or as an expert helping out other users. These many-to-many or participatory options embody the promise that a more actively engaged relationship with traditionally remote processes is now possible, if not the actual democratization of certain consumerist processes. These changes are, needless to say, not restricted to consumerist processes but spread out into the domains of politics, knowledge creation and knowledge dissemination. Mainly through the 'free' online activity of blogging, the political landscape as well as political processes are influenced by and need to take into account 'political bloggers' (Lovink, 2008). Politicians are expected by voters to maintain a personal blog to voice their political ideas and keep in touch with them. The free, user-generated encyclopedia Wikipedia characterizes a change in the production of knowledge from experts to end-users (Tapscott \& Williams, 2007). With Wikipedia knowledge now being included in official dictionaries, users seem to have more influence on knowledge production. This shift from the domination of expert knowledge and content to end-user knowledge and content is appreciated by some and condemned by others. According to critic Andrew Keen, due to the celebration of the amateur over the expert, quality loses terrain to quantity, to the number of viewing times, to popularity and the 'politics' of search engines that rank number of hits above reliability of information (2007). On the other side of the spectrum are writers like Henry Jenkins who celebrate the advent of participatory cultures in terms of the democratization of content generation and the empowerment of consumers (1992; 2006a; 2006b).

Significantly, participatory cultures are less utopian and egalitarian than the many-to-many term suggests. People have to have a computer, Internet access and technological skills to enter this many-to-many paradigm. Also, many social networks have evolved from open, accessible and egalitarian platforms towards so-called 'walled gardens' that exclude as much as they include, that allow only those in the possession of a user name and password to enter, that keep your personal data locked inside within these walls. Besides problems of access, there are also technological aspects of new media that pose serious questions about the democratic or empowering potential of these participatory cultures, such as the black-box nature of many computer-related processes and the fact that users are expected to participate according to scripted lines. While most Lugnet users were happy about Siskind's success, others worried whether making MOC sets official is not a shrewd way to control the fans (Lugnet, Blacksmith Shop). This points 
towards a crucial characteristic of the commercialization of the many-to-many model: the fame and glory of having your creation made official inevitably entail a certain degree of control by the companies over the users. The LEGO Factory is then not only a creative tool, it also provides the LEGO Company with a digital database of user creations and thus with invaluable information about their most active fans. Rightfully, fans wonder what the effects are of this commodified many-to-many model on toys and playing.

Outside of specific Internet uses and applications that signal such a change from one-to-one to one-to-many to many-to-many, the dynamics of the many-tomany model and especially the bond it can create between traditionally remote stakeholders have been experimented with by diverse and wide-ranging industries. Participatory cultures are rapidly expanding and incorporate ever more areas and domains of Western society and culture. In these participatory cultures, consumers of media content are also the producers of this very content. From policymakers to politicians, from artists to architects, the attraction of the many-tomany approach has resulted in an almost ubiquitous user-involvement. People can call in on radio shows, email television stations and have their opinions read on the news within the same hour. Movie directors consult fan communities when considering turning, for example, the Lord of the Rings trilogy into a movie. Politicians add to their blogs on a daily basis and 'directly' communicate through these sites with their voters. The booksellers website Amazon publishes readerwritten reviews rather than reviews written by paid experts. Publisher Penguin launched the Penguin Wiki project A Million Penguins in 2007, inviting readers to become writers of a collective novel. This 'crowdsourcing' was an experiment into the 'open source' movement (PenguinWiki, 2007). Cosmetics firm Dove motivated its users to create their own Dove publicity campaigns for the Cream Oil Body Wash (Brandweek.com, 2006). Mainly female Dove users answered the call and sent in their own pictures and movies promoting the new Dove product. Such user-driven marketing and advertising are on the increase.

In 2006 the Time Magazine Person of the Year was not someone special, like Mahatma Gandhi in 1930 or Martin Luther King, Jr. in 1963, but 'You!'. The cover of Time was not adorned with the face of the person elected that year but with a little mirror in which the buyer saw him- or herself reflected. 'We' were collectively chosen person of the year because the year ' 2006 was about community and collaboration on a scale never seen before' (Grossman, 2006, p. 28). The tagline of the cover read: 'Yes, you. You control the Information Age. Welcome to your world' (ibid.). Others questioned this and asked 'Me? (...) but isn't it really about them?' (Lim, 2006). Such comments rightfully point out the tension between what is hyped as 'our world' and the ways in which industries increasingly tap into and benefit from user-generated content.

The ways in which and the means by which users become producers of media content are multiplying, and the torrent of user-generated content seems unstop- 
pable. Participatory cultures are sustained and facilitated by new media technologies, often labeled 'social media' or 'social technologies', that encourage social uses through the embedded options for the online publishing and sharing of user-generated content and knowledge. Increasingly, users are involved in the design of new products, after-sales support and marketing. These so-called 'prosumers' are no longer 'passive consumers' of commodities but 'active co-producers'. The popularity of the many-to-many phenomenon has reached an unprecedented height; these examples of Penguin, Dove and LEGO toys are only a snippet of a phenomenon in which companies consciously blur the lines between consumer and producer to try and bring fans into the company, invite consumers to be not simply consumers but active residents in a brand's world. Admittedly, many of these exercises in the many-to-many culture are watered-down versions of what the term might literally refer to (by us and for us), or they are blatant forms of self-aggrandizement.

The attractions of this many-to-many model for the companies, industries and organizations tapping into it are manifold. Using and relying on many-to-many mechanisms are partly determined by the wish to establish a faithful relationship between, for example, brand and consumer, politician and voter, city council and citizen. For these consumers, voters and citizens partaking in many-to-many models, participatory cultures provide an individualized experience in a globalized world, carve out a personalized niche in what is increasingly perceived as an impersonal world, give a voice to those who consider themselves unheard and give a sense of active engagement with or even influence over, for example, political or consumerist processes that have become more distant from voters and consumers over the past decades. Within many-to-many structures, lines between different stakeholders, parties, sectors, and users seem to be shorter and more direct. This lends those partaking in these structures a new sense of control, of being part of and belonging to sectors of society and culture that one might feel distanced or even alienated from.

However prodigiously utilized, hyped or criticized, the implications of the many-to-many model, the different forms of and reasons for user participation in content creation are not yet well understood nor researched. This book's strategic research site for analyzing the nature, characteristics, mechanisms and problems of the many-to-many model are toys and computer games. Although these issues are acutely visible within the world of toys and computer games, they are by no means restricted to this research site. Therefore, this book seeks to address not only changes within the world of play but also in other domains and practices of our culture and society. 


\section{Core and Periphery of Play}

Sly as a fox and twice as quick: there are countless ways of 'making do.'

(De Certeau, I988, p. 29)

When describing and analyzing how the many-to-many model changes producerconsumer relationships, the core/periphery model of differentiation is highly suitable. Different authors from different disciplinary backgrounds using the core/ periphery model of differentiation define the relationship between core and periphery in different terms and specify different criteria for what belongs to the core and what to the periphery. A cross-disciplinary notion, however, is that core and periphery are interdependent. As French geographer Jean Gottmann writes in Centre and periphery: spatial variation in politics (I980), there is no core without a periphery and visa versa: 'there is no periphery unless the spatial figure considered has a centre, or central sector; inversely, once a centre is determined, there is to be a periphery around it; otherwise of what is it the centre?' (p. 20).

Using core and periphery as descriptive terms allows us to identify different user strategies or, in the case of this book, practices of play and their position inside what one could call the 'geography of play'. The geography of play is the sum of core and peripheral play practices and consists of both physical and digital elements, of tactile and non-tactile components, of objects and connections. Using a spatial term such as 'geography' to describe this conglomerate of actions, feelings, intentions, objects and ideas related to play allows us to think along spatial (in the physical as well as the mental sense of the word) lines in locating what takes place and where inside these geographies of play; it allows us to map out the different stakeholders, play practices, intentions and discourses related to play. A geography of play consists of mental maps and physical manuals, of actual, physical play elements and mental projections of players, of ideas players have when playing a game or playing with a toy and the physical characteristics of toys or computer games that determine to a certain extent the parameters in which players can act out their ideas. Changing and developing geographies of play that will be addressed within this book are historically located and need to be understood within the context of the processes of commodification, domestication and urbanization that will be addressed in the first part of this book.

The core of the geography of play is understood within the framework of this book as constituted of facilitated play practices. 'Facilitated' denotes making (an action or process) easy or easier, possible, smooth or smoother. To facilitate is to enable and assist but also to promote, encourage and catalyze. Facilitated play practices are shaped by the combination of design characteristics of a toy and the discourse surrounding the toy. The structure of a toy, its technological specificities, its materiality, the rules and manuals, examples and guidelines, its 'reputa- 
tion' and connotations create a network of facilitated play practices. Both the material and immaterial aspects of a toy or computer game create a window of opportunities within whose boundaries the player can act. To be sure, as Science and Technology scholars Nelly Oudshoorn and Trevor Pinch ascertain, 'there is no one essential use that can be deduced from the artifact itself', but 'there may be one dominant use of a technology, or a prescribed use, or a use that confirms the manufacturer's warranty' $(2003$, p. 2). Toys facilitate and stimulate certain practices of play and not others. From a technological determinism point of view, one would argue that toys determine to the full extent how one can and will play with a given toy. However, this stance does not take into account the fact that players use toys in unpredicted and divergent ways as well. From a voluntaristic point of view, one could argue that players can and will play any sort of game imaginable notwithstanding the toy they are using and the possibilities that toy offers. This view on the relationship between toys and play practices does not account for the fact that toys and the way they are designed do in fact shape play practices to a certain extent. The core should not be understood as the essential and sole correct use of an artifact but as the facilitated uses that are reflected in design and discourse.

Design and discourse that shape the core of geographies of play could also be described with the concept of scripts. Scripts make certain things possible and not others. Scripts are embedded in an artifact during the design process of this artifact. Madeleine Akrich compared technological scripts with film scripts that 'define a framework of action' (I992, p. 208). During this design process, specific uses and users are preconceived and set in the design. Designers try to configure the user and uses by contributing to a definition of users, by anticipating and defining user preferences and inscribing these into technical design, by establishing parameters for user action. This means that artifact and practices are prestructured by designers and design processes. Norms and values, knowledge and experiences, rules and requirements are embedded into the design and promote specific user behavior (Lieshout, Bijker, \& Egyedi, 200I, p. 47). During the design process, designers configure 'the' user, a projected and ideal user or a host of different and maybe even conflicting users. It is within the core of the geographies of play that practices and tactics of configuring the user are to be found. They are inscribed into the designed artifacts of toys and computer games and expressed in the discourse that accompanies these artifacts.

However, playing is in essence experimentation and boundary testing, which inevitably results in play activities outside what has been facilitated or prescribed, in other words: in peripheral play activities. Players will almost always, in one way or another, perform play activities that lie outside of the core. The periphery of the geography of play, then, is comprised of divergent practices of play that deviate from the discourse on a toy or game or that use the design of a toy or game in unexpected ways. The latter will almost always implicate a deviation from the dis- 
course as well. Divergent forms of play can be both 'wanted' and 'unwanted'. The term 'divergent' points towards the tendency to be different or develop in different directions and encompasses the wanted - varying, different, dissimilar, unalike - and unwanted - conflicting, incompatible, contradictory - practices of play that are manifested in the periphery of geographies of play.

To give an example, the combination of the design and discourse on Meccano toys facilitates the creation of cranes, planes, bridges and comparable industrial objects. Using the Meccano elements to build, for example, an elephant deviates from the discourse of this toy characterized by masculine, industrial engineerplay. Once players use a designed object in a way that differs from the discourse that companies support, advertise and promote, these activities can be considered divergent. For example, Siskind's military MOC sets use the LEGO design in a way that deviates from the LEGO discourse dominated by connotations of LEGO toys as innocent, playful and educational children's toys. Players can also move away from the facilitated core by altering the design of a toy or game. For example by programming cheating bots that will affect and change the design of a computer game. Of course, a toy or computer game can also be used in ways that fall completely outside of the scope of the geography of play. For example, when one uses the Kapla wooden building planks not to build a construction but to stabilize a bookcase, then this practice is indeed divergent, but it no longer pertains to play and as such it falls outside of the scope of the Kapla geography of play. The periphery, then, contains those activities with a toy or a game that divert from the discourse and/or alter the design while still concerning, affecting and relating to that toy or game. Most contemporary, digital peripheral user activities operate according to the many-to-many paradigm: by us for us.

Game theorist Mia Consalvo sees these peripheral activities as part of what she calls 'gaming capital', the conglomerate of user activities that support the game and its communities (2007, p. 4). This gaming capital that 'shapes our experience of gameplay', that 'isn't the game industry but is closely related to it' has evolved over the course of the last two decades 'from a trickle to a torrent' (p. 8). These 'peripheral industries' function, according to Consalvo, as a 'paratext' (p. 9). The term paratext is taken from the work by French structuralist Gérard Genette who considered elements that 'helped shape the reader's experience of a text', such as 'a table of contents, a title, and a review', as belonging to the paratext (p. q). Consalvo considers the use of the word 'periphery' in relation to gaming capital as 'dismissing or ignoring the centrality of these industries to the gaming experience' (p. 8). This is a good point to stress again that core and periphery are interdependent: no core without a periphery and no periphery without a core. The term periphery as it is used in this book very much recognizes the centrality of peripheral user activities to the overall experience of both toys and computer games. 


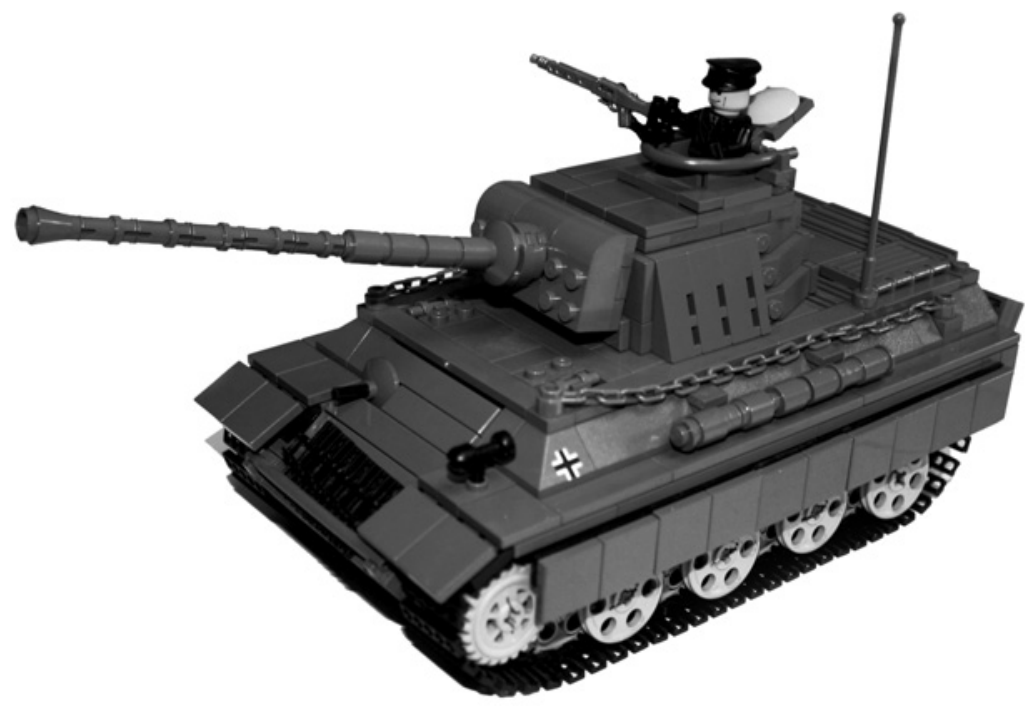

1 Deviating from the LEGO Discourse

This Panther tank is a World War II tank replica Siskind designed, constructed and sold as a LEGO MOC set (Siskind, personal website). This design, created in the periphery of the LEGO geography of play, uses the LEGO bricks in a way deviating from the LEGO discourse that centers on LEGO toys as innocent, playful and educational children's toys.

As already stated, divergent, peripheral play practices can be both wanted and unwanted. Certain excursions outside of what has been facilitated can be useful (capitalizable, insightful, instructive) to the toy or computer game companies, fortifying the brand, helping or strengthening the user community, or improving the player's experience of the toy or computer game. These play practices are wanted, applauded and welcomed by different actors in the field - from producers to player communities to individual players. For example, the designing and selling of the Blacksmith Shop was a divergent player activity (peripheral) that resulted in a successful commercial design (core), which aided the LEGO Company to overcome its image of an impermeable company and strengthened fans' loyalty to the LEGO Company. The Blacksmith Shop is then a good example of a wanted peripheral player activity.

However, certain transgressions or excursions outside of the facilitated core might not be capitalizable, might even damage a brand's image and reputation, irritate the user communities or frustrate the player's experience. These peripheral activities are unwanted play practices. Unwanted play practices illustrate that there is indeed, as Gottmann observes, 'some possibility of opposition and con- 
frontation' between the core and periphery (1980, p.8). The cheating bots designed for the The Sims Online game discussed in the fourth part of this book are a good example of unwanted, peripheral player activity. These bots created unfair competition in the online game and led to a differentiation or distinction between players using these bots who would have certain advantages over players not using these bots. These bots not only created differences between the users and the non-users of the cheating bots, they also damaged the overall image and reliability of the game. Although certain practices of play might be perceived in general as being either positive and constructive or negative and disruptive additions to the geography of play, this is not to say that all actors within the geography perceive and experience these activities in the same way. The LEGO fans who worried on the Lugnet discussion board that turning the MOC Blacksmith Shop into an official LEGO set was a way to control the fans indicate that a play practice might be perceived as wanted and unwanted at one and the same time by different actors in the field (Lugnet, Blacksmith Shop). And the players of The Sims Online using the cheating bots might have been aware that their actions were unwanted by other players of the game, but they still welcomed these bots that made the playing of the game easier and more lucrative.

The examples of what can take place in the periphery of geographies of play, both wanted and unwanted, alert us to the fact that there is movement within these geographies of play. As already stated, the Blacksmith Shop was created in the periphery by Siskind but became part of the core of the LEGO geography of play upon being turned into an official LEGO set. The cheating bots for The Sims Online were created in the periphery but moved to the core of this online geography once players in the game started using them. There are two possible movements between core and periphery: centrifugal (moving away from the core) and centripetal (moving towards the core). Centrifugal movements are very common and consist of all those instances when players diverge from the design and/or discourse on a certain toy or game. In this divergent act, players move away from the core in a centrifugal movement into the periphery. The centripetal movement consists of those moments when peripheral player activity 'migrates' from the periphery to the core, when user-created content becomes part of the core of geographies of play.

These movements or forces within geographies of play can be understood in terms of appropriation and configuration. As stated, the core of the geography of play is the sum of the design and discourse and embodies practices and tactics of user configuration. When users buy an artifact, they familiarize themselves with the embedded scripts. Importantly, users will, more often than not, adapt it, 'modify, design, reconfigure or resist' it when adopting a new artifact (Oudshoorn \& Pinch, 2003, p. I). Users might change the physical properties of the artifact or accommodate the rules to their personal wishes (Lieshout et al., 200I, p. 47). In Making technology our own? (1996) Lie and Sørensen frame this appropria- 


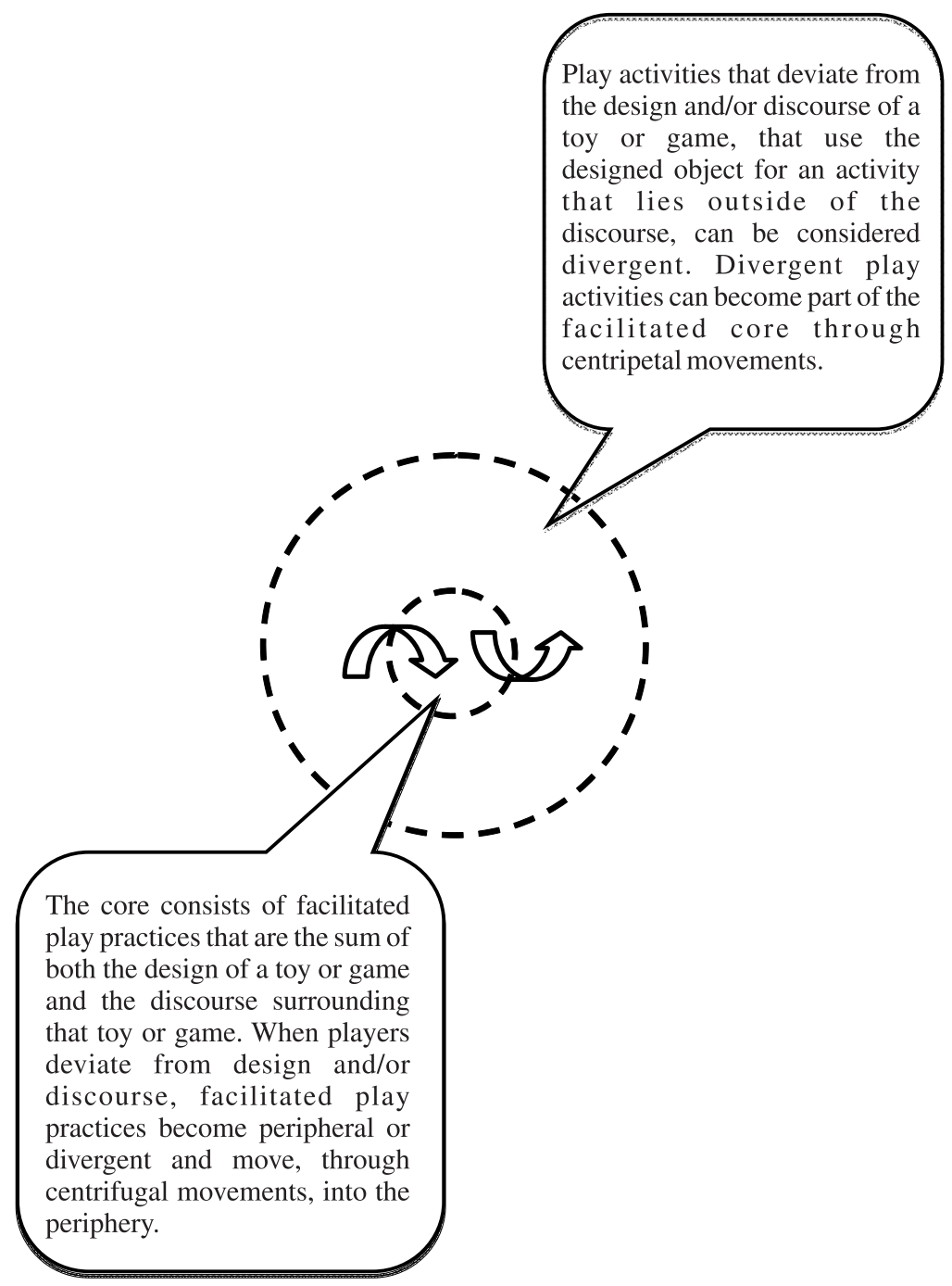

2 Geography of Play

Core and periphery of play are interconnected through centripetal and centrifugal movements. Centrifugal appropriation indicates the divergent use of the core. Centripetal appropriation can take place within the realm of one and the same product (fast force - implicates the ability to co-configure the user) or over the course of a new product launch (slow force - reconfiguring the user).

tion of artifacts by users as a form of taming and domestication of technological objects. 
Users should therefore be considered not passive consumers but 'tinkerers or 'bricoleurs', (co-)designers and (co-)producers who use the 'room for action at the users' end (...) to shape their lives through creative manipulation of artefacts, symbols, and social systems in relation to their practical needs and competencies' (p. 5, 8-Io). By appropriating artifacts to personal, local or circumstantial wishes, users deviate from the embedded scripts. They use the design in unexpected and unforeseen ways, or they bend the discourse to their own personal needs. In doing so, users and their practices move from the facilitated core to the divergent periphery. This constitutes the first movement within the geography of play: the centrifugal force. The core, the facilitated design and discourse, the embedded scripts have to 'tolerate' and sustain these deviations and transgressions, the divergent uses of an artifact and the unforeseen user practices.

Reverse movements or forces also exist within geographies of play. Divergent, peripheral play practices can become part of the facilitated core through centripetal movements. This is a form of appropriation of the periphery, not of the core. For new product development, companies and designers can use peripheral and divergent activities as their input. Companies and designers incorporate actual user activities within a new product or the redesign of an existing product because this might lead to a more successful or popular product when users see their adaptations and usages reflected in the design scripts. These centripetal appropriations implicate a commodification of the periphery, of the many-to-many activities of players. Through this movement, divergent peripheral activities can become part of the process of reconfiguring the user in new products or product updates.

Through centripetal appropriations whereby peripheral activities and actions become part of the core, players can influence the design of and discourse on an artifact to a certain extent. Their divergent play practices can become facilitated play practices. Various forces shape how and when this border crossing happens. There are the powerful actors in the core, the game designers and policy-makers, who, in general, will have to approve of this migration. However, as we will see with regard to The Sims Online, players may find ways to circumvent these official and approved channels for border crossing and 'illegally smuggle' their peripheral creations into the core of a game in the form of the aforementioned cheating bots. Besides the powerful actors in the core, the design of a toy or a game has to facilitate centripetal appropriations as well.

In order to further clarify how to identify what takes place and where in the geography of play, it might be useful to draw some parallels with other useractivities. For example, a famous chef using a coffee grinder to pulverize herbs and seeds rather than grind coffee beans is a divergent use of a designed object that lies outside of the coffee grinder discourse. Or people using a blowtorch not to weld or meld things but to create a caramelized surface on their crème brûlée desserts are diverting from the blowtorch discourse. In both cases, the designed 
object is used for a purpose other than the envisioned one. And here it becomes interesting: divergent uses of designed objects will often lead to the design of new consumer objects that have at the intersection of design and discourse, in the core, exactly those unintended uses. For example, one can now buy expensive and fancily designed blowtorch look-a-likes to caramelize crème brûlées (although these objects, tamed and domesticated versions of the blowtorch, do not do the trick as well as the blowtorch). As a final example let us look at the fashion industry. Changing a pair of jeans at home, making additions to it or wearing it completely differently than anticipated by the designers (e.g. by wearing it inside out or changing it into a skirt or a tote bag) is not an uncommon practice among fashionistas. Trend watchers are on the lookout to spot these divergent manipulations of standardized consumer goods in order to be able, when proven popular, to bring exactly such appropriated trousers on the market for the next season. These examples illustrate that through centrifugal and centripetal movements between core and periphery, practices and objects can migrate from one area to another, and users can influence and shape the facilitated core of consumer goods to a certain extent.

Forms of user appropriation of existing technologies and discourses are also discussed in French philosopher Michel De Certeau's The Practice of Everyday Life (I988). In this book he traces and identifies practices and tactics of what he calls 'making do'. Consumers, television watchers, walkers, readers, cooks are all involved in 'manipulation', in 'composing an antidiscipline', in 'appropriation and reappropriation', in 'poaching', 'poiesis' (from the Greek poiein, to create, invent, generate), 'bricolage' (used by Claude Lévi-Strauss to analyze the production of things from leftover materials), and 'la perruque' (French expression for 'worker's own work disguised as work for an employer') (p. xii, xiii, xv, 25, 165, 174, 205). ${ }^{2}$ These activities are 'hidden and scattered over areas defined and occupied by systems of production', systems that, De Certeau stresses, leave less and less 'place for consumers to indicate what they make or do with products of these systems' (p. xii). Nevertheless, 'there are countless ways of "making do"' and in these tactics of making do, 'work and leisure flow together, repeat and reinforce each other' (p. 29). Instead of considering consumers as passive recipients, De Certeau labels them 'unrecognized producers, poets of their own affairs, trailblazers in the jungle of functionalist rationality' (p. 34). The movements within the geography of play are indicative of this: when divergent player behavior becomes part of the core, the lines between player, consumer and producer become unclear.

Through this changing relationship between producers and consumers, toys and players are interconnected in a relationship of mutual shaping and co-construction. Not only are players increasingly and inevitably consumers, nowadays they are also being incorporated into production processes to an ever greater extent. With the shift from a one-to-many production process to a many-to-many model of design, production and marketing, the way in which toys and players 
shape one another intensifies, becomes more direct and instrumental. This manyto-many model, part and parcel of the history of the computer game industry, has turned since the late I9gos into a template for non-digital toy companies as well. Moreover, the many-to-many model has been used in multiple areas outside of toy and game production as well. In diverse policy domains, reestablishing a meaningful and positive relationship between 'producer' and 'consumer' is sought through the use of the many-to-many model. The many-to-many model relies precisely on the willingness of users to enter into a process of co-creation, mutual shaping and interdependency with diverse companies and governmental institutions. 


\section{Part I: New Children, Different Toys}

In recent years, many scholarly books have appeared on the subject of computer games. While these recent publications all provide valuable insights into the inner workings and cultural context of computer games, they do not focus on the longterm historical perspective of play as a cultural practice, the role of technological innovations within this history and the changing dynamics between players, toys and companies. Notable exceptions are Digital Play: The Interaction of Technology, Culture, and Marketing by Stephen Kline, Nick Dyer-Witheford and Greig De Peuter (2003) and Henry Jenkins's article, Complete Freedom of Movement: Video Games as Gendered Play (2000). Most contemporary computer game research, however, focuses on computer games - their coming into being and maturing, the different genres discernable, the type of rules and systems deductible, and the sort of players and player behavior witnessed. As Erkki Huhtamo points out in his article on arcade gaming, the historical component in game studies is largely missing:

electronic games did not appear out of nowhere; they have a cultural background that needs to be excavated. The existing literature on the history of video games has done little toward achieving this goal. In fact, the (hi)story is usually told in a remarkably uniform fashion, built around the same landmarks, breakthroughs, and founding fathers (2005, p. 4).

Generally speaking, when non-digital and digital toys are 'compared' from a game studies point of view, this is generally done to claim the uniqueness of the latter (in terms of interactive possibilities, massive virtual worlds and unprecedented social opportunities). When non-digital and digital toys are 'compared' from the more pessimistic point of view of computer game adversaries, this generally leads to an equally simplified comparison that applauds the first ('real' interaction, physical activity, tactile play) and condemns the latter (isolated, immobile and escapist play).

This book offers a historical view on the manner in which the many-to-many model, under the sway of technological innovations, produces changes within the world of toys and playing. The context for studying and analyzing the changing interrelationship between technological innovations, toys and players is the societal and cultural processes of commodification, domestication and urbanization. It is within this historical context that new technologies are introduced and used. The broad societal and cultural processes of commodification, domestication and urbanization are exemplary processes illustrating how societal shifts and the changing world of toys co-evolve, mirror each other or resist one another. More- 
over, these processes influence the production, consumption, place, goal and form of play.

What has changed since the mid-Igth century is, on the one hand, the way toys are produced and consumed, the scale and variety of this production and consumption, and, on the other hand, the way in which society looks upon children and the function of toys in their lives. It was not always the case that parents got lost in gigantic Toys ' $\mathrm{R}$ ' Us stores when searching for the toy that is their children's favorite that season. It is a rather recent phenomenon that children have their own rooms to sleep and play in, that they have their own clothing styles, their own furniture, food, medicine, therapists, education, entertainment and toys.

During the igth and early 2oth century as our Western consumer culture was taking shape, the Victorian family became the locus of civilization, and urbanization led to tensions between city and citizen. From the rgth century to the postwar period to the 2Ist century, we see significant changes in how these processes play out. The relationship between the individual, the processes of commodification, domestication and urbanization, and toys changes drastically during the postwar period with the maturing of a commercial culture, the suburban obsession with the private sphere, and the growing fear of the world outside the private (suburban) home. The 2Ist century witnesses another phase of consumerism with late capitalism, the reintroduction of the outside world inside the family home via the Internet, and attempts at reestablishing a constructive relationship between city and citizen. Within this changing context of commodification, domestication and urbanization, new technologies are being introduced and their effects experienced. Against the background of these historically changing societal and cultural processes, the many-to-many model will be analyzed, the role and function of technological innovations examined. A historiographical perspective on the complex interplay between societal processes, technological innovations, toys and players shows the many-to-many model at work and on the move, its rise, manifestations and ways of involving users.

The interplay between societal processes, toys and children in the second half of the igth and first decades of the 2oth century needs to be understood within the framework of a drastically altering image of childhood. With the work of various pedagogues and child-rearing experts, artists and writers, the Igth century saw a dramatic change in the image of and thinking about the child and childhood. The Pre-Raphaelite painter John Everett Millais has famously immortalized the new-formed ideas about children and the child's culture in his I886 Pears soap advertisement. The child depicted in the advertisement is a kind of cherub, a beautiful, innocent, vulnerable dreamer that had to be taken care of, washed, dressed, fed and cured. The Innocent Child was very much situated within the pastoral tradition - with its longing for and wish to preserve childlike innocence. The igth century has been notably phrased the 'Age of the Child' by Swedish pedagogue Ellen Key because of its focus on the child and his/her well- 
being, education and health (Igog). Specialized shops and products reflected this changing attitude towards the child: the 'Victorian awakening to the preciousness of childhood helped ensure that children's goods would expand along with other markets' (Kline, 1993, p. 53).

A phrase like the 'Age of the Child' might seem in line with the 'Invention of Childhood' reasoning based on Philippe Ariès's influential book Centuries of Childhood (1962). According to this idea, childhood as a distinct phase in life as well as parents' feelings of tenderness, love and protection for their children date from the 17 th century. Opposing Ariès's theory are historians - most notably Linda Pollock (1983) and Daniel Blake Smith (1980) - who found proof in diaries and letters that even before the I7th century, children did have some sort of separate culture and that tenderness did in fact exist between parent and child. Although it is hard to hold on to the 'Invention of Childhood' theory, it is legitimate to say that the culture of the child was less developed and less crowded with specific objects and ideas targeted at the child before the igth century. The 'Age of the Child' phrase as used here but also the title New Children, Different Toys should thus be understood in the sense of 'marking a difference' rather than 'marking a break', as indicators of shifting attitudes towards the child.

This changing attitude towards the child, this emergent child culture, this 'Victorian awakening to the preciousness of childhood' worked out differently for girls and boys, for the working classes, middle classes or upper classes, for people living in rural or urban areas. In addition, there were significant geographical differences. The Dutch government formulated a law against child labor in I874 for children younger than 12 years. Working as a household help, a personal servant or on a farm was excluded from this law (Boon, 1935, p. 13). The law was intended mainly to reduce the number of children working in factories. England saw the formulation of factory acts in 1802,1816 and 1833 that dealt with the hours children were allowed to work and safety in the factories (Kline, I993, p. 47). Nevertheless, working children were and remained one of the thriving forces of the Industrial Revolution, even after laws against child labor were effectuated. Sometimes up to two-thirds of factory employees were children in mid-Igth century England. In most Western countries, it was the laws regarding school enforcement (passed in the Netherlands as late as I9or) that would constitute an actual decline in child labor.

It is hard to exaggerate the gender differences that mark the interplay between societal processes, toys and children. Toys were mostly objects designed for boys; girls had dolls and miniature household replicas that were often too fragile to play with. The Igth century Boy and Girl Books exemplify these gender differences. The 'sharp differentiation of male and female roles (...) which accompanied the advance of industrialization (...) mandated separate books for girls and boys' (Segel, I986, p. 170). The British author of children's literature, Geoffrey Trease, wrote, 'Books were labeled, as strictly as school lavatories, 'Books for 
Boys' or 'Books for Girls" (I975, p. I4). The literary genre of the Boy Book was characterized by romantic and pastoral notions of a boy's formative years and embodied the male longing to break free from domestication (Jacobson, I994; Jenkins, 2000; Segel, I986). Conservative American theorist William Graham Sumner lamented, on the other hand, that boys' literature (both books and periodicals) depicted 'quiet home life as stupid and unmanly' and 'real life as breaking with respectability and joining the vagabonds and swell mobs' (I877, p. 684). Bestsellers such as Treasure Island (Stevenson, I883) promoted this 'good bad boy' image of the autonomous, adventurous but honest rascal (Segel, p. 173). While Boy Books were about 'escaping domestic responsibilities', Girl Books, such as the equally popular What Katy Did series (Coolidge, I873), centered on 'accepting domestic obligations' (Jenkins, p. 280). The Girl Book dealt with 'growing up and becoming little women' (Jacobson, p. I4), with 'devotion', 'suffering' and 'courage' on the domestic front, with the 'fate of a plum pudding boiled by the untrained hands of a girl of fourteen' (Salmon, I886, p. 516-517). This schism between boys' and girls' literature prevailed as late as the ig6os (Segel, p. I65). The Boy and Girl Books have recently been revitalized along their historical lines: adventure for boys with the The Dangerous Book for Boys (Iggulden \& Iggulden, 2006) and domesticity for girls with The Great Big Glorious Book for Girls (Davidson \& Vine, 2007).

Domestication mostly affected upper and middle class girls; boys enjoyed more freedom because they were thought less fragile and corruptible. Boys' games are therefore better documented because they were visible to the observer. Percy Green writes in his I899 A History of Nursery Rhymes that 'Girls' pleasures are by no means so diversified as those of boys' and dismisses the business of girls' games with a few sentences (p. 6r). At the same time, the changing work conditions and the demand for skilled labor was hardest on boys 'whose adult lives would differ more from those of their fathers than girls' lives would from those of their mothers' (Jacobson, p. 9). The playground marks a minor change in the gender differentiations in the sense that both girls and boys were allowed on the playgrounds. However, children of different sexes were discouraged to play together, and different, suitable activities were arranged for both sexes. One feared especially the possibility of sexual excitement in young girls. Therefore, spicy foods, sharing a bed with servants, a nurse or siblings, playing together with boys, and especially sitting on a swing or horse riding were discouraged for girls. This meant that suitable playground activities for girls were different from those for boys.

'The awakening to the preciousness of childhood' was thus a gradual yet irregular process - generally taking root first among the upper classes and in urban areas and then filtering through (or being forced upon by reformist movements) to other classes and regions. Although these processes and the problems they brought about played out differently depending on gender, class and geographi- 


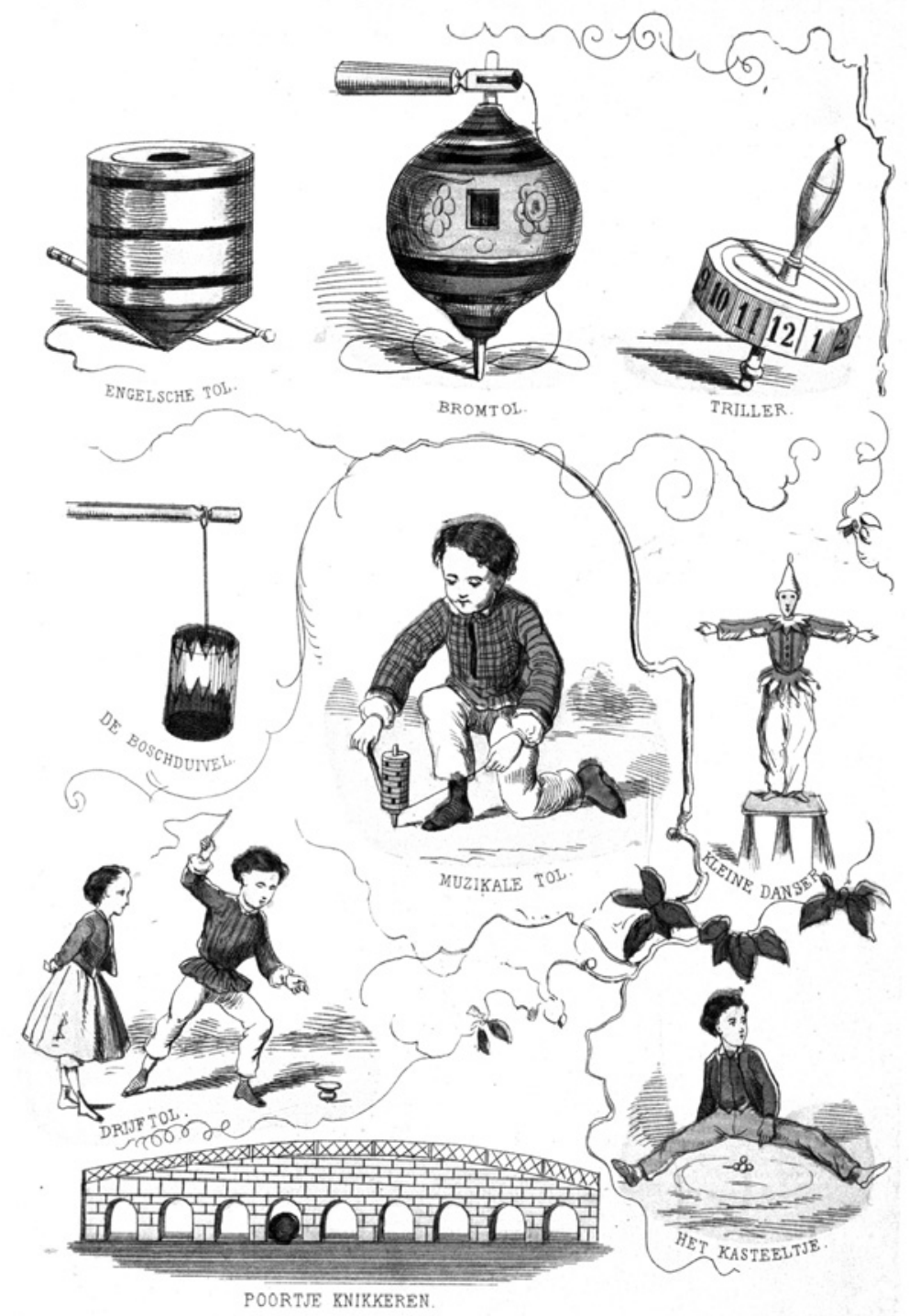

\section{Toys for Boys}

This engraving from a Dutch play instruction book from circa 1865 depicts many games that could be played indoors or outdoors. Most of the written explanations of games in the book were accompanied by drawings like these. The texts and illustrations refer to boys mainly. Girls feature in the book in the role of sisters who can be awed and have tricks played upon them. In this drawing we see a girl looking on, with her hands behind her back, as a boy spins a top (Beets \& Sandwijk, ca. 1865, no page numbers). 
cal location, the broader processes of commodification, domestication and urbanization were felt all through the West.

\section{The Child as Consumer}

My sled is better than yours; yours was made, mine was bought.

(S. Hall \& Smith, 1903, p. 173)

The manner in which shops displayed their goods, priced them, renovated their storefronts, attracted customers, dealt with customers and the types and variety of merchandise they sold changed drastically in the course of the igth century. These changes culminated in the establishment of department stores in the midIgth century. The change in the display, pricing and dealings with customers was met at first with vehement opposition, concern, disbelief and even disgust, especially in Europe. People were used to small craftsman shops where they could strike a bargain and buy on credit.

However, increasing competition pushed more and more shop owners into displaying fixed prices and creating attractive window displays and storefronts. The perfection of various technological means to create cheap and large sheets of glass (e.g. with the glass-pressing machine built in 1827 or the method for machine-drawn cylinder sheets of glass patented in America in 1903) allowed many shop owners to buy and fix such sheets of glass in their storefront. Artificial lighting - gas and later electricity - increased the visibility of the stores and their goods both from the outside and the inside, during the day and at night.

Renovating a storefront to insert a large window often went hand in hand with a renovation of the shop as a whole and the annexation of neighboring houses. The resulting bigger shops had more space available for merchandise, and instead of selling more of the same they started to sell all sorts of different goods. A former umbrella vendor, for example, would now include things such as rain jackets, walking sticks, shawls, and bags in his arsenal of products. Needless to say, this new way of doing business fuelled more competition.

Whereas the shopkeeper of the previous generation was content to rely upon a solidly built reputation as sufficient advertisement, the shopkeeper of today, buffeted by an abnormally developed competition, has to adapt himself to the needs of the times to seek a more pronounced advertisement than a good, honest reputation. He sees in his shop front a happy medium for a properly expressed and unique advertisement (Dan, I907, p. I5). 
The refurbished shops put their goods on display in the most appealing ways, often accompanying these with (sensational) news of the day in word and image.

Shop owners selling diversified products in their expanding stores paved the way for the new shopping concept of the department store. Some of the earliest ones, Le Bon Marché in Paris or Harrods in London for example, evolved gradually from small shops into fully fledged department stores. Other cities saw the advent of the purpose-built department store, such as Delany's New Mart that opened in 1853 in Dublin, Ireland.

A department store has no dominant merchandise line but sells different products in one and the same store for fixed prices and offers the possibility to return goods or exchange them. The guidebook How Department Stores are Carried on in America listed some of the basic principles of successful American department stores: 'One of the great underlying principles of Modern Department Stores is cash. (...) A few years ago nobody sold for cash. Nobody in those days marked the price on goods in plain figures and stuck to it' (Anonymous, I900, p. 7). Besides cash and fixed prices, the department store differentiated itself from an 'ordinary store (...) by being big enough to deal in almost everything that people need' and through its customer service based on ease and comfort and the possibility of 'cheerful refunding' (p. 7-9).

There were important differences between the early European and American department stores. A Dutch accountant, E. Schönberg, gathered information on German, French and American department stores and was startled to find that American stores had many female employees, which would have been fine if only they did not chew so much gum! (1908, p. 72). He also noted that in America the cash-principle was soon replaced once again by the credit principle because this would stimulate the ladies to buy more (p. 70). European department stores were not so eager to return to the credit principle that they still associated with the traditional ways of doing business. Schönberg found that American department stores were ridiculously, even offensively generous in changing items or returning money, even when clothing had already been worn to a party or china had been used to impress guests (p. $70 \&$ 72). Schönberg also noted differences in the societal acceptance of department stores. Germany knew 'rancorous opponents of the department store' while in America they were 'recognized as a necessary and useful part of contemporary society' (pp. 69 \& 7I). German department stores were, for example, restricted in height to minimize 'unfair' competition and could thus never be so large as the American ones, which even sported rooftop gardens and playgrounds (pp. 68 \& 85). Not only Germany knew such 'rancorous opponents', there was a lot of resistance throughout Europe to department stores. Feelings of contempt towards merchandisers who changed to the department store way of doing business is masterfully described in Émile Zola's famous novel Au Bonheur des Dames (I883). Connected to this resistance in France was a French discourse on female kleptomania as a hereditary disease spurred on and awa- 
kened by seductive window and shop displays and the availability of an abundance of goods. In Window Shopping Anne Friedberg recounts other neuroses and disorders that accompanied the desires instigated by the new culture of consumption, such as shopping bulimia and compulsive stealing (1993, p. 42).

Toys played an important role in the coming of age of the late Igth-century department stores. Harrods, one of England's biggest and oldest department stores, held a yearly Christmas Toy Fair that attracted thousands of children and their parents year after year (Dale, I98I, p. 82-83). One of the top five bestselling departments of New York's famous department store Macy's was the dolls and toys department. Department stores tried to lure in children with Christmas specials, clearance sales, children's days and pamphlets stating: 'Bring your children along! In our toys department they will sure find diversion and amusement' or 'Pay us a visit with your children! In our stores, children are always welcome. The displays entail series of delightful surprises' (Schönberg, p. 32 \& 62). Children were mainly addressed through their mothers with promises of the wholesome effects of this toy or that one.

Since the main target of the department store and its advertisements was the female shopper, the history of the department store is often written from a gender perspective. On the one hand, in the department store women acquired their own public space where they could be the female equivalent of the male flâneur, the city dweller. On the other hand, shopping was also a new means of subjecting women to the game of male onlookers. As salesgirls and as shoppers, women were eyed with both longing and disgust (Furnée, 2003, p. 94). Schönberg, for example, describes women as 'excited female shoppers' who might need to take a rest from all the excitement in one of the 'comfortable beds in the relaxation area that American department stores so conveniently provided for them' (I908, p. 64 \& 68).

The department store signals a change in consumerist practices: from consumption as an activity 'closely linked with that of production' prompted by necessity rather than desire, to consumption as an act in itself and for itself (Williams, I99I, p. 2-3). As Hannah Arendt states in The Human Condition, the labourers' free time is spent consuming not only 'the necessities' but rather 'the superfluities of life' (1998, p. 133). From the I850s onwards, consumerism was enjoyed by many and feared by some. Consumerist practices and the démocratisation du luxe, entré libre, the fuelling of desires, were condemned and criticized by conservatives, moralists, politicians and the clergy (Bowlby, I985, p. I-2; Friedberg, 1993, p. 77). They feared the unsettling effects of democratized luxury on social hierarchies, of free entry on compulsive female buyers, of greed and jealousy on the Innocent Child, and they bemoaned the fact that shopping was not rejected as a sinful activity.

We can see some interesting changes in the attitude towards the child and consumerism. During the latter half of the igth century, both European and Ameri- 
can educators, moralists and child-rearing experts 'expressed the fear that the dresses, toys, wagons, and other playthings which were being mass produced, and which store windows, catalog pages, and magazine ads prominently displayed, would corrupt the nation's youth' writes historian Susan Matt (2002, p. 284). They stressed the need for teaching children emotional control and contentment so that the moral damage caused by the material world and all its temptations would be reduced. Both the growing body of literature on child rearing targeted at parents and the textbooks children used in school preached emotional control and warned of the dangers of envy and jealousy.

In spite of this warning literature, consumerism, desire and envy for material goods and the status they embodied were nourished through the talk of family and friends, catalogs, magazines, advertisements, movies and department stores. In terms of status, there was a difference between handmade toys and factorymade toys, the latter being a status symbol for the families and their children (p. 286). Also, the transformation of holidays (and especially Christmas) into opportunities to purchase gifts and spoil children went contrary to advice on a moderate stance towards consumerism. In I906, psychologist and pediatrician Arnold Gesell found, for example, that playthings featured prominently in rooo accounts of the reasons, occurrences and forms of jealousy among children (p. 455). Psychologists and educators Stanley Hall and Theodate Smith studied 363 cases of showing off and concluded that girls were more likely to brag about possessions, their clothes and accomplishments while boys would brag most often about 'muscular activity' (1903, p. 190). The authors state that the tendency to brag - in itself an evil character trait - is also useful in building a child's self-respect, as long as it is well balanced against bashfulness and timidity (p. I8g).

The idea of jealousy as a positive quality became more common between 1915 and 1930. During those years the message on children and consumerism changed with a new generation of educators and child-rearing experts advising parents to give their children more so as not to deprive them and turn them into unhappy adults (Matt, p. 284). Giving children what they longed for would make them happy and content and eventually lead to a more stable personality. 'Much of [the] advice reflected a belief that consumer goods might be the solution to children's social and emotional problems rather than the source of their woes' (p. 292). Underlying this change were the weakening of the authority of religious writers, the fact that the new generation of advisors had grown up in the consumer society and the overall weakening of the moralistic Victorian tradition. Rather than preaching contentment, the idea that one could and should aim for a higher status was encouraged. 'Schoolbooks (...) implied that envy, discontent, and materialism, traits once considered sins, were now emotions and character attributes worthy of cultivation' (p. 294). Toys went from 'corrupting objects which encouraged an immoral love of material things' to 'important tools for socializing chil- 
dren' (p. 296). Part of this socialization was training the child for his/her future role as a consumer.

A 1928 advertisement leaflet in the form of a children's book published by the London-based department store Gamages illustrates this neatly. The advertisement story Edward's Birthday Gift deals with little Edward who is constantly changing his mind about what to ask his auntie for his birthday. He wants what Jones or Jimmy Shaw has and changes his mind from 'some soldiers and a model fort' to a 'good cricket set' to 'a camera' to 'a Meccano' set with which you can make 'aeroplanes, bridges - anything nearly!' to a 'tennis-raquet' (Ingham, I928, no

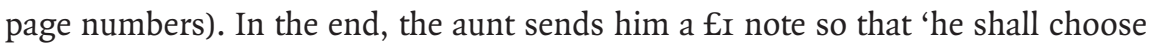
his gift on the day itself and for himself', hoping to 'escape future regrets' (ibid). The story at once shows the rapid succession of fads, the industry's encouragement to want what other children had, and the assumed educational effects of handling an allowance. Letting children spend money on their own was not considered good practice, however. Allowances or personally owned money was best spent under parental supervision. Working class children were expected to hand their wages to their parents. They could keep a small amount to pay for transport to the factories and lunch. Historian David Nasaw writes that it was easy to protect working class girls from the bad influences of money because they worked at home for no pay. Boys, however, were harder to control; they would keep money for themselves to spend on candy, toys, adventure books and the movies (I985, p. I3I).

\section{Domesticating Play}

The igth-century process of becoming a consumer was very much related to the family, the private home and more particularly, the private room where the child would play with his or her new toys. A child's private room took different forms depending on the child's age and the parent's means, and it gained in importance and presence between the mid-Igth and early 2oth centuries. From the mid-Igth century onwards, moralists, architects and household experts proclaimed the importance of a child's private quarters for moral, educational and health reasons. The private room within the private home had to shield the child from unsuitable influences that might enter the house through visitors, adult conversation or servants. Having a private space to play kept children off the streets as well. The city streets were generally considered a 'bad teacher' and an unhygienic place to play. Most mid-Igth century guidebooks on the building, upkeep and daily ministrations of the private home would combine advice on child-rearing with theories about ventilation, hygiene, warmth, sunlight and space. Only those rich enough to live in more than one room would be able to afford thinking about a private room for their children. Most working-class families rented a room or a 'corner' of a room, and their children roamed the streets after work or school. The nur- 
sery, schoolroom and private bedroom are therefore truly upper- and middle-class phenomena.

Domestication went hand in hand with urbanization; fears of the outdoors made people turn to the inside. Needless to say, differences between classes and geographical locations are numerous. The wealthier Londoners (and many Americans as well) left the city altogether and became suburbanites. The flight from the city to the suburb was driven not only by fear and disgust of the dirt, low morals and dangers of the metropolis, but also by a desire to get away from the developing commercial culture, its pressures, high-paced tempo and demands on everyday life (Mumford, 1961, p. 560). From the I95os onwards, however, the suburb became itself an epitome of the postwar consumerist culture. The suburb, both the igth-century historical suburb and the postwar suburb, was in essence child-centered. The move to the suburb was often motivated by the wish to raise children in a better environment and in proximity to better schools (p. 563).

In 1838 botanist and garden designer John Claudius Loudon (1783-1843) and his wife, the novelist Jane Webb Loudon (I807-1858), published the widely read Victorian guidebook The suburban gardener, and villa companion (1838) addressing those who had been able to leave the city and who lived in a private, freestanding house in the English countryside. They felt the need to briefly explain what a nursery was: 'The Nursery is a room set apart for the children, till they are three or four years of age' (1982, p. 680). This indicates that it was not yet a common practice to outfit a nursery room amongst the middle classes in the first half of the Igth century. However, the fact that nurseries were not yet a common part of early igth-century households does not mean that the nursery as such was a Igthcentury 'invention'. It is mentioned in I8th-century educational literature, for example in Practical Education by the Edgeworths (1798). Nursery rhymes, nursery books and children's literature from the early I8th century further demonstrate the existence of nursery rooms. Loudon \& Loudon go on to instruct that after the age of 4 , children should be moved to the schoolroom, a room not exclusively meant for taking lessons, but also described as a playroom or exercise room. 'The School-room (...) should be sufficiently large for the children to take their dancing lessons in it, and to serve for them to play at battledore and shuttlecock in, or to take other exercise during inclement weather' (p. 680). Battledore and shuttlecock is an old ballgame comparable to badminton. Guidebooks alternately situated playing in the schoolroom or (day) nursery, indicating that play did not have as yet a fixed location within the child's private quarters. Rooms specifically 'designed and furnished for play did not gain popularity until the turn of the century' (Calvert, I992, p. I3I).

Another popular guidebook was the 1883 Our Homes and How to Make Them Healthy, edited by British physician Robert Brudenell Carter (I828-I9I8). This book addressed every detail of housekeeping - from the number of pictures one should hang on the walls to the desired position of the bed between window and 
door. This guidebook also deals extensively with the place of children inside the family home and provides us with useful insights into the domestication of children, toys and playing. Parents are advised to set aside a large portion of the home for their children and their nurses. The authors realize this might be difficult to arrange for parents of lesser means (let alone for working- or lower-class families). Those families who did not have a whole floor to spare for their children and their nurses were advised to use the attic - although never the basement - for child-rearing.

When possible, the children's rooms should be close to the 'mistress's bedroom' but not too close.

The nursery department should always be placed within a convenient distance of the bed-room of the parents. At the same time it should be effectually shut off from the rest of the house. This is essential for the comfort both of the elders and of the children: for the elders, because, however fond people may be of children, there are times when the noise and unrest essential to childhood become wearisome; and for the children, because an undue restraint on their amusements, especially in the point of noise, is both unnatural and unfair (p. 87).

The ideal nursery department consisted of a day room, a bedroom for the head nurse and the smaller children, smaller additional bedrooms for the older children and the under nurse, a scullery, bathroom and toilet. Nurses used the scullery to make tea, dry sheets and store the children's china. A separate schoolroom should be placed 'conveniently near the nursery suite' (p. 89). The day room or day nursery could double as a playroom where 'children have the whole floorspace for their games' (p. 88). Children would also enjoy their meals, separated from their parents, in the day room - although the toys would then need to be cleared away (p. 844). A nursery corridor should connect these rooms with one another. The guidebook advises the installation of a separate staircase with a lowered handrail formed in 'such a manner that sliding on them should be an impossibility' and with adjusted steps for a child's shorter legs (p. 89). To top it all off, one is recommended to install a separate door on the ground level so that children and nurses do not have to use the main entrance of the house when they go for a walk or want to play in the garden. The children's door would lead to the children's staircase that gave access to the nursery department - completing the separation between the domestic world of children and adults.

'Frequent access to outer air' was considered very important for children (p. 842). However, 'younger members of a family' (and 'the gentler sex' in general) did spend the largest part of the day indoors. Therefore, 'No attempt should ever be made to rear children in a single room' (p. 844). Change of rooms was a means to provide those staying inside the house with a change of air, and it 


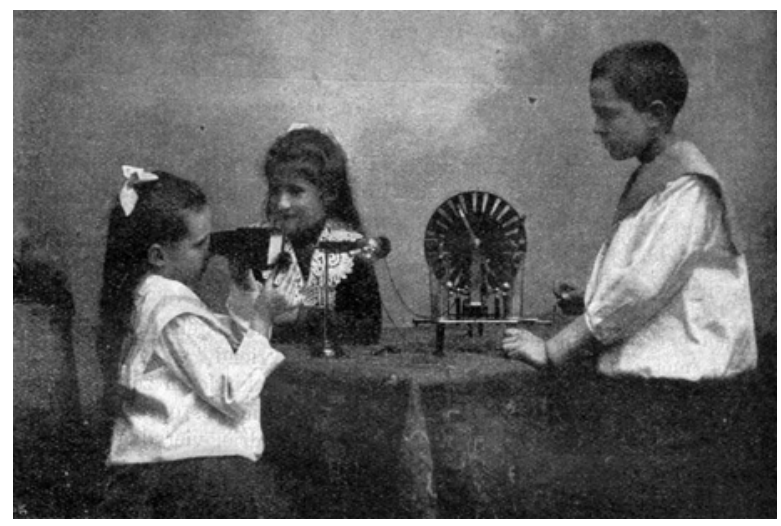

4 Domesticating Toys

Almost every scientific breakthrough, technical invention or industrial success was turned into a toy. Here we see children playing with a Rontgen apparatus (Schrijver, 1907, p. 122). These complex, fragile and expensive toys were truly indoor toys.

allowed the nurses to ventilate rooms currently not being used. Families of lesser means, whose children slept with the nurse on the top floors, should be allowed to enter the drawing room every once in a while (when there were no visitors) to provide them with a change of air. Markedly, the stress on a child's need for fresh air does not result in the advice to take children outside regularly. Opening windows in unoccupied rooms and changing rooms throughout the day is apparently more advisable than going outside.

Domestication was an attempt at protecting children from the dangers lurking on the outside. Inside the home, even inside the child's private room, the child also needed protection. Furniture such as the crib, swing and jumper, the high chair with a tray and the baby carriage, what historian Karin Calvert has labeled 'furniture for containment', were a means to keep children contained, in one and the same place, out of harm's way but at the same time entertained (I992, p. I24I25). This furniture freed the hands of nurse or mother and provided physical exercise for little children. Furniture for containment became more common by the end of the igth century because finding a good nurse, ideally a young unmarried woman or widow from the middle classes, became more difficult. Middleclass girls found better-paid employment as secretaries or shop assistants, or they would simply attend school until a later age. Besides the scarcity of good nurses, one feared it would be impossible to educate nurses about new practices and standards of hygiene, education and upbringing. Guidebooks often referred to nurses as a problem because they would not behave according to the new hygiene guidelines, would hold onto old-fashioned ideas and customs related to child rearing and might taint the child's morals by their divergent cultural and 
religious beliefs (immigrant nurses especially were considered a problem in this regard). This mistrust of servants in relation to the children's upbringing is already to be found in the late I8th century, most notably in the work by Maria Edgeworth. In the educational treatise Practical Education as well as in her fictional work (which had a strong educational tone), parents are advised to reduce contact between children and servants. She gives an assortment of examples of the erroneous ways in which servants treat children. She also warns parents to be aware of the cunning nature of servants and nurses: 'A nurse's wish is to have as little trouble as possible with the child committed to her charge, and at the same time to flatter the mother, from whom she expects her reward' (I8or, p. Io).

With the aid of high chairs and swings, nurses or mothers raising children without a nurse would be able to take their work with them into the nursery. While the children were happily swinging away or safely playing in the high chair or crib, nurses or mothers could continue with their household chores or hobbies. There were, however, other incentives that popularized high chairs and swings from the mid-rgth century onwards. One of these incentives was the growing knowledge of the effects of opiate drugs on children and the practice of swaddling (wrapping babies tightly in cloth). Both practices were used to keep children calm and suppress their 'spastic' body movements. But they became discredited because physicians stressed that opiate drugs and swaddling accounted for many early deaths as well as mental and physical disabilities.

The nursery was more than an area in the home dedicated to child rearing. It is described as the locus of the home, as that which makes a house into a home and knits together 'generations each to each' (Carter, I883, p. 843). All the general requirements of a home, its cleanliness, warmth, air and light, 'should be most perfectly represented' in the nursery (p. 844). Certain rooms of the nursery department could therefore double as visitors' rooms because 'no better accommodation could be offered to friends or visitors than what is designed for the most cherished members of a family' (p. 843).

The developing culture of the child enforced a redefinition of the child's place and occupations. The world of the middle-class, Western child became the 'world of the home, and more specifically, of the toy-filled playroom within the home' as opposed to the 'workplace and the public city street' (A. Friedman, I995, p. 8). Play changed accordingly, from 'street games which involved neighbourhood children or strangers' to 'play activities such as building blocks, board games, and dolls which could be enjoyed alone or with siblings' (p. 8). The Igth century witnessed the design and production of many indoor toys. These toys often referred to or mimicked the changing world outside of the private home. Popular toys included building toys and mechanical toys such as fully functional little cooking stoves, steam engines or model train sets. These toys provided playful learning and socialization - not only in future roles as mother or provider of the family but also in 'solitariness' (Sutton-Smith, I986, p. 23-4I). The Igth-century 
toys answered the need for indoor entertainment while reinforcing the domestication of the child and play as they were unsuitable for outdoors play and required a flat, large and clean surface. Children's magazines and books would typically dedicate large sections to indoor play, mind games, riddles and tricks - illustrating what children could do inside the home, even when they did not have that many toys. Nursery picture books would bring the wonders of the outside into the home with sketches from the animal kingdom and marvels from Moscow, Egypt and China.

\section{The Child in the City}

Urbanization did more than just fuel domestication and suburbanization for those who could afford it. It had quite a different effect on the rural families migrating to the industrial areas. These families would trade their large farms for small living quarters. Because land in urban areas was expensive and rents were high, they often could not afford to rent private rooms. Sociologist and Benedictine Edgar Schmiedeler lamented how families went from being proud homeowners to tenants sharing small apartments and the high rent with other families and lodgers. All the moral strength that derived from being a responsible homeowner, the sense of security, protection and a family's privacy, had come to ruins among the lower and working classes living in urbanized areas (1927, p. 82). The Igth- and early 2oth-century working-class dwellings were so cramped that children could not play inside the home. These slum children dwelled in the streets, played on the sidewalks, hustled or went to the movies. The streets, however, were a dangerous place to play and hang out - that was where children learned bad habits, foul language and turned to crime.

From the mid-Igth century onwards, anxiety regarding the physical and moral health of slum children could be felt all over Europe and America. They were considered in need of saving: their health was threatened by the unhygienic streets and poor living and working conditions, by malnutrition and lack of clean, healthy air and physical exercise. With the assumed connection between physical health and moral development, these children's souls were at stake as well. The age-old adage Mens sana in corpore sano (sound mind in a sound body) had been actualized through the writing of Charles Darwin (1809-I882) and Herbert Spencer (I820-1903) on the connection between bodily health and moral development. Based on such biological and environmentalist assumptions, the idea that a healthy body is necessary to house a healthy soul became a key concept in relation to children and child rearing during the igth century. A child's physical health and moral development were considered related processes, dependent on one another.

Adding to the concern for urban children's physical and moral health was the growing demand for educated laborers and the pending wars for which many 
young men turned out to be unfit. With Europe moving fast towards military confrontation, the 'quality of the nation's heirs acquired a political significance' (Hardyment, 1984, p. 99). Physical education and outdoor play opportunities became all the more pressing when it turned out that boys growing up in the Igthcentury industrial cities did not meet the basic physical requirements for entering the military (Hendricks, 200I, p. I6). After the First World War, the American War Department continued 'its campaign to reduce the high percentage of physical unfitness discovered by the war' (Anonymous Reporter for the Time, 1923).

From the I88os onwards, this fear and anxiety related to urban, working-class children grew into various legislative decisions regarding working hours and working conditions, schooling and physical training. The European and American responses to the slum cities and their slum children were different though. As British urban theorist Peter Hall states, the 'problem and the perception of it were similar on both sides of the Atlantic. (...) But the remedies were different' (2002, p. 46). In Europe, the 'first and overwhelmingly the most important response to the Victorian city was the garden city concept by Ebenezer Howard' (p. 8). Saving the urbanites led at the end of the Igth century to the establishment of the garden city movement by Howard. Garden cities were purposely planned and built, selfcontained and green communities with a careful balance between residential, industrial and agricultural areas. Garden cities were built all over Europe and America from the turn of the century onwards. They were utopian cities characterized by pastoral images, glorifications of a simpler and less tainted life in the countryside where both adults and children would be safe to work, play and live at a healthy and secure distance from the industrialized metropolis.

The municipal interventions known in Europe were lacking in America where voluntary reformist movements took on the task of saving the inhabitants of the slum cities (p. 42-43). Reform movements characterized the end of the igth and the first decades of the 2oth century, when America was completing its rapid shift from an agrarian to an urban society. These reform movements were concerned with the rights of lower- and working-class women and children and the 'Americanization' of the steady gulfs of immigrants. Child saving was 'the most widely supported reform movement in the United States between I880 and 1920' (Cavallo, I98I, p. I). The inner cities were the battleground of the reformist movements, and the playground was at the heart of their mission.

One of the principle threats to the moral and physical demeanor of slum children identified by the reformist movements was the way in which children spent their free time. Schmiedeler calculated that only one-fifteenth of the child's time is spent in relation to school. Minus time spent sleeping, studying, doing small jobs like selling papers (mostly done by boys) and helping around the house (an unpaid job done by girls), the average child is left with 6 to 8 hours of free time, he stated ( 1927, p. 63). And a 'surprisingly high proportion' of this time was spent idle (ibid.). Neither commercial entertainment nor idleness was considered 
a proper way to while away the free hours. The common idea was that 'Satan speedily found some mischief for idle hands to do' (ibid.). Schmiedeler quotes studies by American sociologists Henry W. Thurston (IgI8) and John L. Gillin (I9I8) in which they claimed that there was a direct correlation between delinquency and the lack of active play amongst youngsters (p. 64). Active play was considered vital to both bodily health and moral development. The problem, of course, was where to carry out this active play.

The playground seemed the perfect vehicle for both the moral and physical education of urban children, for socialization and Americanization of immigrants and the regulation of free time. Instead of spending time idle, in mischief, inactive or at the theaters and movies - children would be better off on a playground, reformists argued. American reformist Jane Addams pleaded in The Spirit of Youth and the City Streets (1909) for decent public recreation facilities. Outdoor play facilities would build team spirit among youngsters, keep youth away from delinquency and provide 'the activity which cramped muscles of the town dweller so sorely need' (p. 95). American photographer and reformist Jacob Riis complained in Playgrounds for City Schools (1894) that there were not enough playgrounds in New York City and that the streets were the only playground available to poor children. The street, however, was 'an educator with its own plan' and that plan was 'not a safe one' (Quoted in: Brett, Moore, \& Provenzo, 1993, p. 20). Nasaw makes a distinction in his Children of the City between children working in factories who were considered to have too little freedom and children working the streets (as vendors, pickpockets or prostitutes, for example) who were thought to have too much freedom (1985, p. 138). As much as the reformers lamented the effects of long hours of factory work on young children, they also considered the street workers and the children playing in the streets a nuisance and a threat to adults (p. 20). The conservative theorist Sumner feared the dangers to society coming from the 'wild behavior of the idle, vicious and dissipated boys of the great cities' (I877, p. 68I). In I894, the Dutch illustrator Johan Coenraad Braakensiek depicted a street boy as a king in one of his cartoons - high on a throne, surrounded by his gang and a circle of bowing and fearful citizens.

At the end of the Igth century, playgrounds were created in parks, next to schoolyards, or on pieces of wasteland. In I885, Boston saw the construction of a sand garden (commonly considered the first U.S. playground), modeled after a Berlin sand garden. The number of playgrounds in America and Europe increased, professionalized and became more popular at the turn of the igth century. Early playgrounds served a broader communal purpose with clubhouses, libraries and many purposeful activities for not only children but teenagers and adults as well. In Europe, playgrounds were on the rise between the end of the I 9 th and the first decades of the 2oth century. The playground situation in the Netherlands has been well documented by the different active playground organizations. The incentives for establishing such playground organizations are com- 
parable to the American Reformist mission: moral and physical education for lower- and working-class children in dense urban areas. In the beginning, playgrounds were privately funded by the upper classes who lamented the moral and physical decline of the nation's youth and feared the street gangs who made the streets their playground (Boon, I935, p. 9-I5). In I880, philanthropist Nicolaas Tetterode created a public playground in Amsterdam to deal with the growing mischief among working-class youth (Selten, Adriaanse, \& Becker, 1996, p. I5). Many Dutch cities followed Tetterode's lead. Ulke Jan Klaren (known as father Klaren) was probably the most significant and best-known supporter of playgrounds in the Netherlands. In Igor he established a playground organization that opened playgrounds throughout the Netherlands. Most Dutch playgrounds during these early years served multiple purposes for children, teenagers and adults. The clubhouse would contain a library, and on rainy days educational activities were organized in this clubhouse. There were strict rules of behavior for those entering the playground (disobedience was punished with eviction from the playground), and trained supervisors guided children in group play (p. I7 \& 32).

Although playgrounds increased, children did not wholeheartedly embrace this form of socialization of play, this domestication of their outdoor play space, as Nasaw indicates. New legislative regulations prohibited playing in the streets and street working, and children caught committing these crimes were arrested (1985, p. I45). Children struggled to hold on to their former freedom to play where they pleased and earn their own money the way they pleased. Sumner quotes from a typical late Igth-century boy story illustrating the struggle between society's pressures to be a 'good boy' and children's resistance to this:

'James,' said he, 'you are breaking my heart with your incorrigible conduct.' (...)

'Think of what you might be, a pattern boy, a -'

'Brass-bound angel, silver-plated cherub, little tin missionary on rollers,' put in Jimmy (1877, p. 683).

The playground, the equipment especially designed for healthy and purposeful play and the group activities reflect the projected need for moral and physical education of the urban child. Within the confines of the playgrounds, however, children 'did not relish the adult 'supervision' that came along with it' (Nasaw, I985, p. 36). Interviews with children using the early playgrounds indicate their 'disdain for the adult efforts to teach them how to play' (ibid). Nor did all citizens like the introduction of playgrounds - commonly visited by lower- and workingclass children - in their neighborhoods (Rosenzweig \& Blackmar, 1992, p. 443447). 


\section{Toys as Containers, Mediators and Promoters}

The rise of our Western consumer culture during the igth and early 2oth centuries facilitated the design, development, marketing and selling of diverse toys on a larger scale than witnessed ever before. These toys mimicked the changing world in their miniature versions of technological wonders (e.g. steam engines for boys and cooking stoves for girls) and brought these changes into the home. Also, the ritual of buying, of giving and receiving presents became an important part in 'becoming a consumer', in training children how to survive in a consumerist society. While this aspect of commodification was first condemned and considered dangerous and corruptive for the Innocent Child, it later became accepted and even considered valuable to children's upbringing.

The home was the new prime location for wealthier children's play since urbanization had frustrated the outdoors as a safe playground. Urbanization and domestication prompted the need for suitable indoor toys, for toys that would keep children occupied safely indoors. These toys would often mimic the 'dangerous outside world' that children were being shielded from, such as building sets that allowed the young engineer to construct, for example, bridges and factories. These toys were mainly targeted at boys because they were expected, when older, to leave the private home on a daily basis to work and provide for their families. No such thing was expected of women. Girls, therefore, did not play with miniature, contained versions of what they could expect on the outside. Neither did their toys prepare them for a career on the outside - as an engineer or an architect, for example. Their toys reflected new technologies that were revolutionizing the household and the lives of their mothers. The new toys for girls demonstrated the workings of the girls' future work tools, the engineering of the household (A. Friedman, 1995, p. I4).

The road to the future through play would be sharply divided for boys and girls. Toys designed for boys idealized technology, constant innovation, and the values of competition and teamwork. Those for girls were mostly dolls and were designed to train girls to become 'modern' housewives and nurturing mothers (Cross, 1997, p. 5I).

Boys were introduced through their toys into the world of science and industrial production. Girls were introduced into the world of consumerism and modern homemaking because in a consumerist society, 'developing shopping skills was becoming an important part of growing up' (p. 5I). However, as Aaron Alcorn (2006) demonstrated with his research on model airplanes, boys were also constructed as consumers through the systems of collecting different airplane models, memberships and contests but under the guise of male activities such as airplane building and the creation of future-oriented technological men. 
Obviously, many children living in the Igth-century industrialized cities did not partake in these upper- and middle-class processes of commodification and domestication. Children from the working and lower classes would often work in the factories producing the new commodities and would share a single room with their family. Saving these children became a late Igth, early 2oth-century effort that crystallized in, among other things, the building of playgrounds in urban and industrial areas. Urbanization had, in other words, two different effects. On the one hand, urbanization prompted parents to keep their children indoors if they could afford it financially and space-wise. This in turn stimulated the production of indoor toys (with construction sets as a most important example) that reinforced the domestication of child and play. On the other hand, urbanization fuelled the belief that working- and lower-class children were in need of saving from the factories, streets and commercial entertainments. This in turn led to the construction of playgrounds and the creation of outdoor play equipment. Slides and swings, balls and hoops, sand gardens and sporting fields were attempts to domesticate outdoor play and socialize the urban child.

Toys and playing are central in bridging societal processes and changes on the one hand and the individual on the other hand. Toys bring a changing society into the private home and can as such be considered to function as mediators. Toys function as intermediaries in bridging the outside world and the child's universe. In this role, toys are often at the heart of anxieties, fears, longings and battles. Toys can be considered a terrain, a site, on which crucial battles concerning a changing society are being debated. The use of toys, the users of toys and the importance adhered to toys have changed dramatically since the beginning of the igth century. From objects created from leftovers to machine-made and massproduced toys, from pastime amusement for adults and children to instruments for a child's education and learning, toys have become invested with expectations, longings and fears. Toys as containers for emotions and expectations become instrumental, that is to say, they become something else than simply things to play with. Toys have turned since their commoditized and instrumentalized Igthcentury incarnation into vehicles for mediation between societal processes and individuals. They have become tools for learning, for socialization and training. Not only do toys mirror societal and cultural change, they will often promote, reinforce and spur these changes on. For example, construction toys answer the need for indoor toys while reinforcing the domestication of child and play in their design. Toys are then more than simply a hatch-like object, a passageway or vessel. Toys are at the same time mediators, mirrors and promoters. Toys are involved in a relationship of mutual shaping or co-construction with societal and cultural processes on the one hand and with the individual or the player on the other hand. Moreover, toys are 'generation-shapers'. Toys can either tie generations to one another through communal play, shared toys and play-related mem- 
ories or create a rift between different generations when (grand-)parents and children cannot find a common ground in play.

The interplay between the societal processes of commodification, domestication and urbanization, toys and children still resonates today, although it has changed in shape and direction, intensity and target. The nature and objective of many debates related to the effects of playing computer games illustrate that the mid-Igth and early 2oth century issues related to toys and children are still very much alive today. ${ }^{3}$ Computer games are, for example, often criticized as the embodiment of a consumption-obsessed culture and society. Computer games are advertised through movies, card and board games, action figures and animated movies. Their heroes feature on pajamas, bed covers and lunch boxes. They are characterized by what could be labeled the 'expansion pack and serial' economy that has children wanting these new additions and installments to their favorite games. Moreover, many games' internal logic is based on consumerist principles of gathering, trading, and accumulating.

Another often-voiced critique about computer games relates to what we could call over-domestication. It has never been so easy, attractive and addictive to stay indoors. Computer games have added to existing 'couch potato' forms of entertainment, such as television, an even more captivating form of staying indoors. Children play computer games indoors, hunched over a keyboard or controller, eyes glued to the screen. They overuse certain muscles and totally underuse others. Computer games are un-put-down-able, and while playing, children forget to eat, take a break, go to the toilet or stretch their legs. Instead of being in the open, getting fresh air and physical exercise, they sit the whole day breathing the stale indoors air. The game industry, traditional toy makers and a range of oneproduct, opportunistic companies respond to this problem of over-domestication with the production of what we could call 'off-the-couch games'. These games require the player to physically move in order to play. The Smart Cycle by FisherPrice is 'a stationary bike, a learning center, and an arcade game system-all rolled into one!' (Fisher-Price, 2007). One-product company XMAT sells the GamerCycle promising to turn 'the completely sedentary activity of playing home video games, into a calorie-burning, aerobic activity for your children. (...) the GamerCycle is a way to add fun and exercise to video game time' (XMAT, 2007). Better-known examples are Sony's EyeToy (2005) and Nintendo's Wii (2007).

One of the central tensions in contemporary child rearing is that between domestication and urbanization. Reluctant to let children play outside unsupervised and lacking the time to accompany them regularly, parents tend to keep children safely indoors. Households are organized so that children have their own room where they can occupy themselves. Many toys are designed to be suitable for indoor, solitary play. Outdoor spaces designated for children's play - playgrounds are domesticated spaces as well in the sense that they are bordered and supposedly safe areas for play. New media technologies in general, and the Internet, 
personal computers and hand-held gaming devices in particular, have recharged tensions between domestication and urbanization. On the one hand, these new media technologies allow for hours of captivating indoors entertainment. On the other hand, they facilitate frequent transfer between the outside world and the family home by means of personal computers and game consoles connected to the Internet. Also, hand-held, portable gaming devices contain the possibility of dislocating play from its interior locality, although players need to stay put in a sheltered environment in order to play on these devices. Portable game consoles are mainly used during car drives and when someone else is using the television set and/or the game console. Computer games not only over-domesticate child and play, they also frustrate the private room as a sanctuary. Game consoles and personal computers connected to the Internet, computer games prompting the player to go online for updates and new input as well as hand-held gaming devices reestablish a connection between the child and 'the mean world' outside of the private room.

Personal electronics have become a source of worry among parents, politicians, educators and health counselors. A personal computer connected to the Internet raises issues of children's exposure to pornography and violent content, of pedophiles lurking in chat rooms and engaging young children and teenagers in unsuitable behavior (web cams have added considerably to this worry because the child is made visible to unknown others), of easy access to (pharmaceutical) drugs and drug dealers and of digital bullying among classmates. Since so many personal electronics have moved into the bedroom, it is all the more difficult for parents to keep an eye on what their children are doing online. The bedroom or playroom, once a safe place for children, has become a battleground. Notwithstanding these worries, many parents perceive digital technologies as an asset rather than a threat. On the one hand, digital technologies smooth the juggling act of daily life, and on the other hand, parents express belief in the educational values of digital tools (Rideout \& Hamel, 2006, p. 32; Rideout, Vandewater \& Wartella, 2003, p.6).

The domestication of the playing child has reached an extreme and taken a wicked turn with digital entertainment. Computer games allow children to kill hours and hours of time without having to leave their room. Children's bedrooms have, over the last decades, become increasingly suffused with personal electronics. In 1999 the Kaiser Family Foundation released its first report on American children and new media. They found that an average of $33 \%$ of children between the ages of 2 and 18 had a video game player in their bedroom, I6\% had a computer, and $7 \%$ of those computers were connected to the Internet. More than half of the children $(53 \%)$ had a television in their bedrooms (Roberts, Foehr, Rideout, \& Brodie, I999, p. 13). Six years later, in 2005, they issued a report stating that an average of $49 \%$ of children aged 8 to I 8 had a video game device in their private bedrooms, $31 \%$ had their own computer, and $20 \%$ of those were con- 
nected to the Internet. Some $55 \%$ of 8 to I 8 year-olds reported having their own hand-held gaming device (Roberts, Foehr, \& Rideout, 2005, p. I3). Only personal television ownership ranked higher, with 68\%. The 2005 report concluded: 'most U.S. kids inhabit rooms that seem to be as much media arcade as bedroom' (p. I6). Hand-held gaming devices allow players to take their game with them and game consoles and personal computers linked up to the Internet allow players to stay in contact with the outer world from within the family home. These options re-introduce 'the mean world' in children's lives.

Mail, the telephone, radio, television and fax machine also establish connections between the outer world and the inner home. However, these communication and information technologies mainly establish a unidirectional flow between the private home and the outside. News enters the home, and a caller's voice might travel from the inside to the outside. With personal computers connected to the Internet, a complex mix of user information and user data, of spoken and written messages, of still images and streaming video travel from the inside to the outside and vice versa. The Internet facilitates fast transfer between the home and the outside world while making it harder for parents to track this transfer. More often than not, children are more knowledgeable in effacing their online traces than parents are in tracking them. In centrifugal and centripetal movements, information, data, text, voice and image are exchanged between the home and the world outside. 



\section{Part II: From Solitary to Networked Geographies of Play}

Construction toys are an outstanding example to illustrate how toys mediate between societal processes such as commodification, domestication and urbanization and the individual child because construction toys exemplify these very societal processes. During the igth and early 2oth century, hundreds of different construction toys were produced and sold. Some companies and their toys survived long enough to be remembered today while others have disappeared and been forgotten. The history of construction toys is closely linked with the coming into being of consumerism. The combination of new production processes that facilitated the mass-production of relatively cheap toys and the rise of department stores secured the mass consumption of toys. Construction toys - to be assembled with care and patience by fitting little pieces together on a flat surface are domestic toys pur sang. According to Tobias Mey, well-to-do German citizens would often devote a whole playroom to construction toys, thereby turning that room into a building room. The little particles could easily be lost, and the player simply needed a flat and uncluttered floor to build on (1999, p. 35). Construction toys are designed to be played with indoors and will keep children occupied for hours while they are safely inside the family home. As such, these toys reflect the reluctance to let children play outside unsupervised. However, most construction toys center on urban design: building houses, bridges and other architectural constructions. The outside world was thus brought to the sanctuary of the family home in a safe and containable format.

Construction toys were (and still are) a very popular genre of toys among educators and parents. Their popularity among children has seen some significant swings. From the early I99os onwards, sales numbers reflect that construction toys suffer from their image as boring and dull toys. The popularity among educators and parents of construction toys is related to the historical entanglement of construction toys with educational notions. From the very start, the educational value of construction toys was stressed. For example, in the British toy trader's magazine Games \& Toys from July IgI4 we find the article Constructional Toys of Merit stating:

We live in the age of construction toys. (...) One thing stands out from the great boon and that is that the average boy of to-day needs a toy which is not only a toy, but one which has an educational value attached to it (Anonymous, p. 8o). 
Reasons for labeling construction toys 'educational' vary, but they all center on the fact that building something is considered a purposeful activity whereby children understand an object through the dismantling and reassembling of it, through being actively involved in decision-making and structure-forming. According to Stevanne 'Dr. Toy' Auerbach, construction toys force children to think about fit, angle, gravity, size, space, cause-and-effect (connect what you see with what you can do) while stimulating eye-hand and small muscle coordination, thereby developing self-esteem, independence and increasing language skills, social abilities and imagination (I999, p. I5). More generally, construction toys are considered educational by psychologist Dorothy Singer because they are about planning, patience, thinking ahead, cooperation, sharing, self-control, delay of gratification while increasing insight in building processes, mathematics and natural sciences (2005, personal communication).

German educationalist Friedrich Fröbel (1782-1852), establisher of the Kindergarten, was both directly and indirectly a key player in the popularization and commodification of construction toys. This is not to say that Fröbel 'invented' the construction toy. Wooden building blocks and alphabetical building blocks dating from the late I8th century are found in many a toy museum. But their popularity and diversity took a flight with Fröbel's construction toy designs and his writing on the educational merits of these toys. Fröbel established his first Kindergarten in Blankenburg, Germany, in 1837 . He considered play 'the highest phase of child-development' and stressed the fact that 'play at this time is not trivial, it is highly serious and of deep significance' (Fröbel, I887, p. 54 \& 55). He designed toys (which he called gifts) for use in his Kindergartens and wrote detailed instructions on how the gifts had to be used (these detailed instructions on how to play with the toys have always been a point of critique on Fröbel's educational system because they were very formal and structured). Building kits played a central role in Fröbel's Kindergarten system, toys number 3 to 6 consisted of wooden building blocks. These gifts were popularized and sold in Germany as 'Fröbel's Building Blocks' and 'Fröbel's Bauschule' from the mid-Igth century onwards. Many toy manufacturers sold wooden building blocks they claimed to be in line with Fröbel's pedagogy. The first German factory to produce wooden building toys - S.F. Fischer Spiel- und Holzwarenfabrik in Seiffen, Oberseiffenbach - produced and distributed Fröbel's toys on a large scale from I870 onwards.

Construction toys have changed since their Igth-century popularization. For one, the main materials used in creating construction toys changed from wood, stone and steel in the Igth century to various plastics during the postwar period and digital technologies from the ig8os onwards. The nature, type and porté of construction toys diversified as well over the years. To put it bluntly, construction toys have changed from wooden and stone generic building blocks to designing toys of diverse materials, with different shapes and, crucially, with an interlocking 
mechanism. The Igth-century building toys were generally sets of wooden or stone building blocks that facilitated the constructing of architectural and/or abstract objects. These toys were mainly meant for young children and focused on the development of bodily skills through building or stacking blocks on top of each other. The design possibilities of these building toys were limited because they did not have an interlocking mechanism.

From the turn of the century onwards, these traditional building sets were supplemented with sets specifically focused on designing objects as a form of play. These second-generation construction toys would often mimic the designs that were revolutionizing the public sphere and allowed the player to construct miniature bridges, skyscrapers, cars and planes. These construction sets were designed to be about design on the level of both play practices and play subject. Meccano, Lincoln Logs and the Erector Sets are well-known and popular examples of the second-generation construction toys. Second-generation construction toys epitomized a culture's belief and optimism that indeed, thanks to new technologies and materials, everything seemed possible. Construction toys mirror fundamental beliefs of our Western culture in construction, design and 'malleability'. Designing more complex and wide-ranging objects was facilitated through more diversified pieces and an interlocking mechanism of one sort or another. The generic building elements of the early construction sets were supplemented with more specific building items, such as wheels or curved pieces. Meccano sets, for example, contained specified items that allowed the player to design elaborate constructions while at the same time facilitating the construction of more than one design.

Design in this context and specific use should be understood as actions taking place at the intersection between the 'thinkable' and the technologically 'possible', between 'models, cultural structures, forms of knowledge', 'availability of materials' and 'technological development' (Manzini \& Cau, I989, p. I7). At the turn of the century, newly available materials and production processes expanded what could happen at the intersection of the thinkable and the possible.

It is important to stress that the change from building to designing toys was not a clear-cut one; neither did the second-generation construction toys replace the first generation. Both types of construction toys exist side by side; there are still many traditional building sets on sale today. Generally speaking, first-generation construction toys are made from wood or stone and second-generation ones from metal or plastic, materials that facilitate an interlocking mechanism. However, during the transitional phase between building and designing toys, wooden design toys with an interlocking mechanism were also on the market. And of course, there are many plastic building blocks on sale as well. First-generation construction toys were mostly focused on abstract or architectural constructions. Many early second-generation construction toys still adhered to this idea of con- 


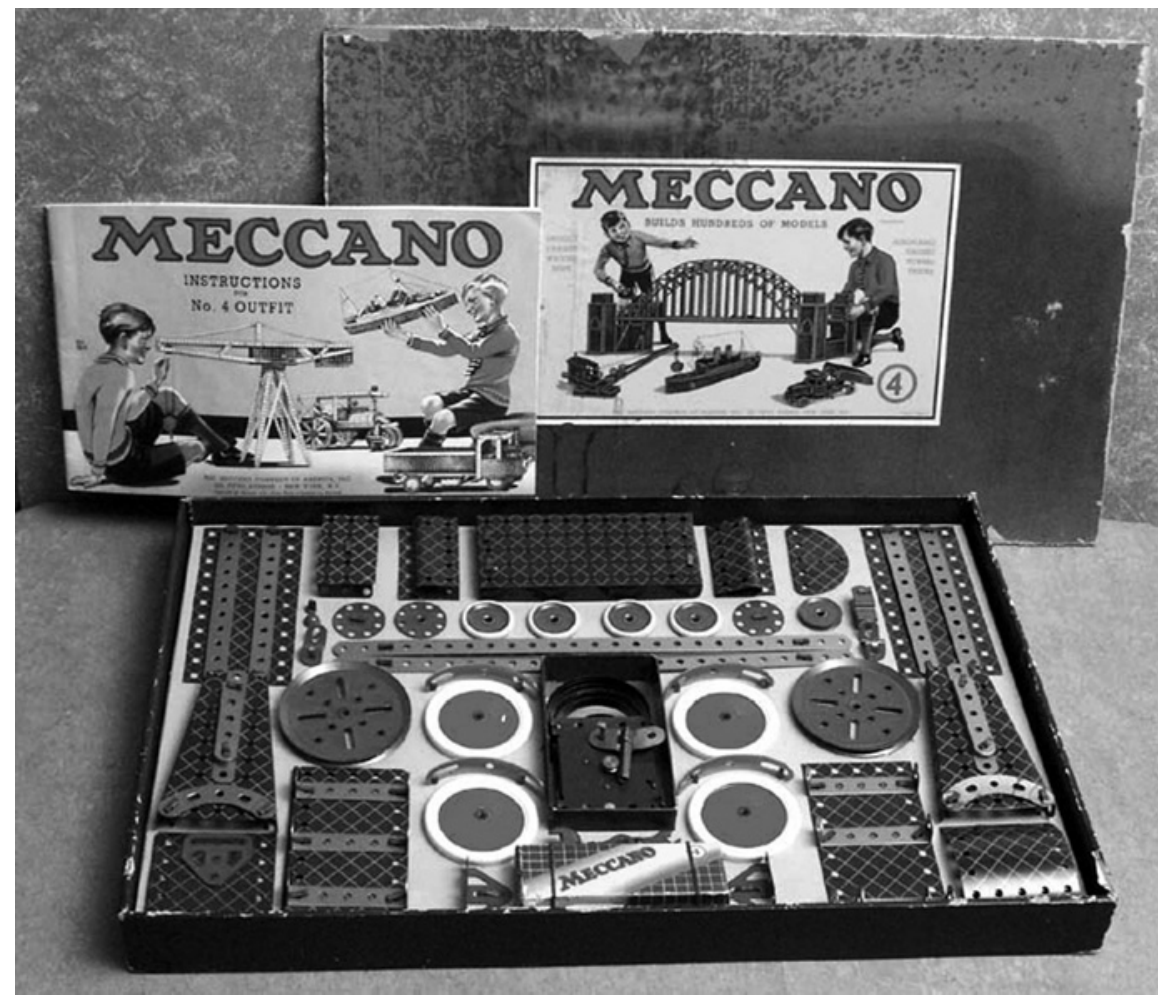

5 Towards Construction Toys as Designing Toys

The many specified items in this Meccano set from 1938 augmented the design possibilities with this toy (Bisset, 2006). The cover of the box itself and the cover of the instruction book show boys building and playing with diverse constructions such as a bridge, a boat, a car and a crane. Inside the box, in the middle, is a key to wind up the constructions and to make, for example, the car or truck ride on itself.

struction toys as architectural toys and focussed on the designing and construction of houses.

Concurrently, this shift from building sets to designing sets entailed a shift from constructions toys meant for both girls and boys to construction sets targeted almost exclusively at boys. Designed-to-be-about-design construction toys were boys' toys, quintessential to the men's world of technology, optimism, progress and new inventions. While the drawing on the Fröbel's Bauschule set still sported two girls, one of them actively building, the Meccano set shows only boys (the Meccano Boys was a popular club for male Meccano fans). Typically, these second-generation construction sets would show a boy at play, often with a father or grandfather hovering over the scene. Mothers, if depicted, would look on the scene benevolently from an easy chair. Sisters, when present in these building 


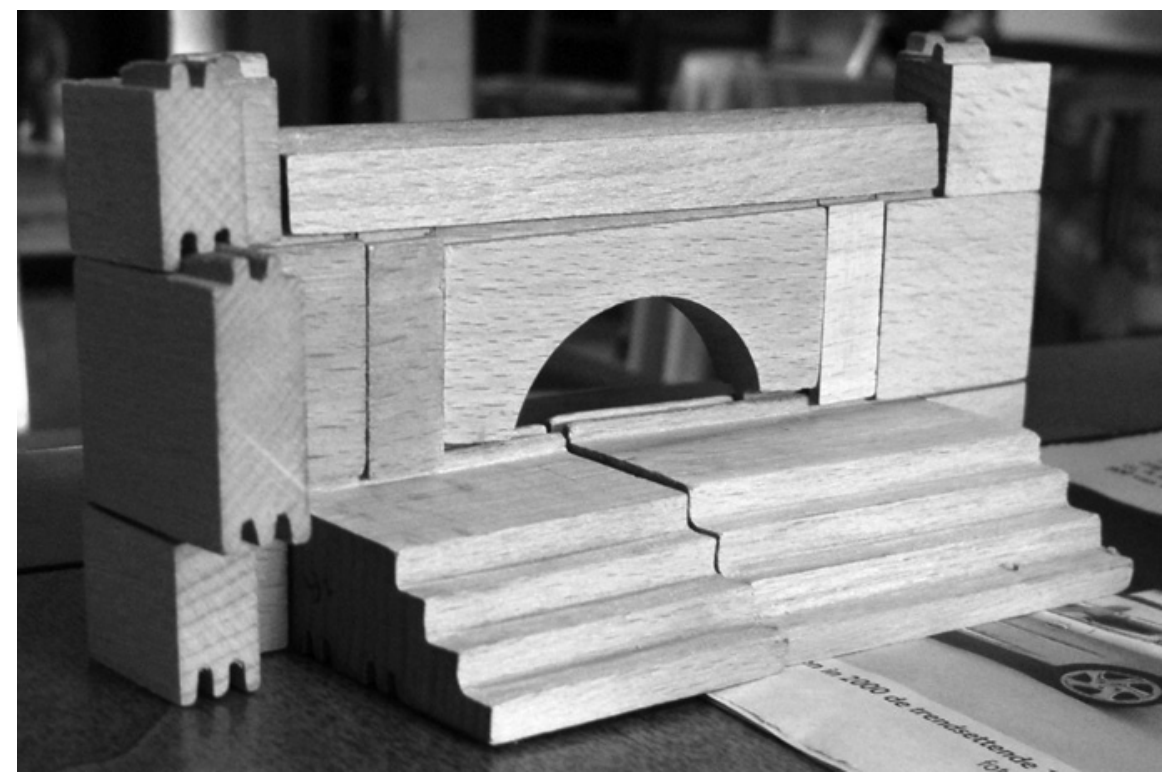

6 Transitional Construction Toys

The interlocking mechanism was a crucial factor in the development from building toys to designing toys. This construction toy dates from 1932; the name and manufacturer are unknown. It alerts us to various aspects of this development. For one, it indicates that the development from building toys to designing toys did not necessarily coincide with the aforementioned material changes. Although wood and stone have been (and still are) the prime materials of the first-generation construction toys (building toys), they have also been used to manufacture second-generation construction toys (designing toys) such as the one depicted above. Especially during the transitional period of the first decades of the 2oth century, wood was often used to create second-generation construction toys. Not always with success, however. The interlocking mechanism of this toy, for example, is not very precise, and the toy therefore came with a little hammer to forge the pieces together. Second, this toy illustrates that, although architectural constructions and models are characteristic of first-generation construction toys, this does not mean that second-generation construction toys would not take architecture or home building as their subject (image courtesy of Van Dorst, 2007).

tableaux, would be helping their brothers. The Stabila construction sets by Firma Walther from the I93os attempted to unify male-oriented construction play and female occupations. The Stabila sets allowed for the construction of objects in line with a girl's future occupations (pram or baby cot, for example). The metal base for the constructions was made homely with colorful woolen threads. 


\section{LEGO Toys: from Wooden Blocks to Plastic Bricks}

In 1932 the carpenter Ole Kirk Christiansen (I89I-I958) established what is known today as the LEGO Company in the Danish village Billund. ${ }^{4}$ Christiansen started making toys in a very typical and at that time common way: most craftsmen used their leftover material to make toys and simple playthings (LEGO, I982, p. I3). The production line of the factory soon changed from toys as a by-product to toys as the main product, and in 1934 the firm was therefore renamed LEGO, the contraction of the Danish words 'leg godt', 'play well', writes Danish historian Ole Steen Hansen (1997, p. I6). The first wooden toys were produced of timber and were distributed and sold without any packaging but with the LEGO logo rubber-stamped underneath or on the side of the toys. The LEGO Company kept producing wooden toys until a fire destroyed the storage spaces for the wooden toys in 1960 (p. 3r). Plastic entered the company after the Second World War when the German occupation ended and new materials and production methods became available in Denmark. A fish-shaped baby rattle dating from 1949 is one of the first plastic toys the LEGO Company made.

To be sure, many toy manufacturers experimented from the First World War onwards with the use of plastics for making toys in response to the shortage of wood and metal for the toy trade. In January 1915 the Games \& Toys magazine reported that in the North of England a firm had 'a very large quantity of wood in stock' and that it 'is in the position to supply the trade with wood for the manufacture of wooden toys' (Anonymous, 1915, p. 280). Even after the war was over, metal toys were scarce, as Games \& Toys reports in January I9I9.

For making tin toys, a substitute called black tin was sometimes used: 'This material is much cheaper and is of no practical value for the war industries, so it has been given to the toy manufacturers' (Anonymous, 1919, p. 246). Nevertheless, 'all manufacturers making lead and metal toys have suffered a great deal' (p. 246). Besides the scarcity of materials for the toy trade, the ban on German toys caused problems as well. Germany had the biggest toy industry after all. While it seemed at first that the First World War would call a halt to the flourishing toy business, experiments with the use of plastic turned out to be - in the end - successful, and the mass production of toys could continue (McClary, I997, p. 35).

Plastic was introduced in the LEGO Company at the end of the I940s when they bought a plastic molding machine. The LEGO Automatic Binding Brick - the forerunner of the LEGO brick we know today - was created with this molding machine and released in 1949. There were two sizes of Automatic Binding Bricks, one with four and one with eight studs and they came in four different colors. The system that connected the bricks was not based on the stud-and-tube coupling system we know today. The bricks had studs on top but no tubes underneath. They had slots in the sides of the bricks to accommodate windows and doors. 


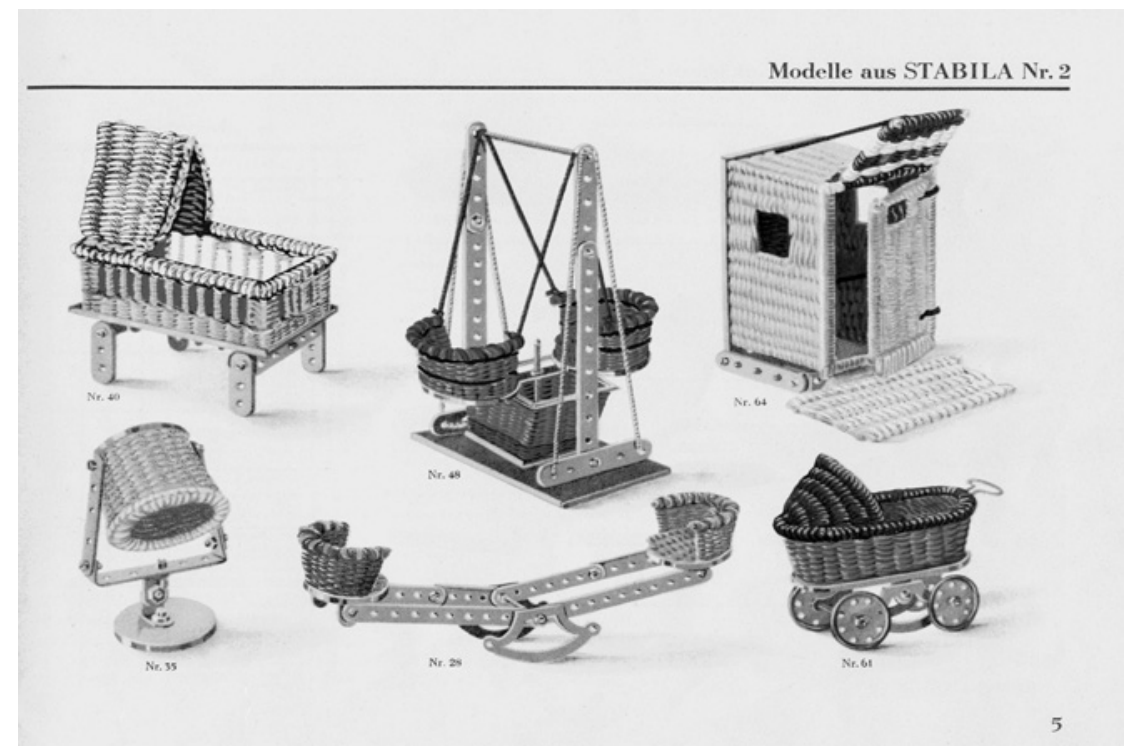

7 Construction Toys for Girls

These are some of the examples of what one could create with the Stabila construction toy. It is part of a little booklet that accompanied the 1933 Stabila set number 2. With this Stabila set, girls could make various objects such as a swing, a baby cot and a beach cabinet for changing into a bathing suit. Stabila sets combined elements reminiscent of male-oriented construction sets, such as metal plates, with woolen and colored threads that made the metal constructions more colorful and homely (image courtesy of the heirs of the Firma Walther. Image online available on the homepage of Werner Sticht).

Strictly speaking, the LEGO Company did not invent the plastic building brick. The English Kiddicraft Self-Locking Bricks designed and produced by British child psychologist Hilary Page (1904-1957) inspired the LEGO design. Page designed and sold Kiddicraft Self-Locking Building Cubes (1940 UK patent \#529580) and Kiddicraft Self-Locking Building Bricks (I949 UK patent \#633055). In Page's educational book Playtime in the First Five Years we find pictures of children playing with the plastic building bricks ( 1938 , p. 5I, 79 \& II5). There is a reference to Page in the article Astonishing secret behind the world's most famous toy by Adrian Lithgow that appeared in The Mail in 1987. According to The Mail, Ole's son Godtfred Kirk Christiansen - then 66 years old - stated that 'he received sample bricks from a Londoner, Mr. Hillary Page, in I947' (Lithgow, I987). In I98I the LEGO Company agreed to an 'out-of-court settlement of 45,000 (British Pound) for any residual rights of the new owners of Mr. Page's company, Hestair-Kiddicraft' (ibid). In the 1997 LEGO publication Developing a Product, the LEGO Company refers for the first time to Page: 
'Automatic Binding Bricks' (...) were inspired by a couple of British plastic building bricks made by the Kiddicraft company and sold only in Britain. (...) we modified the design of the brick (...). The modifications (...) included straightening round corners and converting inches to $\mathrm{cm}$ and $\mathrm{mm}$, which altered the size of the brick by approx. O.I $\mathrm{mm}$ in relation to the Kiddicraft brick. The studs on the bricks were also flattened on top (p. 2-3).

The LEGO Automatic Binding Bricks from the I950s and the Kiddicraft Self-Locking Building Bricks by Page look exactly the same. Then again, Page's Kiddicraft Self-Locking Building Bricks were not the first rubber or plastic bricks with an interlocking mechanism. The Rubber Specialties Company of Pennsylvania sold the rubber Bild-O-Brik from 1934 onwards. Similar to the Bild-O-Brik is the Minibrix by the Premo Rubber Company of Petersfield (UK) patented in 1935 (Hanson, 1993; Smallbone \& Hanson, 2007). Both the Bild-O-Brik and the Minibrix had an interlocking mechanism comparable to the Kiddicraft and LEGO interlocking mechanisms.

The first type of plastic the LEGO Company used between I949 and 1963 was cellulose acetate. But, as technical engineer Ulrik Jørgensen states, this type of plastic was 'easily deformed by heat and water and would undergo slight changes over the years' $(1998$, p. 6). Therefore, from 1963 onwards, acrylonitrile butadiene styrene (or ABS) was used. This type of plastic enhanced the quality of the bricks in terms of life endurance and clutch power. Because ABS allowed for more molding precision, the bricks now fitted together more tightly, and constructions became more stable.

By I95I plastic toys accounted for half of the LEGO Company's output. Nevertheless, the Danish trade magazine Legetøjs-Tidende (Toy-Times) stated at the beginning of the I950s, after having visited the LEGO factory in Billund, that 'plastic would never be able to replace good and honest wooden toys' (O. S. Hansen, I997, p. 22). This demonstrates fittingly how most people felt (and sometimes still feel) towards the use of plastic in toys. Plastic has been met with both liking and disliking. On the one hand, consumers tend to be happy with the cheap, easy to clean, colorful and (generally speaking) durable plastic products. On the other hand, plastic, as opposed to wood, is easily associated with artificiality, superficiality and fakeness. Overall, critique on plastic toys has been voiced by the elite rather than by consumers. The semiotic theorist Roland Barthes (19151980) was one of many to object to plastic toys. In Mythologies (1957) he states: 'Current toys are made of a graceless material, the product of chemistry, not of nature. Many are now moulded from complicated mixtures; the plastic material of which they are made has an appearance at once gross and hygienic, it destroys all the pleasure, the sweetness, the humanity of touch' (p. 54). LEGO toys, however, seem to be an exception to this dislike of plastic toys. 'Part of Christiansen's gen- 
ius was to make the new material feel almost as comforting, as domestically reliable, as wood itself' (Lane, 1998, p. 4).

The change in prime material used for making LEGO toys led not only to different products but also to a different interaction of the child with these products. As stated, toys and play practices are intimately connected, and the design of a toy facilitates certain play practices (and not others). Later on in the LEGO history, the way people play with LEGO toys will also influence the design of (future) LEGO products. When not only the technological possibilities and available materials influence the design of toys but play practices shape and influence toys as well, the relationship between toys and play practices becomes one of mutual shaping and co-creation. At this stage of the LEGO history, however, the direction is still one-way: toys shape, influence and facilitate play in a certain way but not vice versa. The evolution from wooden building blocks to plastic designing bricks changed the way children could play with LEGO toys. Wooden building blocks allow you to make mainly abstract and architectural constructions that are not too high, do not have too many corners, no sloping roof and are mainly twodimensional. Plastic bricks that fit onto and into one another allow for more design and construction versatility. Plastic and an interlocking mechanism are key factors in this change from building to designing toys. It would have been very hard indeed to make a stud-and-tube coupling system in wood. Plastic pieces clutch better than wooden pieces and can endure more resistance.

The interlocking mechanism of the LEGO plastic building bricks changed in I 958 to the new and improved stud-and-tube coupling system that is still being used today. This new coupling system was facilitated by innovations on the level of plastic molding machines. Stud-and-tube coupling bricks have studs on top of the bricks and tubes underneath. With this new coupling system the slots disappeared completely from the bricks (from 1956 onwards, the LEGO Company had been producing bricks with and without slots). Thanks to the stud-and-tube interlocking mechanism, how and what one could build with LEGO bricks multiplied, and the potential of the LEGO bricks increased. The first LEGO bricks were 'rather limited' in their use, 'you could only fit them together in a limited amount of ways' (LEGO, I979, p. 2). 'It was the tubes that gave the product its versatility and building stability' (Wiencek, 1987, p. 50). While constructions built with the Automatic Binding Bricks were still a bit shaky, the new system was extremely precise.

When constructions became more stable due to the new coupling system, one could build larger and more detailed objects such as cars, planes and boats. And since you no longer had to build your constructions around the slots that would accommodate windows and doors, there was more freedom in where to put the doors and windows, and there could be more of them in one construction or none at all. 
FIG.I.
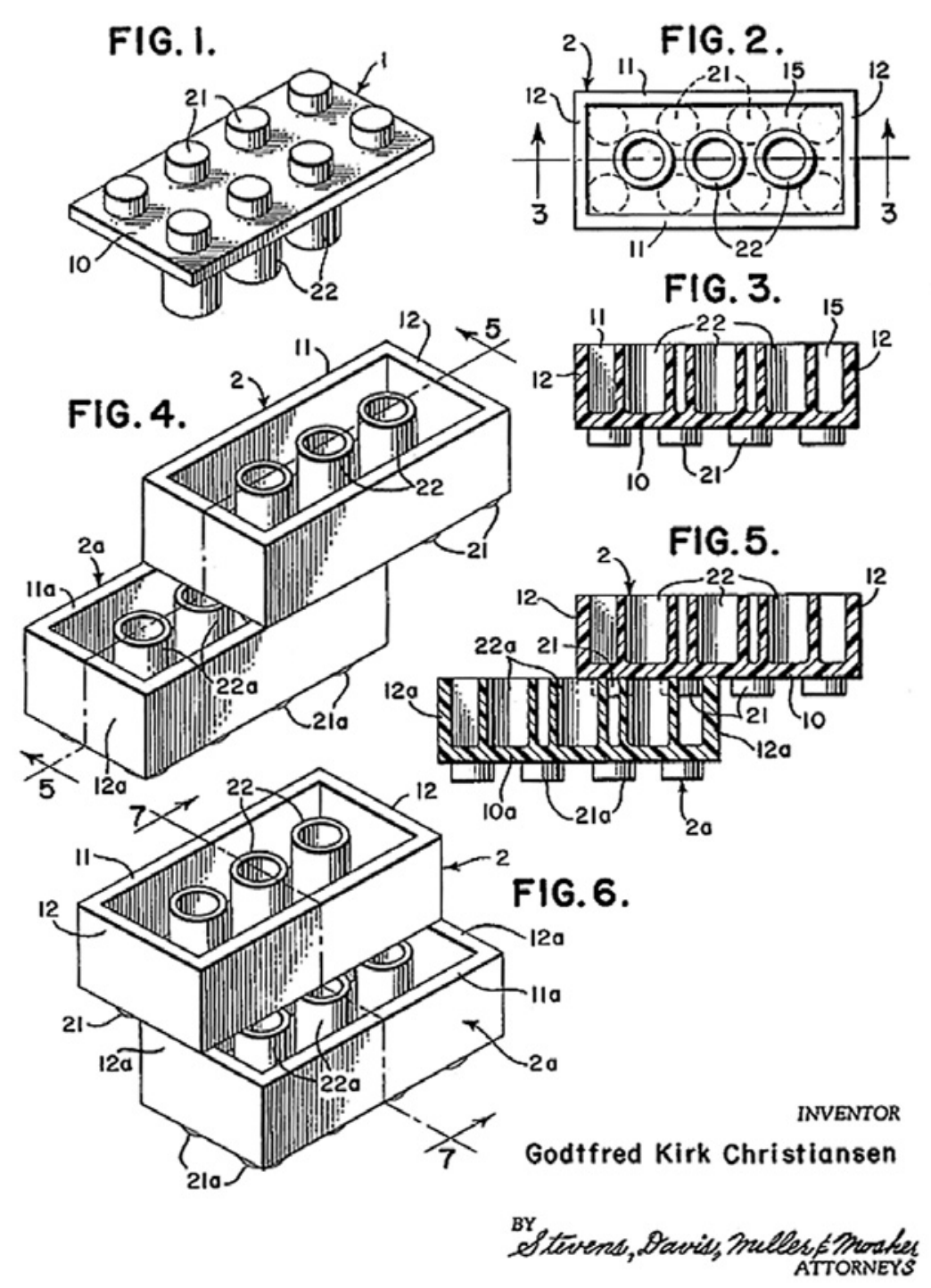

FIG. 3.

2 Sheots-Sheot 2

8 Patent of the plastic LEGO brick with the stud-and-tube coupling system

This is part of the patent for 'Toy building brick' filed on July 28, 1958. The inventor is Godtfred Kirk Christiansen (Hughes, 2007). ${ }^{5}$ The patent clearly illustrates how this new interlocking mechanism enhances the clutch power of the bricks. The studs on top of the bricks fit nicely in between the tubes underneath the bricks, as figures two and five of the patent show. 

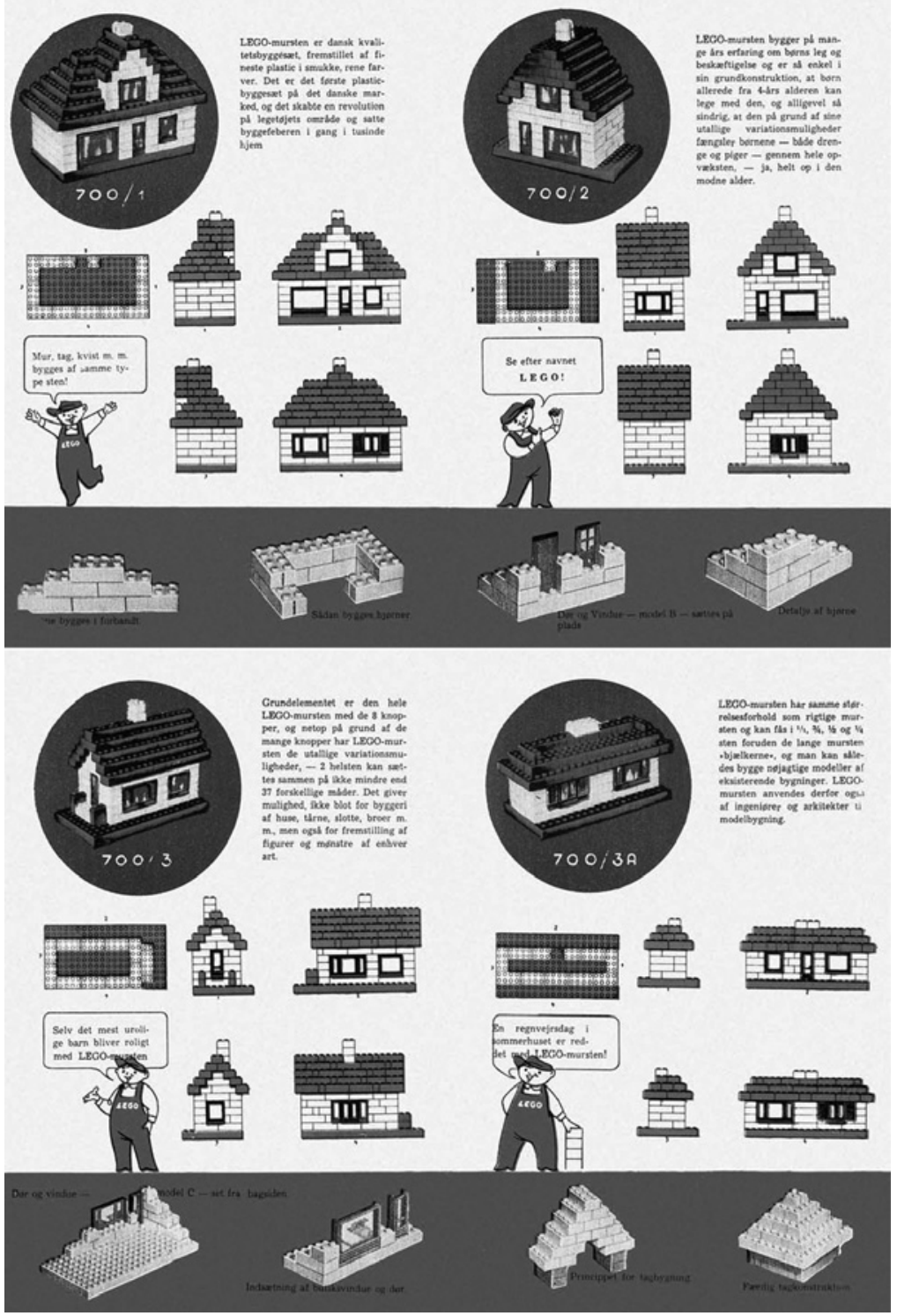

9 LEGO as an architectural toy

This Lego Mursten Catalog from 1954 shows how you can build different houses with the white and red bricks in the set (Hughes, 2007). The LEGO Mursten sets all heavily relied on the idea of construction toys as architectural toys: the building ideas that illustrated what one could construct with the LEGO Mursten sets were almost all architectural. These catalogues enforced the LEGO discourse of LEGO toys as architectural toys. Besides the fact that the LEGO discourse relied heavily on architectural models and constructions, the design enforced this as well. For example, the only non-brick elements in the sets were windows and doors. 
The 1958 molding machine also changed the practices of LEGO play because this new machine could produce different shapes and little detailed particles such as different hairstyles and helmets, flowers and, in time, walky-talkies. Starting with just two sizes of bricks in 1949 , the LEGO Company produced 12,400 different pieces in 2004. With these diverse pieces and bricks, one could make far more detailed and realistic constructions. A good example in this case is the LEGO mini figurine introduced in 1978. Before 1978, people and animals were constructed out of bricks. With the launch of the mini figurines, people and animals became preformed and pre-shaped. While you can still change some parts of the figurines you buy today, they differ immensely from the idea of building figures with LEGO bricks. Figures created with LEGO bricks are big and static while the mini-figures can move their head, arms, hands and legs and can more easily be integrated into a construction (for example, they can sit in a car or a plane).

The introduction of the new interlocking mechanism and small, detailed pieces largely coincided with a transition from LEGO as an architectural toy to LEGO bricks as the basis for many diverse and wide-ranging constructions and with the introduction of the LEGO System of Play.

LEGO construction sets from the late I940s and most of the I950s mainly focused on the construction of houses. This is expressed in both the design of the Automatic Binding Brick and the discourse surrounding these early LEGO sets. The slots in the LEGO bricks were meant for the incorporation of doors and windows, that was the only play option these slots facilitated. Moreover, the first interlocking mechanism did not yet provide the clutch power needed for complex constructions. In the words of the LEGO Company itself: "Automatic Binding Bricks' (...) did not have much clutching power and were best for stacking. (...) all they could be used for was building simple walls and houses' (LEGO, I997, p. 2-3). The early LEGO discourse, communicated through the drawings on the boxes for example, focused on architectural models.

The emphasis on LEGO as an architectural toy can also be seen in the name change that was effectuated in 1952. In 1952 the Automatic Binding Bricks were renamed LEGO Mursten (Danish word for 'brick'). In Danish there are two words for bricks: a more neutral Danish word for bricks would be 'klodser' (Jørgensen, I998, p. 6). The choice for Mursten 'reflects the emphasis on architectural models' (Stephens, 2005) and on 'using LEGO bricks for house building' Jørgensen, I998, p. 6). The word 'mursten' gradually disappears from LEGO packages by the end of the i95os.

The design characteristics of the new stud-and-tube interlocking mechanism facilitated a move away from LEGO as an architectural toy. Their stability and clutch power facilitated more stable and complex constructions and broadened both design and building options. This increase in possible and facilitated LEGO play practices was furthered by the LEGO System i Leg or LEGO System of Play introduced in 1955. The play system originally consisted of 28 sets and 8 
vehicles plus some supplementary elements. The idea behind the System of Play was that not only the individual bricks were interchangeable but the sets as well. All pieces in the system had to be compatible so that a "child who has four LEGO sets can use them all together to create more complex and interesting playthings than he could with four sets that didn't work together' (Wiencek, I987, p. 57). The System of Play and its interchangeability of LEGO pieces multiplied the design and construction possibilities and thereby expanded the LEGO play options.

In terms of the core/periphery model of differentiation, we could state that the change in prime material from wood to plastic and the technological innovations on the level of molding plastics expanded the core of LEGO play practices because the modular, plastic bricks and the detailed particles facilitated the design and creation of more diverse constructions than the wooden building blocks. The embedded scripts of the design of the stud-and-tube brick facilitated diverse play practices. These early LEGO bricks and sets were still fairly generic and could as such be appropriated and adapted in how players used them in their actual play practices. With this enlarging geography of LEGO play, the projected user and uses diversified as well, from playing at being an engineer or architect to many diverse uses and more wide-ranging roles that players could identify with. The System of Play ensured that all LEGO elements would fit together, thereby opening up a large area for divergent design and construction. Moreover, it was not until the r97os that detailed manuals would be included inside the LEGO boxes. These detailed manuals would outline all the facilitated play options, step by step. Before then, LEGO sets only came with playing advice and building ideas.

Besides the fact that technological innovations enlarged the LEGO geography of play, the new interlocking mechanism of the bricks and the addition of smaller particles to the LEGO System of Play also resulted in LEGO toys becoming truly indoor toys. The small particles could get lost, or sand and dirt could get stuck inside the tubes underneath the bricks. Although one of the advertised and popular advantages of plastic was that it was easy to clean, sand and dirt could get stuck inside the tubes underneath the bricks which would ruin the interlocking quality. Because of this, children were less likely to (be allowed to) take their LEGO bricks outside. The creation of an indoor System of Play probably also had something to do with the cold Danish climate with its long and harsh winters. In one of the LEGO Company publications of 1975 we read that LEGO bricks are 'much more convenient for indoor use' than, say, paint, sand or clay and since LEGO bricks can be combined in so many different ways, 'there is enough to do in the long winter evenings' (1975, p. 5 \& 7).

During the post-war years, consumerism changed, and the Americanization of consumption and the economic growth after the Second World War secured a new affluence down to the working classes. Part of this maturing consumerism is a renewed emphasis on the home, the private sphere and the nuclear family, with 
consumer goods targeted at the home and family life. The relatively cheap, easy to clean, durable, colorful and standardized plastic bricks epitomized the postwar vogue of indoor plastic products. The (sub-)urban and domestic designs of the early LEGO sets reflected the sanctity of the private suburban home of the I950s nuclear family. In the I950s, the playroom became an integral part of architectural practices. While the mid-Igth- and early 2oth-century guidebooks on housekeeping advocated a separation of the child from worldly affairs, a distancing of the child from the adult world, I950s architects designed homes that centralized the child and play in the recreation area and the open plan living room. Processes put into motion during the Industrial Revolution gained force in the postwar period with increased leisure time, more consumer goods and a continuing exodus to the suburbs. Both the suburb and the suburban home centralized 'the needs of children', and play became a 'space-determining criterion within the domestic environment,' writes architectural historian David Snyder (2004, p. I42). LEGO toys answered to and reinforced the increasing domestication of child and play by being suitable for indoors and not outdoors play. Therefore, these toys mediated, mirrored and promoted the angst-ridden relationship between child and the 'mean world' outside of the private suburban home.

\section{Brand Extension \& Product Differentiation}

During the late I990s and the early 2Ist century, changing LEGO policies had serious ramifications for the geography of LEGO play. During this period the enlarging geography of LEGO play and the increasing core and peripheral play practices spurred on by technological inovations and new materials came to a stop. At the end of the I99os, the LEGO Company put a plan into motion to extend its brand through the diversification of its product range. The core of this plan was the extension of the LEGO brand beyond the connotation of the 'brick'. The LEGO Company wanted to be known for more than construction toys by extending 'their brand into new areas of the children's universe,' write brand analysts Pernille Gjфls-Andersen and Esben Karmark (2005, p. I67). The reasons for putting this plan into action were 'a declining interest in construction play in the mid-Iggos, the phenomenon known as KGOY (Kids Growing Older Younger) and technological developments that made LEGO sets look boring and old fashioned' (p. I67). Toy companies use the term KGOY to indicate that children from ever-earlier ages turn away from traditional toys towards fancy technological gadgets (cell phones, $\mathrm{MP}_{3}$ players and personal computers) or lifestyle products (clothes, make-up, accessories).

An analysis in 1996 of the strength of the LEGO brand through the Brand Asset Valuator (BAV) test by advertising agency Young \& Rubican had grim consequences. The BAV test is commonly used to research and analyze the weaknesses, strengths, popularity and recognition of brands. The BAV test results showed that 
the LEGO brand was still strong but scored low on the point of differentiation which is, according to the BAV system, usually a sign of a fading brand (Gj申lsAndersen, 200I, p. I63).

In what is now considered by LEGO employees as an overreaction to the BAV outcome, the LEGO Company pushed their plans for brand extension to completion in a few years. From the mid-Iggos onwards, as part of this brand extension strategy, new types of toys and lifestyle products were launched, Legoland theme parks opened, electronic games and children's media produced. LEGO products diversified fast and in all directions. Although the differentiation of LEGO products had been going on for decades, the rate and pace increased exponentially. ${ }^{6}$ Repairing the damage this product differentiation did to the LEGO brand and company (manifested mainly in financial losses) will take 7 years according to the 'rescue' strategy that was put into motion in 2004.

In short, the goal of the brand extension strategy was to replace the 'assembly' aspect of the LEGO brand (which was considered too old-fashioned and not flexible enough in light of the intended product diversification) with the core term 'creativity'. Ironically - and this is what did the brand such damage and caused heavy financial losses - fans considered the new toys and products less creative instead of more. For example, LEGO sets increasingly contained preformed parts. This at once limited the amount of time needed to build a set (which was intended) and the number of other constructions one could build with the pieces inside the box (an unintended consequence). Including preformed LEGO pieces in toy sets to decrease building time was in line with the LEGO Company's goal to loosen the ties between the LEGO brand and construction play. This also solved the problem of those complex and detailed sets which children could only complete with their parents' help. Inadvertently, these preformed elements decreased the play options on the facilitated, core level of playing as well as on the divergent, peripheral level of playing. ${ }^{7}$

Up till the mid-I99os, the LEGO Company was best known for its construction toys, and the LEGO brand was almost exclusively associated with construction toys and play. Between the late I9gos and the early 2Ist century, we can discern a shift in discourse from designing and constructing as the embedded and projected play activities with LEGO toys to narrative and role-playing. Designing and constructing became less important play elements while the play elements of roleplaying, action and narratives were pushed to the foreground. Toys that centered on stories and themes were the key to the brand extension plan. These narrative toys allowed for both the development of more diverse products that did not necessarily have the brick and construction play at its core, and for the integration of these products with other media and other areas of the child's world.

This shift can also be framed as a transition from play as construction process to play with finished product. In relation to both the first- and second-generation construction toys, play centers on the process, the building and constructing of 
an object. For example, playing with a Meccano construction set is mainly about the construction process itself, the designing and building of a construction rather than the playing with that construction. The LEGO toys introduced between the late iggos and the early 2ist century on the other hand focused heavily on the playing with the construction once it was finished. The preformed elements shortened the building process and thus the journey to the projected play practice with the finished construction. Looking at LEGO brochures introducing the new LEGO toys during this period, we see the discourse changing from bricks to action, from construction to narrative, from process to product. For example, LEGO Clikits, LEGO lifestyle products for young girls, were designed and produced as part of the LEGO brand extension plan. The lifestyle and fashion products (bags, bracelets, hair adornments, diaries and so on) were not characterized by bricks and construction play (these LEGO sets simply contained no bricks) but by role-playing and narrative play. With LEGO Clikits the 'player' had to click small elements (hearts, flowers and stars) onto plastic objects like a purse or a diary. LEGO Clikits has been discontinued as part of the strategy to restore the LEGO Company.

The narrative and themed LEGO toys were often tied to other media products such as films, television programs, comics or computer games. Although older LEGO toys were also about role-playing and narrative play - playing at being a little engineer or a housewife during the I940s and I950s for example, and a space invader or pirate during the I96os and I970s - the roles these toys offered were rather limited and were often in accordance with reality. In contrast, the narrative and themed LEGO toys on sale from the mid-Iggos onwards presented diverse and wide-ranging roles to play. These roles and narratives were more often than not 'otherworldly'. The 'engineer-hero' was largely replaced with media heroes of the Western consumer culture such as Harry Potter, Bob the Builder, Anakin and Batman, as film and media theorist Stig Hjarvard points out (2004a, p. 7; 2004b, p. 6o). Role-playing became more extensively facilitated and embedded in the design of the new LEGO products and in the discourse surrounding these products. It replaced construction play at the core of LEGO play practices.

However, the extreme financial losses in the years 2000, 2003 and 2004 made it clear that the brand extension through product differentiation had not been successfully executed. The financial losses were blamed on different things, ranging from new media-inspired toys, such as computer games, which were not within the LEGO Company's area of expertise, to expensive licensing agreements with, for example, the Walt Disney Company, from the high production costs for LEGO toys to the extreme and undirected product differentiation. The financial and brand image problems prompted the LEGO Company to announce and put into process a seven-year rescue plan in 2004. Some of the measures taken reversed in part the product differentiation by selling off or outsourcing certain LEGO divisions such as the software division, clothing line and LEGO theme parks, as Scan- 
dinavian reporter Ivar Ekman writes for the International Herald Tribune (2005, p. II). Product lines that did 'not directly tie in with the core business of the LEGO group' (LEGO, 2005, p. II) or were 'less profitable' (such as LEGO Baby, LEGO Quatro and LEGO Clikits) were cancelled (LEGO, 2006, p. r6). Also, development times were halved (from 24 to 12 months) so that the company would be able to react faster to the changing toy market (LEGO, 2004, p. 8). A more flexible organizational structure had to facilitate faster reactions to consumer feedback and the changing toy market (LEGO, 2005, p. I4). The number of unique LEGO particles has been reduced from 12,400 to around 7000, reports business journalist Brendan Koerner (2006). The classic construction toys were reestablished in 2005 as one of the LEGO Company's core product lines (LEGO, 2005, p. 20). Importantly, up to $80 \%$ of production was outsourced (mainly to China) to reduce production, packing and distribution costs (LEGO, 2006, p. 14). Finally, closer contact with retailers and consumers would allow for the creation of better products and the successful reestablishment of the brand (LEGO, 2005, p. I2). Thus far, the strategy seems to be paying off, for the LEGO annual reports for the years 2005, 2006 and 2007 could announce that the company was making a profit again (LEGO, 2005, 2006, 2007a).

In terms of core and peripheral play practices, we can state that both areas of play - facilitated and divergent - shrunk during the late iggos and early 2ist-century period of brand extension through product differentiation. Reasons for this shrinking geography of LEGO play were diverse. Many of the new products were, for example, not compatible with the System of Play. Preformed elements were often only useful in the context of one single LEGO set. These preformed elements frustrated modular, expansive, open-ended forms of LEGO play and restricted the projected uses and users. Some of the new toys, such as LEGO Clikits, contained no bricks at all. Other sets were so specific in terms of narrative and discourse that combining them with other sets seemed unthinkable. Both facilitated and divergent play practices suffered under these late I99os, early 2Ist-century decisions because the products were more hermetically closed and sealed, less modular and open-ended, leaving little room for designing personal constructions and realizing them.

Since 2005 we see a change (or return) towards more classic LEGO sets that focus explicitly on construction play. Most notable are the product lines LEGO Creative Building, LEGO Creator (with digital and non-digital components), LEGO Digital Designer, LEGO Factory, the retro buckets of bricks with their Book of Ideas and older lines such as LEGO Technic and Mindstorms. Part of the financial success in 2006 was due to the unexpected good sales of 're-launched, classic product lines' (LEGO, 2006, p. 7). The return to the bricks, to the classic construction toys does not mean that popular media tie-ins and themed LEGO products that center on narrative play disappeared. Rather, it means that the LEGO Company intends to keep a better balance 'between the classic lines and 
more 'fad-driven' products' (LEGO, 2005, p. I0). Now the LEGO Company offers both the 'journey' and the 'destination' so to speak, both construction and narrative toys.

\section{Bringing the Fans into the Company}

The LEGO company's future growth and restoration are outlined in the 2006 Annual Report as being based on two major assets: 'the classic LEGO products' and the 'unique possibilities provided by the close contacts to the users' (p. 19). The LEGO Company's efforts at developing stakeholder relationships are directed through the LEGO Community, Education \& Direct (CED) division that deals with the 'cooperation with the company's many fans' (Simonsen, 2006, LEGO press release). The Mindstorms 2.0 (launched in 1998) and Mindstorms NXT (launched in 2006) products show how the cooperation with fans changes over time, becomes more important and results in the adjustment of the LEGO Company to the many-to-many paradigm. Mindstorms consists of computational LEGO bricks that allow you to create your own robots. Mindstorms was developed in close contact with the MIT Epistemology and Learning Group founded by Seymour Papert. It is named after Papert's book Mindstorms: children, computers, and powerful ideas (1993). In 1985 the LEGO Company started working together with Papert 'with an eye toward introducing a computer-driven LEGO product' (Wiencek, 1987, p. 102). ${ }^{8}$ Papert is the founding father of the educational theory constructionism ('learning-by-making'), based on the work by Swiss philosopher and psychologist Jean Piaget (Papert, I99I, p. I).

The ongoing popularity of Mindstorms 2.0 prompted the LEGO Company to develop a second edition of the robotics construction toy. One of the goals was to appeal not only to adults but to children as well. Mindstorms 2.0 is a toy with a specific (adult) user embedded in its design, use of technology and requirements on both the financial and computational level. The projected user of NXT is younger. Through simplifying the programming language, the LEGO Company wanted to broaden the scope of possible NXT users (Koerner, 2006). The new system is PC and Mac compatible, and the programming software has been redesigned and is now far more intuitive and easier to use. Players from age ten upwards should be able to complete a robot in 30 minutes (as opposed to I I 2 to 2 hours with Mindstorms 2.0). Mindstorms NXT (which costs \$249.99 per set) consists of an 'Intelligent Brick', a 32-bit LEGO microprocessor. Its sensor capabilities are ultrasound, sound, light and touch. The robot has a USB port and Bluetooth technology that enables remote control of the robot (e.g. through a mobile phone or PDA). Overall, the robots look and act more realistically and can perform more complex tasks, such as reacting to voice commands (Koerner, 2006).

However, the most interesting thing about the new Mindstorms kit has been its developing process. 'The boldest part (...) is Lego's decision to outsource its in- 
novation to a panel of citizen developers' hoping that this 'will lead not only to a better product but also a tighter, more trusting bond between corporation and customer' (Koerner, 2006). Four dedicated Mindstorms users were selected by the LEGO Company to form a Mindstorms User Panel and help with the design of the next generation of Mindstorms. These dedicated Mindstorms users could be referred to as 'lead users', a term introduced by innovation expert Eric von Hippel (2005, p. 22). Lead users are not only quick in adopting new products (by buying them), but importantly, also in adapting these products so that they might better fit their personal needs. Hippel defines lead users as either persons or companies that are at the edge of market trends and therefore experience needs that others will soon experience as well. More so, lead users innovate products because they anticipate a relatively high benefit from doing so (ibid.). In relation to players becoming producers, this 'high benefit' is in terms of their experience of play, not financially. Most players-as-producers work for free.

Lead users are part of fan communities that, as media theorist Henry Jenkins puts it, do not want to 'jam culture' but see 'unrealized potentials' in relation to products and their possible uses.

Culture jammers want to opt out of media consumption and promote a purely negative and reactive conception of popular culture. Fans, on the other hand, see unrealized potentials in popular culture and want to broaden audience participation. Fan culture is dialogic rather than disruptive, affective more than ideological, and collaborative rather than confrontational. Culture jammers want to 'jam' the dominant media, while poachers want to appropriate their content (2002, p. 167).

The LEGO fan community includes different poachers who appropriate the tools for play handed to them by the LEGO Company in various ways. Jenkins borrows the term 'poachers' from De Certeau and uses it to indicate the possible active and creative role of media consumers (Jenkins, 1992, p. 24). The creators of MOC sets are such a group of poachers who see 'unrealized potentials' of LEGO designs.

Lead users adopting and adapting Mindstorms was not new, however. Mindstorms 2.0 has known a vibrant and innovative user community from the very start. Koerner even claims that the Mindstorms community has, through hacking and modifications, 'done far more to add value to Lego's robotics kit than the company itself' (2006). The free user-generated software to program your Mindstorms robot NQC (Not Quite C) is a good example in this case. Created by David Baum and now being further developed and maintained by John Hansen, this software is very popular among Mindstorms users (Baum, 2007; J. Hansen, 2007). The software allows you to manipulate your robot through typing the programming code rather than through dropping and dragging the digital blocks on 
your screen. At first unsure how to deal with these hackers, the LEGO Company decided that limiting creativity was against its corporate ideology so it gradually warmed to the 'open source ethos' and wrote a permission to hack in the license agreement (Koerner, 2006). The 'hackers were providing a valuable service' because they made the product more exciting and enhanced the experience with a basic Mindstorms set without getting paid for it (ibid). Mindstorms fans have also written numerous books and manuals on how to build Mindstorms robots. Mindstorms 2.0 and the adaptations by users, their poaching and divergent user practices show the centrifugal movements in which users and their activities move away from the core and into the periphery. In this movement, users appropriate the configured user and the embedded scripts. By tapping into these peripheral activities, the one-directional flow between toy and play practices becomes twodirectional. The ways in which lead users actually used these LEGO toys influenced the new Mindstorms product.

The development process and actual use of the Mindstorms products comprise both fast (taking place in the course of one and the same product) and slow centripetal (taking place over the course of multiple products) appropriations of the periphery by the core. The fast centripetal appropriation is manifested in userwritten software for Mindstorms 2.0 that allows players to change the design, embedded scripts and projected uses within the scope of one product. Through this fast centripetal appropriation, certain players can co-configure the user of Mindstorms 2.o. The possibility of fast centripetal appropriations is connected to the digitalization of the LEGO geography of play. These fast movements are not to be found in analogue, pre-digital geographies of play. Centripetal appropriation, both fast and slow, has gained in presence and importance due to digital technologies that facilitate the use of user-generated content within the context of one and the same product, that sustain and cultivate active peripheries and many-to-many communities, that make these communities visible and accessible to both players and companies.

Slow centripetal appropriations are constituted by the LEGO Company tapping into lead user knowledge and the many-to-many culture to launch a new edition of Mindstorms robotics. An elite group of Mindstorms users has thus been consulted in the reconfiguring of the user of Mindstorms NXT. By drawing on the many-to-many culture to design a new product, the slow centripetal movements between periphery and core are commodified.

The strategy to draw on user-generated content to improve products and create a solid fan base and loyal community is common among computer game developers. Also in line with the production process of computer games, the LEGO Company recruited noo beta testers who would be able to buy a pre-release of the NXT at a discounted price in return for four months of heavy tinkering and product feedback. 
Tapping into lead user knowledge and practices for product development is beneficial both marketing- and brand-wise. When the word got out that Mindstorms fans were sitting at the table with LEGO officials to design NXT, the Internet buzz seemed unstoppable. The LEGO Company tapping into lead user communities and user-driven innovations to design the new Mindstorms NXT was a novel approach for a company known for its lawsuits against companies or persons unlawfully using their product or brand.

Besides the user-driven development of NXT, the LEGO Company has initiated many other projects that intend to sustain and support user communities and tighten the bond between brand and consumer. Two examples of community building and 'bringing the fans into the company' are the LEGO Ambassador Program and the LEGO Certified Professionals Program. Being a LEGO Ambassador does not cost money, but only a few people are selected each year. 'The Ambassador Programme is an official program which invites adult LEGO fans to share their enthusiasm for the LEGO idea and LEGO products and encourages interaction in the global LEGO communities' (LEGO, 2005, p. I2). Joining the LEGO Certified Professionals Program costs \$100o a year, but more people can apply for this title: 'the LEGO Certified Professionals programme caters for adult fans who, wholly or partly, live by their LEGO hobby and therefore wish to enter into cooperation with the LEGO Group' (ibid). These explicit attempts at establishing an active user community might seem a bit forced when compared to computer game communities that pride themselves on being independent and unendorsed and considering the fact that active LEGO communities have been thriving for a very long time.

One of the advantages of an active user community is invaluable feedback about the products being used by these users. In the 2006 LEGO annual report, this feedback is referred to as 'unique' and 'extremely significant' knowledge 'of the wishes and needs of the users' (p. I8). This knowledge is used in both the development and the marketing of new LEGO products (ibid.). Closing the gap between company and consumer through loops of feedback or centripetal forces is a means to include the consumer in the magic circle that is a brand and to keep that brand vital. As sociologist Celia Lury puts it: 'the aim of the feedback processes in which information about competitors and the consumer is fed back into production is to make the brand itself dynamic' $(2004$, p. 3). By including the consumers in the design of Mindstorms NXT, the LEGO Company intends both to reestablish its brand as dynamic and vital and to launch a participatory relationship with its consumers.

A distinction needs to be made here between adults and children. The consumers the LEGO Company involved in the development process of Mindstorms NXT were adults. The gap between the LEGO Company and children is targeted through initiatives such as LEGO Factory, competitions, forums, exclusive membership advantages and a more 'individualized and branded shopping experience' 
both online and in stores (LEGO, 2006, p. I8). For example, in many new LEGO stores you can pick and choose your own bricks instead of buying pre-assembled sets. And in 2007, the first indoor Legoland Discovery Centre was opened in Berlin on the Potsdamer Platz. This branded LEGO shopping center is far more than a LEGO flag store. It combines an indoor playground with adventure rides, a fun shopping experience with playing and experimenting, learning about how LEGO bricks are produced with a LEGO mini Berlin. The Berlin Discovery Centre is not so much about selling LEGO products as it is about brand strength and involving children (and their parents who can 'relax in the restaurant') within the experience of the LEGO world (LEGO, Discovery Centre website).

\section{Many-to-Many Geographies of Play}

In 2003, the LEGO Company effectuated a color change for certain shades of their grey and brown pieces. This caused considerable unrest in the community of older fans who associated the colors being taken out of production with their childhood. Some of these fans simply refused to accept the new colors. Fans wrote about the LEGO Company's 'terrible decision to "improve" the gray, dark gray, and brown colors' (Walters, 2004), confess they are 'a bit upset' (White, 2007) and 'will not adopt the new colors' (Simmons, 2007). The reason for the color change was related to the characteristics of the ABS plastic of which LEGO bricks are made. $A B S$ is a very strong type of plastic, but it does 'yellow' when it gets older and from exposure to sunlight. The new coloring was meant to prevent this yellowing and also, some fans suggest, make the colors stand out more in stores that use tube lights. Both the yellowing of the bricks and the color change had ramifications for the core and periphery of playing with LEGO toys. Some players complained online about yellowed bricks in their constructions and tried soaking them in peroxide to revive their color. Long time LEGO users refused to accept the new colors or buy sets including these colors. And unwary players could end up with slightly different shades of grey and brown in their constructions. The complaints all round were numerous and diverse, ranging from sorting and buying issues to construction problems. But as one fan writes, changing the material of play does change the core of play: 'TLG's [The LEGO Company's] emphasis since the introduction of the brick has been on the system of play. Changing a 20-year-old core color is inconsistent with this focus' (Walters, 2004).

Both this incident related to the color change and the LEGO Company's brand extension strategies are exemplary of a one-to-many model in which the powerful actors in the core make decisions that affect design and discourse and thus the facilitated play practices. These decisions can be either accepted or rejected by users. This one-to-many model characterized the geography of LEGO play until the beginning of the 2Ist century. Innovation was manufacturer driven, and the geographies of play were rather static with little exchange between core and peri- 
phery. The LEGO Company has made a step from a manufacturer-driven innovation culture to a user-driven innovation culture by tapping into the peripheral culture of user innovations. Bringing fans into the company, learning from fan cultures, incorporating what happens in the periphery of the geography of play into the core mark the transition from a one-to-many to a many-to-many geography of LEGO play. This entails crucial shifts in design and marketing processes and the ways in which the LEGO Company deals with their key stakeholders: players.

The transformation from a one-to-many to a many-to-many geography of play largely coincides with a shift from non-digital to digital or digitalized geographies of play. For example, the fast centripetal movements that are characteristic of the many-to-many geography of play are facilitated by digital technologies. The many-to-many model has gained in force and importance due to technological innovations that facilitate easy contact and exchange between users. These same technologies also facilitate the participation in and access to many-to-many communities by companies. They become part of the 'by us for us' network of activities and play practices. Companies increasingly bank on the many-to-many culture for product design, marketing and brand strength. In the many-to-many geography of LEGO play, the LEGO Company not only taps into the periphery, LEGO employees themselves increasingly venture into the periphery. They take part in user groups and post on fansites, data mine personal websites and fan community databases, announce new products and programs on private initiative websites. By doing this, the core splinters and disperses.

The move from one-to-many to many-to-many geographies of play also entails a power shift or a redistribution of power on different levels. While it is correct to situate the company in the core and the user in the periphery of a one-to-many geography, this situation becomes more complex in largely digital geographies wherein the core splinters and disperses, companies increasingly enter the periphery, and users shape and control the core to a large extent. In migrating from the periphery to the core through either fast or slow centripetal forces, divergent play practices become part of the embedded design scripts and they co- or reconfigure the user and uses. In the one-to-many geography, the periphery is of less importance to the companies, and therefore it has less influence over the core while being at the same time more autonomous and independent than in the many-to-many geography. In one-to-many geographies of play, there is less movement between core and periphery, and thus, these geographies are more static. There is less movement because access to the core is company-controlled and fast centripetal appropriations are not facilitated in the design of analogue toys. In the many-to-many geography, the periphery gains in importance for the companies, has therefore more influence over the core but loses some of its autonomy. Largely facilitated by digital technologies, there is more movement between core and periphery in many-to-many geographies of play. Although the 
periphery of the LEGO geography of play has a certain influence on the core, access to the core remains mediated by the LEGO Company. The strict rules for the LEGO Ambassadors and the incorporation of a permission to hack in the Mindstorms 2.o license agreement indicate that while the LEGO Company might have opened its doors to lead users, it still controls what goes through that door.

The LEGO Company has, in adapting or surrendering to the many-to-many paradigm, realized that a lot of good and commercially successful ideas for new products are likely to be found within the divergent peripheral play activities of dedicated fans, in the user-driven culture of fan communities, and that a vital and dynamic brand in the 2ist century incorporates its users (or at least some of them) in design and decision taking. For an elite group of lead users (be it codesigners of Mindstorms NXT or the designers of MOC sets) who possess the necessary know-how, time and money, the 'journey' of LEGO play is considerably extended through their inclusion in design and production processes. This implies that some of the divergent, peripheral play practices are incorporated through centripetal appropriation in the facilitated core. This blurs the lines between player, consumer and producer. As Hippel states, 'consumer' is too passive a term for lead users who are actively involved in innovation processes (2005, p. I9). Players can become co-producers in direct or indirect ways. Directly through, for example, being invited to partake in design processes or having your creation turned into an official set. Indirectly through online communities that have never been so easy to monitor, take part in, lurk in and learn from. ${ }^{9}$ In adapting to and tapping into the many-to-many culture of user communities in terms of design, production and marketing, the focus is increasingly on adults. While it would have been unthinkable in the I950s to envision adults in the geography of LEGO play in any other role than as supervisor or helping hand, now adults are considered a unique and extremely important source of valuable information and input. What the LEGO Company is losing in the age bracket 7 to 17 due to the KGOY trend, they are gaining in the age bracket 17 to 47 due to the ASYL (Adults Staying Younger Longer) trend.

An often-heard critique on user-driven innovations, on bringing the fans into the company, on tapping into the many-to-many community is the 'free labor' critique. Soren Lund, LEGO Mindstorms Product \& Marketing Development Director, remarks in an interview with Joel Greenberg that this free labor is not necessarily cheap to tap into because a lot of the company's energy and resources are invested in working with user communities (Greenberg, 2006). More importantly, it is exactly the fact that users are not being paid to co-design a new product that makes this system work, according to Lund. Paying users would reallocate them from the communities' 'can culture' to the companies' 'must culture' (Greenberg, 2006; Jenkins, 2006c).

Although user-driven innovation is often hailed as the democratization of consumers, they are not the ones earning money from their creative labor. Players 
gladly work for free for the LEGO Company and give up their creative rights for others to earn money with. In this we see De Certeau's concept of la perruque upended. La perruque indicates the masking of private activities as work activities, for example in "writing a love letter on "company time" ( 1988, p. 25). Within a commodified many-to-many model, the reverse is manifested. In this case it is not so much leisure that penetrates work, as De Certeau describes, but work that penetrates leisure. The effect, however, is the same: 'the dividing line no longer falls between work and leisure. These two areas of activity flow together. They repeat and reinforce each other' (p. 29). The slow centripetal appropriation of the periphery by the core that serves new product developments has become indispensable in the course of the LEGO history. By incorporating peripheral, manyto-many activities and practices within new products, these activities and practices are commodified. In such a partly commodified geography of LEGO play, work penetrates play. Practices of play and production meet and converge at the intersection of peripheral play practices that become core play practices. The result is a partly commodified geography of play in which certain divergent user practices are 'harvested' and commercially used. Through this partial commodification, the stakeholder positions of player, consumer and producer can implode for certain actors. The fact that peripheral play activities are increasingly 'harvested' for use in the core does not necessarily result in a shrinking geography of play. In 'tolerating' (in design and discourse) divergent user practices or centrifugal appropriations, the periphery is 'irrigated' and kept from shrinking.

More generally, we could state that the solitary igth- and early 2oth-century geographies of play have been largely replaced by densely populated and heavily networked geographies through the incorporation of the Internet within the geography of play. The Internet adds new playgrounds, enlarges existing play areas, interconnects players, facilitates fast traffic within geographies and brings the outside into the private home and the child's private room. This impedes the separation of the child from the outdoors, from unwanted contact with strangers and adults. This is not to say that the pre-Internet solitary geographies were completely devoid of such participatory elements. There was contact with peers, siblings and adults through and about play. And from the 2oth century onwards, toys were increasingly linked to clubs and magazines, radio programs and contests, special days and festivities. However, such peripheral, social and participatory activities have increased immensely due to new media technologies and have moved, for the largest part, to online environments. The Internet has knitted players together within the geography of digital play in an unprecedented interconnectedness. Within geographies of digital play, the core/periphery relations tighten, the peripheral play area expands, traffic within that periphery and between core and periphery increases, and the tapping into the many-to-many culture intensifies. 



\section{Part III: Commercial Geographies of Play}

Toy companies increasingly depend on user communities for creating challenging new products or extensions of existing products, for keeping a brand alive and commercially successful. Within the LEGO geography, part of the many-tomany activities are commodified and used for new product developments. This gives players a more active role in the design of new products. As such, players become to a certain extent co-constructors of new products and of the embedded design scripts and user configurations of these products. When individual users or a community of users shifts from being consumers and users of products to co-designers of new products and co-establishers of a brand image, their actions lose a certain inconsequentiality and triviality. With so many user activities now taking place on the Internet, these activities are more easily accessible by larger numbers of users and can, besides establishing a positive and constructive brand image, also damage a company's image.

The well-known American game designer Will Wright created popular computer games such as SimCity and The Sims and the less successful online version of the latter called The Sims Online. These games could be considered digital construction toys: in SimCity the player constructs cities, in The Sims a household and in The Sims Online relationships. SimCity and The Sims have, since their introduction, been surrounded by fantastic stories that involve female and gay gamers, Will Wright as a genius, eyebrow-raising sales numbers, a revolution in gaming, the American Dream, a critique on our consumer culture and last but not least, the saving of the gaming industry. In an industry oversaturated with and endlessly criticized for its male machismo, ridiculously oversized guns, wars, battles, blood and more wars, there was a sigh of relief by those who care about computer games either as players or as developers, when these peaceful games about urban planning and domestic life became immense hits. And the relief was even bigger when a large part of the The Sims gamers turned out to be female and non-gamers. The gaming industry considers non-gamers or non-users a problem. They want to attract these non-users not only to extend their market reach but also to shake off the image that computer games are only played by nerds or teenagers. The Sims is considered one of the only games that has as many male as female gamers. As game critic Charles Paulk has pointed out, the biggest surprise is that male gamers like the game as well (2006), because this interior design game (aptly baptized 'the IKEA game' by computer game designer and analyst Celia Pearce) lacks many, if not all, stereotypical masculine game activities such as battles, fierce 
competition and levels that are often thought necessary ingredients for reaching the male gaming market (Pearce, 2004). The Sims is not a stereotypical heterosexual game: no need to be a white, Caucasian male with a large gun. As such, the game is a 'deviation from the dominant game formula of 'militarized masculinity" (Kline et al., 2003, p. 275).

To analyze the connotations, underlying ideologies and practices of play of SimCity, The Sims and The Sims Online, it is fruitful to compare them with toy villages, toy homes, dolls and dollhouses. Wright himself often compares his games to railroad sets and dollhouses and calls them toys rather than games. As Pearce states in her article Story as Play Space, at the core of Wright's games 'are fundamental paradigms of play' such as 'role-play, constructing miniature towns, 'playing house" (2002, p. II6). Through the investigation of continuities and discontinuities between non-digital and digital toys, the role and function of the many-tomany model within the geography of digital play and the mechanisms of user involvement at work in this many-to-many structure can be teased out and addressed.

Digital construction toys add an extra layer to second-generation construction toys, the designed-to-be-about-design construction toys. Digital construction toys are not only designed objects that facilitate designing as a play practice and that take designing as their subject, they are also coded and programmed computer applications. The rules and interactions with the game are inscribed within that programmed code. Wright's games are, like the second generation of construction toys, designed-to-be-about-design. However, they are also procedural - they evolve visually over space and time. They evolve not only through the handling of the toy by the player but also through the built-in mechanisms of rules and behaviors that dictate what the evolution is of variable $\mathrm{A}$ or $\mathrm{B}$ in relation to variable $\mathrm{X}, \mathrm{Y}$ or $\mathrm{Z}$.

Designed artifacts contain the potential to be actualized through use: a set of building blocks can be actualized through building and constructing various objects with the individual blocks or bricks. Digital, coded objects take this actualization further because they provide the interactor (the user who is interacting with the object) with a string of options to actualize the design, thereby making this actualization into a procedural activity. ${ }^{\mathrm{II}}$ In the case of Wright's games, characterized by their lack of a 'you win' or 'you lose' moment, these games provide the player with a never-ending string of actualizations of design potentials. This lack of a decisive moment when the game ends makes Wright's games toys indeed. Toys have no clear ending either that indicates when the playing is over and a new game should be commenced. But Wright's games are also very much games in the sense that they are designed and rule-based systems. SimCity, The Sims and The Sims Online are digital and procedural construction toys that center on the journey in the play practices they facilitate, the process of building and constructing rather than on the destination or the playing with a finished construction. 
Crucial in studying digital practices of play within such designed and coded play environments is the question of 'anarchy': how far do and can players divert from the facilitated play practices and counter the original intentions of the designed artifact? In terms of Akrich and Latour, are there possibilities for establishing an 'antiprogram'? (1992, p. 261). Or in De Certeau's words, what is the space players have to 'indicate what they make or do with' consumer products? (I988, p. xii). Can players establish an 'antidiscipline through manipulation, appropriation and reappropriation, poaching, poiesis and bricolage?' (p. xii, xiii, xv, 25, I65, I74). Within these designed artifacts, is there room for the 'countless ways of 'making do"? (p. 29).

\section{Toy Towns and Simulated Cities}

The player of the SimCity games is a godlike urban planner trying to create and run the perfect city. ${ }^{10}$ The first SimCity game was launched in 1989 , and it popularized the genre of the so-called God games and simulation games. The first SimCity game (Maxis, I989), commonly referred to as SimCity Classic, was very popular, and it was followed by SimCity 2000 (Maxis, I992), SimCity 3000 (Maxis, 1999) and SimCity 4 (Maxis, 2003). Throughout SimCity's history the technology involved in creating and playing these games has changed significantly. Since the late 1980 computational technology has seen a dramatic change towards faster, bigger and cheaper machines. Also, the gaming industry has expanded, and more and more people are now involved in the creation of a computer game (teams might consist of up to 200 people), it takes longer to develop these games (up to three years), and it costs more money (typically ten million dollars). On the production side, computer game development changed from a low-budget, hobbyist basement endeavor to a multi-million dollar industry. On the receiver or consumer side, this development resulted basically in two things. Bigger game development companies and larger amounts of money involved mean a conservative stance towards what sorts of games are being developed. The big game companies would rather produce yet another sequel to a popular game than an altogether new and out of the box game. If violence and skimpy clothes sell, then that is what will be produced. Evidently, this is a self-fulfilling prophecy because it is hard to test the popularity of unconventional games when none are on the market.

Secondly, more money, larger teams and faster technology mean that games become more realistic, three-dimensional and graphically detailed. Computers can nowadays store far larger amounts of information than in 1989. For example, SimCity Classic consisted of 66 objects, 2 transit options and 3 zone types. The sequel, SimCity 2000, had I84 objects, 4 transit options and 8 zone types. Both SimCity 3000 and SimCity 4 have 250 objects and 9 zone types. The transit options increased from 8 with SimCity 3000 to Io with SimCity 4. Throughout the SimCity 
history, the map on which players could build increased dramatically and it now takes players far longer before they have filled the complete game canvas with cities and urban sprawl. Moreover, since SimCity 2000 game developers rely more and more on the Internet as a means for players to exchange objects or whole cities, stories, tips and tricks. These technological changes demand a heavier investment of time and money (to keep both computer and Internet connection upto-date, for example) by players.

The geography of digital play broadens due to technological advances that allow for the design of and playing in expansive game worlds. The geography of SimCity is not only to a large extent digitalized but also literally enlarged through the incorporation of Internet domains within the geography of play. A significant part of both core and peripheral play practices now takes place on the Internet. In the 'About SimCity4.com' section on the official website, we read for example: 'By using this site, you can extend your game play experience and keep on the cutting edge of what's going on in the SimCity 4 community!' (EA.com, "What is SimCity. com?"). On the website players can chat with the SimCity 4 team, other players, find information, goodies, cheats, tips and tricks and download new content for the game. Effects of this digitalization on the practices of play can be brought to the forefront with the use of the core/periphery model of differentiation.

Wright himself uses a pyramid to visualize four different ways in which players engage with his games through and about user-generated content: I) Tool-makers create tools; 2) Object-makers use the design tools to create game objects; 3 ) Webmasters host Sims websites that distribute game objects; and 4) Game players make use of objects in their game (Salen \& Zimmerman, 2004, p. 540). The top three activities of the pyramid - creating software, using this software to create objects and distributing these objects - take place in the periphery of the SimCity geography of play. The activity on the bottom of the pyramid - using usergenerated content in actual gameplay - is situated in the core. Because the pyramid deals with user-generated content alone, it does not cover the whole range of either peripheral or core play practices. Nevertheless, it is a useful starting point for unraveling what sort of play practices take place and where in this geography of digital play.

On the top level of the pyramid, Wright situates toolmakers, players who have enough technological know-how to write software programs. On the second level are the players who use the software tools to create, for example, new buildings for SimCity. The top two levels are rather restricted, specialized and thus elite peripheral play areas mainly populated by adult lead users who possess the required technological know-how, time and money. The distribute level is more densely populated. It is easier for players to host SimCity-related websites and distribute user-generated content through these websites than to create the content for these websites. 


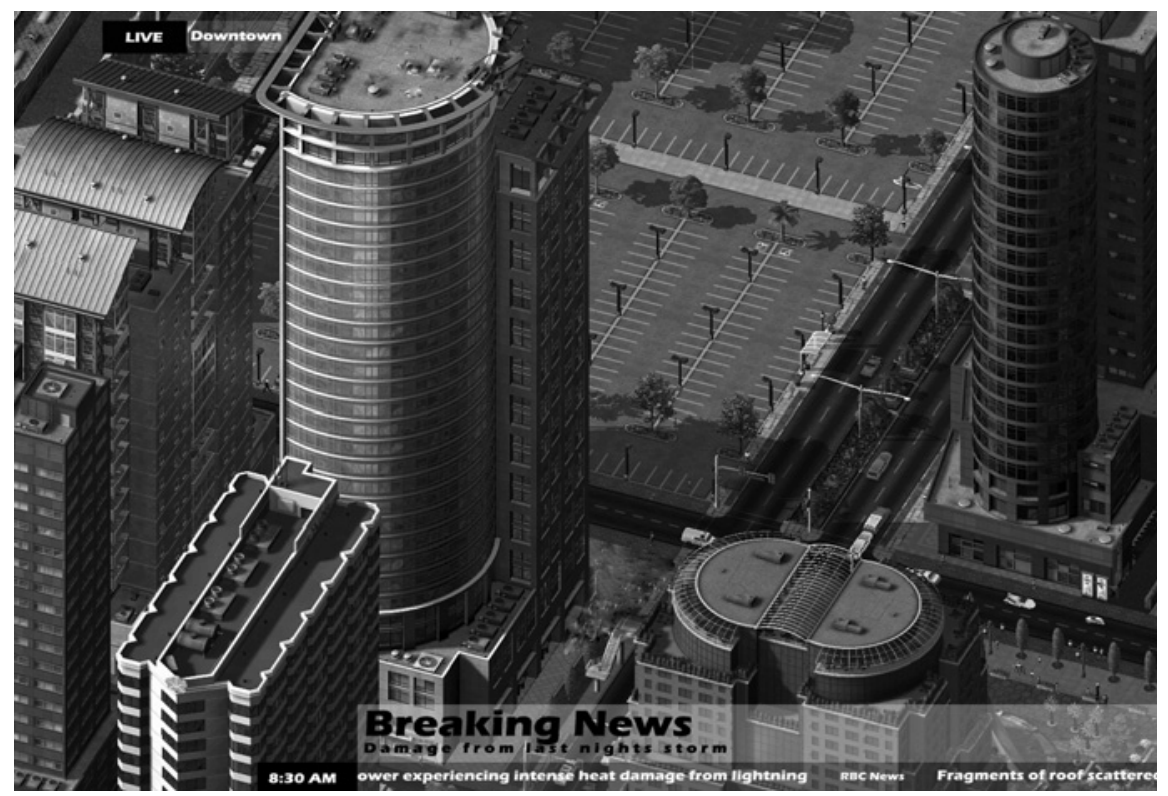

10 User-generated stories for SimCity

This image is part of a City Journal that can be found on the Simtropolis.com fansite where SimCity fans exchange user-generated content. City journals like this one document the evolution of a player's city in SimCity. Gamer Riley Riffel (also known as rusty_777 on Simtropolis) created this particular image. The image is part of his City Journal called Revelstoke County \& Surrounding areas. This image shows the damage done to his city after a lightning attack struck the city (image courtesy of Riffel, 2008). He has added a news-like layer of information over the image so that visitors of the website who keep track of his City Journal can see what has happened to his city and why the image is part of the story he wants to tell.

The top three levels of the pyramid do not cover the whole range of peripheral play activities. For example, players share more than user-generated content, they share knowledge, experience and expertise. And they create more than objects. User-written walkthroughs might be a hundred or more pages long and are written and assembled, corrected and revised by dedicated fans. Some peripheral play practices fall completely outside the scope of this pyramid; players might, for example, talk about the game offline, illegally download the game, become a beta tester for a new installment of the game or use it as inspiration for an altogether different game. ${ }^{\mathrm{I2}}$

Two instances of peripheral play activities on the 'create' level of the pyramid deserve further attention: the creation of mods (modifications) and patches. There are roughly two categories of mods: complete mods offer a new game based on the engine of an existing game, while partial mods provide players with new levels, weapons, items and the like to complement an existing game. In rela- 
tion to SimCity, one can only create partial mods because the game is not an open source game that allows modders to build a new game on its engine. One example of a mod created by a player for SimCity is the Cactus Flora Mod by JonhB: 'Finally realistic desert regions are possible! This mod consists of 3 different types of saguaro cacti' (2006). Generally speaking, partial mods operate on the 'cosmetic' level of a game in the sense that they are extensions of the design of the game and provide more variations on the existing themes and scripts.

A patch on the other hand is a small piece of software operating on the core level of the game that offers users an update or fixes a bug in the game. There are official patches created by game companies and distributed through the official websites as well as unofficial, user-generated patches. User-generated patches that effectively change the game play are instances of player appropriation that result in a change on the level of the design of the game, the embedded scripts and intended uses. Game companies will generally discourage players from using user-generated patches because these patches might - when designed badly introduce bugs and faults in the game and thus thwart the facilitated game experience.

User-generated mods and patches are centrifugal appropriations of the core and are situated in the divergent periphery of play. However, this divergent usergenerated content does not stay in the periphery. These adaptations of the design 'migrate' through a system of online distribution from the periphery of the geography of play where they are created to the core where they are used. These fast centripetal appropriations that take place within the life-span of a single product, are an extremely important form of interaction between player and game because it keeps the community surrounding a game as well as the game world lively and dynamic.

The indispensability of a peripheral many-to-many culture that communicates with the core is best understood by reconsidering the progress in computational technologies since the Ig8os. There has been a dramatic change towards faster and computationally stronger personal computers and game consoles. This has not only resulted in more realistic games and bigger play worlds, but also in an economic problem related to the costs involved in creating content for these ever expanding game worlds. In his talk The future of content, Wright states that to win the battle of game content, the industry needs to start relying more and more on players and move towards open-ended games that allow for more player input and player-generated content (2005a). Wright stresses that the fact that he relies heavily on players to create content for his games, is not a poor alternative since players love custom-created content and they love to be able to 'participate' in the game development process. In other words, a win-win situation: on the one hand game developers need this free labor by gamers to keep the game worlds rich and diverse and running smoothly, and on the other hand gamers feel they are being taken seriously and belong to a community that they can contribute to. 


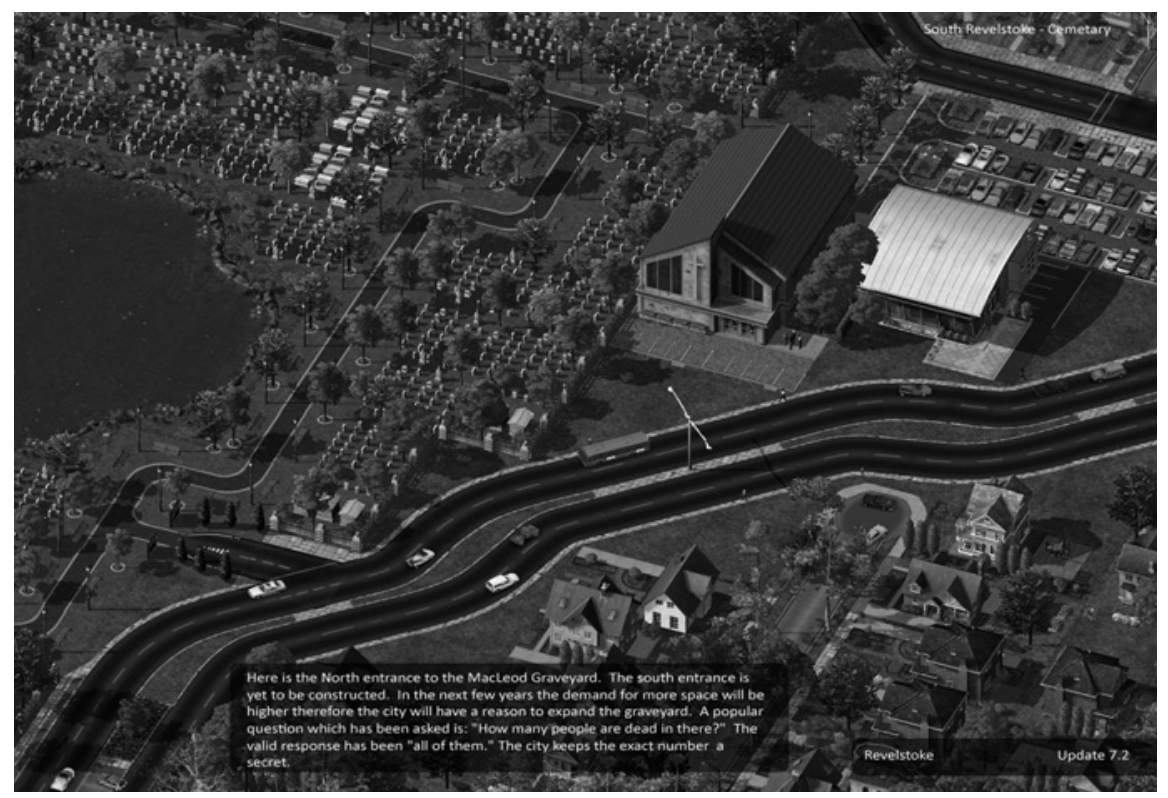

11 User-generated stories for SimCity

This is another image of Riffel's City Journal Revelstoke. The image shows his city's graveyard where dead sims are buried (image courtesy of Riffel, 2008).

Game companies increasingly rely on, hope for and capitalize on peripheral player activity that moves through fast centripetal forces from the periphery into the core. This constitutes a shift in relation to the geography of LEGO play where many-to-many play practices were used and commodified for new product releases or re-releases. An important advantage of online peripheral player activity is that game developers can (and do) data mine user groups, official websites and fansites and learn about how their game is actually being played, what the complaints are and what players wish and hope for. This information is then fed back into new releases or updates of the game series, which ensures a warm welcome from players who might find their wishes reflected in the new installment. In the digital geographies discussed here, the game company not only relies on these slower centripetal movements for new product design and development, but also on the faster forces. This second form of appropriation of the periphery by the core is also commodified within the context of Wright's games. Players adding to and filling the game world with user-generated content is counted and capitalized on and their divergent activities commodified.

Although game companies and user communities approve of, support and often capitalize on most divergent player activities, one can also find unwanted peripheral activities, such as 'trolling', in geographies of digital play. The occurrence of unwanted divergent user activities is by and large a phenomenon of digi- 
talized geographies that make the periphery more 'visible' and accessible and interconnect players more closely. Trolling is a term used to refer to the intentional disruption of user groups and online forums through anti-social and offensive verbal behavior. 'Trolls can be costly in several ways. A troll can disrupt the discussion on a newsgroup, disseminate bad advice, and damage the feeling of trust in the newsgroup community' (Donath, 1998, p. 45). Trolling is a peripheral activity that goes against the discourse of constructive and helpful user communities, and it might even hamper the centripetal and centrifugal movements between core and periphery. On official discussion websites, EA retains the right to remove trolls and their posts from the discussion boards. EA has been accused by users, however, of also removing posts by players who questioned EA's policies. This has also been the case in relation to the unsuccessful The Sims Online. For example, questions I posted concerning the status and future of The Sims Online on the official weblog called Stratics were removed by EA moderators.

Concerning the core of SimCity play practices, much more is facilitated than the use of user-generated content specified in Wright's pyramid. The core of SimCity play - building and running a city - is shaped by the combination of the design of the game and the discourse surrounding the game (advertisement, official manuals, official websites). The SimCity discourse does sustain the idea of the game as a borderless playground offering the player endless options and the freedom to create, manipulate, build and destroy. What shapes the core of SimCity play even more than this discourse, however, is its design. The game is designed to evolve based on interactions between variables. Feedback mechanisms alert the player to how this interaction is working out - whether the extra green zone you implemented augments the citizens' experience of your metropolis, for example. Keeping an eye on the different feedback mechanisms in the game is a way of knowing what needs your attention urgently in the game, what is going well and what is heading for disaster. The feedback mechanisms are also a way to learn how to play the game and to keep an overview over the large number of things you have to keep balanced. As such, the feedback loops also shape and form how the player plays the game. In the design of the core of the game, norms and values, knowledge and experiences, rules and requirements are embedded. To bring these to the forefront, it is useful to compare SimCity with toy villages and toy towns.

Typically, toy villages consist of a set of miniature houses, a church, trees and maybe some people and animals that can be arranged in different formations. The first toy villages date from 17 th-century Germany, when it was still the center of toy production, and little hand-carved German villages were exported throughout Europe. These early toy villages consisted of 'a church, town gate, houses, and perhaps some commercial structures or a town hall, a few trees and animals,' writes historian Cammie McAtee (1997, p. 15). The more recent American toy villages had an equally strong visual vocabulary but were comprised of different 
elements: 'a set of small wooden buildings reflects the organization of a semirural New England community' (p. I6). Both European and American toy villages idealized the village (as opposed to the city) as the locus of humanity and as a shelter from debasement. As such, toy villages are strongly rooted in the pastoral tradition with its longing for a return to rural life and the countryside as the best place to raise a child. Toy villages were 'a suitable way to recapture wholesome country values in the midst of a corrupt metropolis' (p. 20). By the end of the Igth century and the beginning of the 2oth century, toy towns and toy cities rather than toy villages started to appear as well. These toys did not mimic rural and preindustrial configurations but centered on urban and industrial designs. Both toy villages and towns mediate between the outdoor world and a child's private rooms by bringing rural or urban configurations indoors in a containable and manipulable format. Through the history of toy towns, one sees the changing conceptions and realities of villages and towns. These toys would often serve as a means to come to terms with these very changes by 'making new ideas of urban form comfortable and familiar' (p. 15).

SimCity embeds and mediates very specific ideas about the modern American city in terms of space, urban planning and politics. Professor of Urbanism Witold Rybczynski 'discusses (...) early colonial assumptions about cities that, consciously or not, SimCity has adopted,' writes urban designer Daniel Lobo (2004). Rybczynski points to the crucial difference between European and American cities formed through the 'sense of abundant and open space' experienced by the early American settlers that created a 'laissez-faire' attitude towards the consumption of land (ibid). Early planners envisioned continuous growth, and to accommodate this, the only form of planning was often the laying out of a grid structure that would 'grow proportionately with the population' (ibid). Change and growth are cornerstones to the playing of SimCity; trying to maintain the status quo will not make you a successful player. It is embedded in the internal workings of the game that cities have to grow in order to prosper. In the game the player recreates the typical American sprawling city space. You do not start to build your city with a square or a church, but by zoning the available space in residential, commercial and industrial zones and by laying out a grid structure.

Concerning politics and urban planning, we can discern in SimCity elements of Realpolitik as it was put into practice in California during the rg8os. To make the city of Los Angeles prosperous, the solution was sought in a combination of 'low taxes, high land prices and a forceful police corps' (Beckett, 1996; Kerstens, 1997, p. I5). The core of the SimCity geography, the design of the game and the discourse surrounding it, bears witness to the Realpolitik of the I980s. In the official Playing with SimCity 2000 manual, the internal dynamics of the simulation are explained. In order to play the game successfully, cities have to grow, and high property value is a key factor in this growth. Keeping the property value high is achieved by proximity to the city center (the city center is defined by 'attractions' 
like a zoo or a club), the size of a city (bigger is better), proximity to trees, water, a park, or a hillside. Pollution has a bad effect on property value (Dargahi \& Bremer, 1996, p. 405). Property value has a direct influence on criminal rates: high property value means less crime, low property value more crime. By building police stations, enlarging your city, adding water and green areas, the property value will rise, and criminal rates will drop (p. 406). Another means to keep criminal rates low is by decreasing the population density (ibid.).

Looking at user-generated walkthroughs for various SimCity games, we see yet again the importance of this threesome. A walkthrough written by CaptainSyrup for SimCity Classic has as one of its many tips: 'If you keep the crime rate low, your city should quickly progress into a capital. Continue to increase police coverage, (fire coverage isn't important) (...) Drop the tax rate' (2002). Throughout this walkthrough, the importance of a police force and low taxes is stressed, the first will increase the property value and in combination with the second, the Sims (simulated citizens) will be attracted to move to your city. A SimCity 3000 walkthrough by gamer Tim Wuyts (1999) states that you can easily save money on public health because it is 'less important' than, for example, the police force ('no cutbacks'). The SimCity 4 walkthrough by John Jung (2003) indicates the growing sensitivity of the Sims living in your city to pollution and traffic jams. The residential zones, for example, prosper when pollution and crime are at a low level and the commute to work is short.

Wright himself often states the influence of architect Christopher Alexander on the development of his games. In an interview with Ingrid Whitehead Wright states: 'The Sims (...) is based on the theories of architect Christopher Alexander (...). He's really the 'anti-architect'. His gig is to empower regular people to design their own homes and become their own client (...). SimCity was based on similar principles' (2000, p. 246). In A Pattern Language (1977) Alexander pleads for a move away from the modernist top-down approach to architecture and urban planning with the architect as absolute and sole source of ideas and power. Alexander's work has been of significant influence on New Urbanism, a movement in urban planning that strives to give people a choice in the where and how of their urban life. Both Alexander and New Urbanism want a return to community-based urban planning where ecological and human needs come before more highways and suburbs that force people to drive long hours to work, school and shops.

Although the works of Alexander influenced Wright, and he aims to provide players with an empowering tool that will make them aware of the processes involved in urban planning, the player of SimCity is subject to the rules of the game, Wright's vision on what constitutes a city and successful urban planning, the scripts, projected users and uses embedded in the game. As game researcher Shawn Miklaucic states: "While game designers often invoke the open-endedness of such games as SimCity (...), such games necessarily involve metanarratives con- 
cerning human nature, economics, social interaction, technological progress and so forth' (2003, p. 32I-322). Contrary to Alexander and New Urbanism's beliefs, the cities you construct in SimCity are zoned, and there is no integration of these functions. Moreover, in Wright's games driving is the dominator, and not providing a highway network will make your city into a failure. Needless to say, the Realpolitik strategies that are deeply ingrained in the inner workings of SimCity are very much opposed to the theory and teachings of Alexander and New Urbanism.

For SimCity to be an empowering game and educative tool that surpasses the internalization of Wright's vision on urban planning, it 'should enable the player to play with the system itself, not just the system's effects,' says Jamais Cascio, a designer of future scenarios and games (2004). Bogost counters that integrating "policy knobs' that could alter the simulation rules of a game like SimCity' does not necessarily lead to opening the black box (2007b, p. 63). Rather, he suggests, players need to be sensitized to the 'rules that drive that system' (p. 64). Players have to gain 'procedural literacy' through, for example, designing games themselves, which will teach them to read the system critically (ibid.).

Notwithstanding that one can draw parallels between toy towns and SimCity both consist of modular building elements, both familiarize the player with rural or urban conditions through the representation thereof - there is a crucial difference between the physicality of the first and the digitality of the second. SimCity is a dynamic, coded and programmed simulation that develops over space and time and that simulates not only the physical objects that constitute cities but also processes of growth, decay, aging, gentrification and the likes. We could describe the effects of digitalization on play in part as a 'tyranny of the algorithm' ${ }^{13}$ While new media technologies enlarge play worlds and create new play possibilities (such as the option to incorporate user-generated content in a game), they also constrain. For example, the Realpolitik principles of SimCity (or the consumerist ideology of The Sims that will be discussed later on) are unalterable. Needless to say, truly borderless games would be absolutely unplayable. Players need rules, limits and scripts in order to play at all.

The use of cheats in SimCity is a way for players to make the facilitated practices of play less pressing, to escape, so to speak, the tyranny of the algorithm. There are many different ways and means of cheating in computer games: from searching for solutions to difficult puzzles or riddles online to the activation of codes that make your game character rich or immortal, from the creative use or abuse of design mistakes in the game, so-called 'exploits', to gain the upper hand over other players (think for example of players who use a design mistake such as an elevation of the ground to get a better vantage point for shooting) to buying valuable game objects online instead of spending hours and hours looking for them. Some of these forms of cheating alter the design of the game (e.g. the cheat codes), others use the design in an unexpected way (e.g. the exploits), and still others deviate from the discourse on the game (e.g. buying items online). Some 
players will start playing a game by activating certain cheats, while other players might consider all forms of cheating beneath the true gamer. However it may be, the fact remains that contemporary computer games are so expansive, complex and time-consuming that the bulk of players will cheat in one way or another, even if it is in the form of simply consulting an online walkthrough for the best way to tackle a complex mission.

Certain cheats, such as the cheat codes, will allow players to divert from the prescripted play path. Cheats can tip the balance between the design and the embedded scripts of the game and its player. This does not mean that cheating is always a divergent or unwanted play practice. Generally speaking, cheats are part of the game's fabric, they have been designed and programmed in the game and finding and using them is intended and foreseen by the game companies. Cheats might be leaked on purpose by game companies or be found by players who know what to look for in the software code of the game. Popular and common cheats will make the player rich, immortal or will simply have a funny or weird effect on the game. For example, in SimCity 4 Deluxe Edition activating the "fightthepower' cheat will 'remove power requirement for all buildings' which makes the overall playing of the game less difficult because it makes some design scripts less dominant (Gamespot).

At this point it is interesting to consider once again the technological progress that has taken place within gaming technology. STS scholar Sherry Turkle argues in Life on the Screen that the increase in technological possibilities led not only to more realistic, larger, graphically more detailed games but also to an increasingly difficult set of rules that are less accessible to the player (1996, p. 67-69). She links the growing user communities surrounding games to the fact that games are ever more difficult to play, and more and more players need tips and tricks, walkthroughs and manuals to get through a game. They consult lead players online to tap into their knowledge and expertise. Technological advances in gaming technologies have thus created a divide between lead players and players tapping into lead knowledge.

Turkle takes the argument further and states that there is only a small group of players (hackers and hobbyists) who dive into the rule-based simulation while the largest groups of players are 'interested only in the surface of the simulation' (Quoted in Raessens, 2005, p. 377). This last group therefore does not grasp the 'assumptions that underlie simulations' which is a 'key element of political power' (Turkle, p. 7I). Technological innovations that open up a range of playing possibilities and play areas thus come with a price: the coded, designed and programmed core is inaccessible to the largest body of players.

This undermines in part the critical potential that communication professor Ted Friedman attributes to games like SimCity. He states that new media applications like computer games 'reveal their own constructedness to a much greater extent than more traditional texts' (I995, p. 82). In this he reacts to technophobic 
accounts of the attractions of simulation games not as a simulation but rather the simulation of reality. Friedman states that this constructedness is revealed through gameplay:

Learning and winning (or, in the case of a non-competitive 'software toy', 'reaching one's goals at') a computer game is a process of demystification: one succeeds by discovering how the software is put together. The player molds her or his strategy through trial-and-error experimentation to see 'what works' - which actions are rewarded and which are punished (p. 82).

However, as Turkle states, most players will surrender to the 'seductions of the simulation' (1996, p. 7I). Gameplay is then not so much an unraveling and demystification of the underlying ideological biases of the simulation game but an internalization of the rule-based, designed core of the simulation. On the other hand, as Friedman notes, the discourse surrounding a game will reveal to a certain extent the ideological bias of that game (1995, p. 82). As we have seen in relation to the official SimCity manual, the authors were clear about the power and political structures that make the world of SimCity turn. The question is whether anyone other than lead players will dive into these hefty manuals. Most players will consult online walkthroughs that are free and user-generated. These walkthroughs typically explain what works best in a certain game without exploring the underlying ideological assumptions, like the official manuals. Or as game critic Joost Raessens aptly puts it: 'In everyday practice (...) computer game players, seem to me, more superficial (...), at least if we define superficiality as staying at the surface of the (...) game' (2005, p. 378).

\section{A 21st-century Dollhouse: The Sims}

The Sims was introduced with, among many things, a commercial that demonstrated the differences between SimCity and The Sims. In this advertisement the camera zooms in on a SimCity style metropolis, getting closer and closer until you are level with a moving van that crosses a bridge, leaving the sim city behind and heading for unexplored terrain. The van drives on a straight asphalt road, passing some modest homes amidst green surroundings. The van then turns into a plot where a big advertisement announces that new homes are available. We see homes in a new suburban community under construction. A group of people stands chatting near one of the unfinished houses. The one man kisses one of the two women and gets slapped in the face by the other. Then they notice us, the spectator, and they start waving at us. As this early commercial shows, the move from SimCity to The Sims is a move from city to household, from a macro perspective to a micro perspective, from construction play on the level of cities to construction and narrative play on the level of neighborhoods and interpersonal 
relationships. The Sims games combine the practices of construction play (the journey) with narrative, role-playing and the playing with your construction (the destination).

The Sim games could be typified as digital dollhouse games because of their focus on domesticity. In the game the player constructs a home, household, family and relationships. The Sims universe consists of The Sims 1 (Maxis, 200ob) and 2 (Maxis, 2004) and a seemingly never ending string of expansion packs and stuff packs for The Sims 2 that enlarge the play world, add variations to game play and keep it interesting to keep playing the game. A few of these expansion packs and stuff packs are Livin' Large (Maxis, 2000a), Hot Date (Maxis, 200I), The Sims 2: Glamour Life Stuff (Maxis, 2006a) and The Sims 2: H\&M Fashion Stuff (Maxis, 2007).

It is important to note that narrative play in Wright's games is different from narrative play as discussed in relation to LEGO toys. LEGO toys are coupled to media content from which they take narrative structures, figures, and plots. As such, there is a multitude of stories and roles available for children to play with such as Bob the Builder, Star Wars, Harry Potter, Batman... Wright's games are not explicitly linked to media content, but a game like The Sims stands in a tradition of TV soaps, ironic, mediaclastic movies (such as the Scary Movie series that consist almost exclusively of quotes and references to other media products) and a makeover and reality TV culture. The tool to create your own video clips in the game is promoted in these very terms: 'Zoom in close to record every detail as your very own Sims sitcom unfolds' (EA.com, "About The Sims 2").

In this, The Sims can be compared to (construction) toy homes that are also characterized by this combination between building a home and life within that home, between construction and narrative practices of play. Both Igth-century toy homes and The Sims center on the cult of the private home and the separation of the public and the private sphere. Toy villages and toy towns brought the city into the private home and children's lives. Toy homes mirror and reinforce in their design the focus on the private sphere and the domestication of child and play. Toy homes are typically 'separated, comfortable and safe single-family dwellings with a strong emphasis on the domestic sphere,' writes historian Alice Friedman (1995, p. 10). Both toy homes and The Sims symbolize and reinforce the domestication of children and play by focusing on the home, life within that home and by being toys for indoor use.

The private home of The Sims stands in a stereotypical American suburb, rich with clichés of what constitutes the American suburb: freestanding, standardized private homes and cars as the only means to go from A to B. In The Sims you cannot but build freestanding houses, you need a car to go to work, walking might bring you to a neighboring house, but the tarmac roads lead to nowhere. The sacredness of private property and the attachment to domestic comforts are part and parcel of the design and discourse of The Sims games. The Sims mirrors and reinforces domestication in a complex and multi-layered way. The subject of 


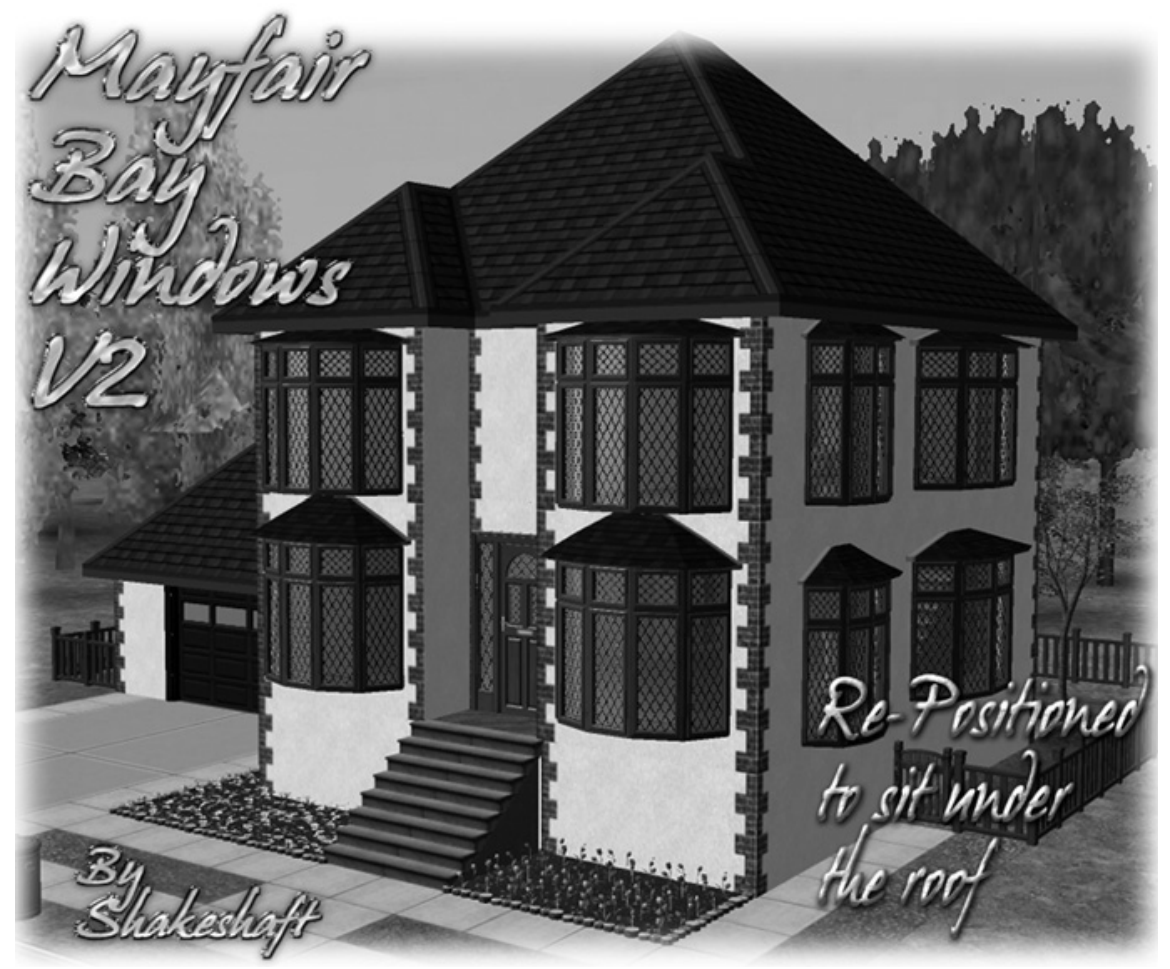

12 Freestanding, Comfortable Private Homes in The Sims 2

Gamer Andrea Shakeshaft creates many items for The Sims 2 that are online available to download and use in your game. She created these bay windows entitled Mayfair Bay Windows V2. They come with 'Deco Roofs to fit the Bays' and curtains (image courtesy of Shakeshaft, 2008). This home is a typical The Sims home: private, comfortable and freestanding.

the game and the projected players mirror one another. The game 'demonstrates an uncanny mirror-world effect' because 'The Sims invites its gamer-subjects to identify themselves with the daily lives of middle-class home-owning professional North Americans' which constitute exactly 'the very computer-owning demographic bracket to which the game is predominantly marketed' (Kline et al., 2003, p. 275-276).

The game space (inside the suburban private home) and the place where the game is predominantly played (indoors) mirror one another as well because the game takes place and is played mainly indoors. In most Sims games you do not follow your Sims to work, they leave the house, and the player stays at home. ${ }^{\mathrm{I}}$ This is very much a child's perspective on things. Parents leave for work and come back from work while the child goes to school or remains at home. The game itself is suitable for a domesticated lifestyle because computer games in 
general do not take up much space (far less than many non-digital construction toys), and they will keep children occupied for hours without them needing help, attention or assistance from their parents. So the player is literally domesticated and plays at being domestic and domesticated.

Computer games in general are, in being domestic technologies, 'constitutive of the domestic' as well as themselves 'domesticated' at the same time (Silverstone \& Hirsch, 1992, p. 6). In the history of computer games, the domestic plays a crucial role. Moreover, 'design and domestication are the two sides of the innovation coin. Domestication is anticipated in design and design is completed in domestication' (Silverstone \& Haddon, I996, p. 46). On the one hand game consoles and games played on personal computers domesticate the player in the literal sense that these objects are meant for indoor use. Handheld gaming devices that can cut the ties between the child and its domesticated play location also need a sheltered play space and require the child to stay put in order to play. On the other hand, these technological artifacts are domesticated through their incorporation within the household. Domestication of technological innovations is 'quite literally a taming of the wild and a cultivation of the tame' (p. 6o).

Most computer games will compensate for their domesticated nature by being violent, rough, taking place in a digital outdoors or otherworldly realm. Generally speaking, 'the domestic space of gameplay (whether living room, bedroom or rumpus room) is destroyed in the process of gameplay' (Flynn, 2003, p. 559). Because mothers (but fathers as well) were often unaware of what Jenkins calls 'the messy process by which western culture turns boys into men' before the domestication of 'boy culture', they are often shocked by the violent video game culture that has entered the living room (2000, p. 275). Most mainstream computer games underline the generational gap and want to distance themselves from the place where they are being played. The Sims, however, does no such thing. The game's subject and the digital playground offered to players is this very domestic sphere. In accordance with television soap operas that mirror the lives of those watching, this game takes the place of play, the location or situation where a game is actually being played, as its subject.

Domestication and commodification are intimately connected. 'Consumption (...) is (...) deeply ingrained in the structures of the domestic sphere: local, private, persistent' (Silverstone \& Hirsch, I992, p. 5). The recent IKEA Home Stuff extension pack for The Sims 2 combines the domestic angle of this game seamlessly with the commercial aspects to the game (EA.com, 2008a). The postwar private home has been from the start a domain for entrepreneurs wanting to launch new products, and it provided consumers with so many new reasons to spend money. This relationship between the private sphere and consumerism has developed over the years into a cult of lifestyle products, trends and fashions. The home has not only become the prime location where Westerners spend their 
time after school or work (as opposed to church, café or village square), it has also become a (if not the) principal reason for spending money.

Consumption, a key feature in The Sims games, is probably 'the most controversial feature' of the game, writes game developer and researcher Gonzalo Frasca (200I). Overall, The Sims games are not controversial. While articles on the games might stress the idolization of consumerism and the household as sole raison d'être, they will almost always end on a positive note by stating, for example, that this game, being focused so heavily on consumption, in fact prompts the player to reflect on his or her own consumerist practices. Some people claim the game is a cynical parody on our consumer culture meant to wake players up. Game theorist J. C. Herz writes, for example, that 'By building a window into Sims' souls, it prompts us to consider our own' (2000). Frasca on the other hand finds this hard to believe: 'I am not able to find satire within it' (200I). ${ }^{15}$ Does this game function as a wake-up call by poking fun at our shopping-obsessed consumption culture? Or does this game train its players in over-consumption? Does it raise awareness of how to deal with money, or is it a shameless celebration of shopping as a cure for existential angst? If playing this game changes anything at all, it normalizes consumerism rather than showing players the absurdity of over-consumption because the game's internal logic, the scripts embedded in the design, are based on what amounts to a 'consumerist ideology', and players are not offered the possibility of stepping outside of this design or altering it. Players are configured in The Sims only as consumers, and their projected actions within the game are all in line with hyper-capitalist principles. The Sims is at the same time an object 'to be consumed' and the 'means (...) for the continued stimulation of consumption' (Silverstone \& Haddon, I996, p. 45). A good example of this is The Sims 2: H\&M Fashion Stuff that was launched, in part, to familiarize American players with the European H\&M chain stores that were being opened around the USA (Maxis, 2007). In an H\&M press release we read: 'The stuff pack contains replicas of garments - all inspired by H\&M's summer collection. Players can also create their own H\&M store and fit it out with mannequins, clothing racks, cash registers, fitting rooms and more' (H\&M, 2007). ${ }^{16}$

As said, The Sims games not only simulate home-building but also the lives within that home. These play practices in The Sims that center on family life inside a suburban home can be compared to dolls' play and playing with a dollhouse. Playing with dolls centers on 'the building of warm interpersonal relationships', the staging of narratives, rehearsing for parenthood, being a good friend and a good consumer (Cross, 1997, p. 67 \& 73). Dolls are described by Auerbach as 'a timeless way for children to relate to the world (...), a source of comfort' and a means to cope with 'feelings, developmental stages, (...) social experiences, (...), fear of separation or emotional upsets' (I999, p. 43). There is a crucial difference between the conception of dolls' play and playing with the Sims. While the first is described by Auerbach as offering children 'a positive, nurturing, and enjoyable 
experience' (ibid.), the second offers cruelty vis-à-vis the Sims as a playing option: 'Create your Sims, push them to extremes, control their world, fulfill their life dreams or realize their fears' (Maxis, 2004). Of course, many children perform cruel acts towards their 'real' dolls and stuffed animals as well; the difference lies in the discourse, in how this type of play is described and promoted.

Comparable to (construction) toy homes, the dollhouse symbolizes and reinforces domestication: the move to the inside, the interior and the private. Playing with a dollhouse often consists of creating tableaux inside the dollhouse rather than actively moving the little dolls around. Historically, dollhouses were a means to display wealth, although the displayed luxury items might have been only affordable in their miniature versions (Stewart, 1993, p. 6I-62). In The Sims as well, players can fill their digital houses with luxury goods that they might never be able to buy in real life.

The same holds true for the digital dolls within this dollhouse, players can dress their onscreen dolls in ever-changing clothes, which they might not be able to do with their real-life dolls. As a 9-year-old fan of digital dress-up games explains: 'With Barbie, if you want clothes, it costs money (...) You can do it on the Internet for free' (Richtel \& Stone, 2007). In the article Welcome to the New Dollhouse, a I2-year-old girl explains why she prefers playing with The Sims to playing with dolls: 'in the Sims you're building the houses and putting the characters into different situations. You can actually decide what you want to happen (...) And also you can see how they get older and how they grow over time' (Schiesel, 2006). What this girl values in The Sims (and many with her) is that the more or less static tableaux of traditional dollhouse play and the imaginary world of dolls' play come to life in a dynamic simulation that develops visually over time.

Another difference between real-life dolls and Sim characters is that these Sims are largely independent and programmed dolls that go about their business while the player meddles with their lives or simply looks in on them. Sims will independently turn on the television, go to the bathroom, sleep, hug, fight and so on without your intervention being needed. Due to this 'independency', the Sims' behavior is partly unpredictable. Players love this 'independency' of their Sims because it makes them surprising. On user groups, players report the latest funny quirks of their Sims: 'The funniest event I've had so far is when Titan (after putting his kid in the crib) turned away and he farted, waved behind his butt and then left the room. The green smoke went RIGHT into the crib and into his kids face!!!' (SmokeD, 2006). In the building and shopping mode of the game, the player is free from possible hindrances from the largely autonomous Sims. You can let the simulation run on 'auto-pilot', but the Sims will never shop, redecorate and renovate on their own.

With the focus on narrative in The Sims, construction play shifts from being the core of the game (as in SimCity) to being one of the many facilitated play options. Practices of construction play might even become the bühne for narrative play, 
depending on player style. By combining home building with narrative play, The Sims unites the journey and the destination. Although strictly speaking, there is no destination in the game because you never win or lose. In facilitating both construction and narrative play practices, it might appear as if this game succeeds in combining the world of boys' toys (construction, engineering) with the world of girls' play (housekeeping, narrative play, nurturing, social relationships). However, these two types or forms of play never actually meet in play. The masculine activity of building and the feminine domain of social relations are united within The Sims but not in the playing of The Sims. These two aspects correspond to different playing modes that never merge. When you switch to the (masculine) building mode, the social life inside the house is put on hold. When you have finished rebuilding, you can switch to the (feminine) shopping mode or My Sim mode where life will re-continue, and the Sims will either be happy or disgruntled with the changes you brought down on them.

The extensive co-creation of The Sims 1 is a case of user-driven innovation par excellence that illustrates the extent of the commodification of the fast centripetal movements in the The Sims geography. The co-creation of The Sims 1 by players was part of the development, marketing and launching strategy of the game and the The Sims brand. 'Several months before The Sims launched, Maxis released an initial set of design tools. These tools were quickly taken up, shared across the community of players, and prodigiously utilized - before the game ever hit the stores' (Salen \& Zimmerman, 2004, p. 540). What was being leaked was the very programming code for the new game yet to be released, a programming code that was not an airtight, closed system but rather a modular system, a 'flexible code' that allowed for expansion and manipulation, for players to become producers (ibid.). This 'careful community design' together with an already existing 'base of Maxis game fans' resulted in an 'immense player-producer community' (ibid.). Herz writes concerning the extent (more than 90\%) to which players co-constructed The Sims 1: 'In the months leading up to the game's release, a network of player-run Web sites sprung up to showcase and exchange 'handcrafted' Sims objects and custom characters. (...) This is a completely bottom-up, distributed, self-organizing process - none of these people are on the Maxis payroll' (2002, p. 3-4).

In this extreme case of commodified centripetal appropriation, fans were given design tools with which they were invited to create content for a game yet to be released. This user-generated content was created in the periphery before the game was released and incorporated within the core of the game that was ultimately launched in 2000. These peripheral activities were orchestrated and harvested in order to create loyalty among SimCity fans for the new game Maxis and Electronic Arts wanted to launch, secure a solid offset for the game upon its release, and save money on the expense of creating all game content in-house. The 
many-to-many culture is thereby commodified and becomes part of the circuit of capital.

Slower centripetal movements that implicate a new game release between peripheral creation and implementation in the core are commodification as well. Game developers working on The Sims games learn from studying and datamining fansites, chatrooms, discussion boards and the like. Either they lurk these sites and learn about their fans and how these fans are using their game, or they actively post questions and news announcements to gather specific information on for example, what sort of expansion pack is most desired by the user communities. What the Maxis team learns from tapping into the user communities is often fed back into later installments of the game, official patches or expansion packs. This is a slower movement between core and periphery but equally important. Players are being heard and therefore they feel that they are being taken seriously, they are delighted when a new expansion pack features the sort of items they campaigned for. A good example of slower centripetal commodification is the documentation function in The Sims 1 and 2.

Originally, the 'Family Album' function in The Sims 1 was intended as a documentation tool that players could use to document how their game was evolving. But players started to use this game feature to document other things than strictly game-related play: 'What the designers did not anticipate was that players would use this feature to craft stories starring their Sims' (Frasca, 200I). To create a story inside the world of The Sims, players have to be patient because of the programmed 'independency' of the Sims. Players have to manipulate the Sims into the configuration they want to photograph. However, the Sims never stay put for very long because of the programmed independency of these digital dolls. Orchestrating a story in The Sims is thus a time-consuming process. By staging stories in The Sims, the game becomes the bühne for a story players want to tell, document and share with others. These staged stories often tell an altogether different story than the one that is evolving in the game at that time. Storytelling and staging stories in The Sims adds a divergent, peripheral play activity to the geography of The Sims play. In these practices of play, players use the design of the game in an unexpected way. Players publish their pictures online accompanied by written stories. The end result is a sort of photo roman, with the same type of romantic and personal dramas that typified the photo roman from the I950s and ig6os.

Maxis responded to this divergent player practice by facilitating this unexpected use of the Family Album as much as possible in The Sims 2 and on their website. In The Sims 2 a video-making device is embedded that allows players to stage moving clips. Maxis will hold contests for best video clip, and players can post their clips on the official website. From the massive use players make of the website, it is clear that this is a very popular feature. In August 2007, some 24,000 user-generated stories were online on the official Maxis Exchange site (EA.com, 2007). Besides the dotcom website for The Sims 2, there are 19 other national 
websites, some of them with their own considerable amount of uploaded, usergenerated stories. The example of the Album Function illustrates how a divergent peripheral play activity can become part of the facilitated core through slower centripetal appropriation.

However, things are not always harmonious between core and periphery. Unwanted peripheral play practices might damage the brand image, compromise the company's 'moral' stance, damage the user communities or frustrate some player's experience of the game. One example of a divergent player activity that was unwanted by many actors in The Sims geography was the creation and distribution of a nude patch for The Sims 2. Normally, the Sims are never visibly naked when they change the clothes they are wearing, take a shower, go to the bathroom or have intercourse - a cloud hides their private parts. With the nude patch, the cloud has disappeared, and the Sims are naked. The patch is free to download from the Pandora Sims website which contains many other I8+ items for the game (PandoraSims, website). The nude patch has resulted in moral outcries from computer game adversaries and has led to agitation among certain users. Which is not to say that the items offered on the Pandora Sims website and the nude patch are not enjoyed by certain players. The nude patch diverges from the discourse on innocent, fun games for all ages that surround Wright's games.

The core of The Sims play is shaped by the combination of discourse and design of the game. In the official 'About The Sims 2' section on EA's website we read for example: 'direct your Sims over a lifetime and mix their genes from one generation to the next. You set your Sims' goals in life: popularity, fortune, family, romance or knowledge. Give them a long, successful existence or leave their lives in shambles' (EA.com, "About The Sims 2"). Although the core is dispersed, open to user-generated content, and both fast and slow interactions between core and periphery are manifest, this does not mean that the core is not a powerful influence on what goes on in the periphery. It is striking how true divergent player behavior remains to the overall porté of the game (a suburban lifestyle based on consumer bliss), the discourse that surrounds the game and the scripts embedded in its design. Silverstone and Haddon ascertain that the 'freedoms' we have to 'impose our meanings' on technological artifacts are limited by the discourse and design of such artifacts: 'These freedoms are not infinite. They are constrained (...) by the rhetorics of technology, expressed through design and marketing' (1996, p. 70). On top of this, Consalvo states, 'various industry elements work to constrain certain readings or activities, promoting certain ways of seeing gameplay and ways of playing that are valued over others' $(2007$, p. 2). In other words, the discourse surrounding computer games, the embedded scripts, the projected users and uses have a strong influence over intended as well as divergent play practices. Overall, the adaptations and appropriations by players of the core never stray very far from that core and can easily be re-incorporated within the core. Most user-generated content for both the SimCity and The Sim games 
thus adds to the existing game world without establishing an antidiscourse within or surrounding these games.

Players' overall 'conservative' peripheral activities can in part be explained by the fact that players cannot alter the designed core of the game. They cannot, for example, design an eco-minded, bike-riding community. There have never been so many building elements to construction play as in the digital realm, nor has narrative play ever been so extensively visualized and been made procedural. However, as Kline, Dyer-Witheford and De Peuter argue, abundant options in how to design the décor of your play do not necessary equal constructive freedom:

But the interactive enthusiasts need to take a closer look at the degree and kind of 'active' participation of young audiences in the construction of their 'own' digital culture. Choosing a corridor, character, or weapon (...) can be very absorbing. But it is hardly a matter of radical openness or deep decision about the content of play. Gamers['] (...) actions consist of selections (rather than choices) made between alternatives that have been anticipated by the game designers (2003, p. I8-19).

Exactly because computer games are designed objects and players are not granted access to the programmed, designed core of SimCity or The Sims, there are certain restrictions as to what can be modified, patched, cheated upon or otherwise appropriated. The variables underlying these simulations are not alterable by the players. Frasca considers this a disadvantage in terms of playability. He states that future The Sims games would do well to allow players to create not only narratives but also simulations, for example on the level of the variables that constitute the Sim characters (200I; 2006, p. 9I).

Again, cheats are a means to make the tyranny of the algorithm less pressing on the actual playing of the game. In The Sims, players can activate cheats that will make them never run out of money, have twin babies or have their house surrounded by water (ConsoleCheatCodes). When you have all the money you might ever need in The Sims, the structure of the game, its designed characteristics will be far less pressing on how players actually play the game. When you have a bottomless supply of simolean (the game currency), you can build and decorate all you want, like in an endless LEGO game, without having to rely on your Sims' paycheck, without having to switch to the My Sim playing mode and deal with your Sims' social and professional problems. This results in a completely different game experience.

Moreover, the constant appropriation of the periphery by the core, either through slow or fast appropriative forces, blurs the lines between core and periphery. The result is an increasingly diffuse geography of play in which it is hard to locate what play practices are taking place where. Since game developers increasingly rely on and tap into what goes on in the 'can' culture of user-driven innova- 


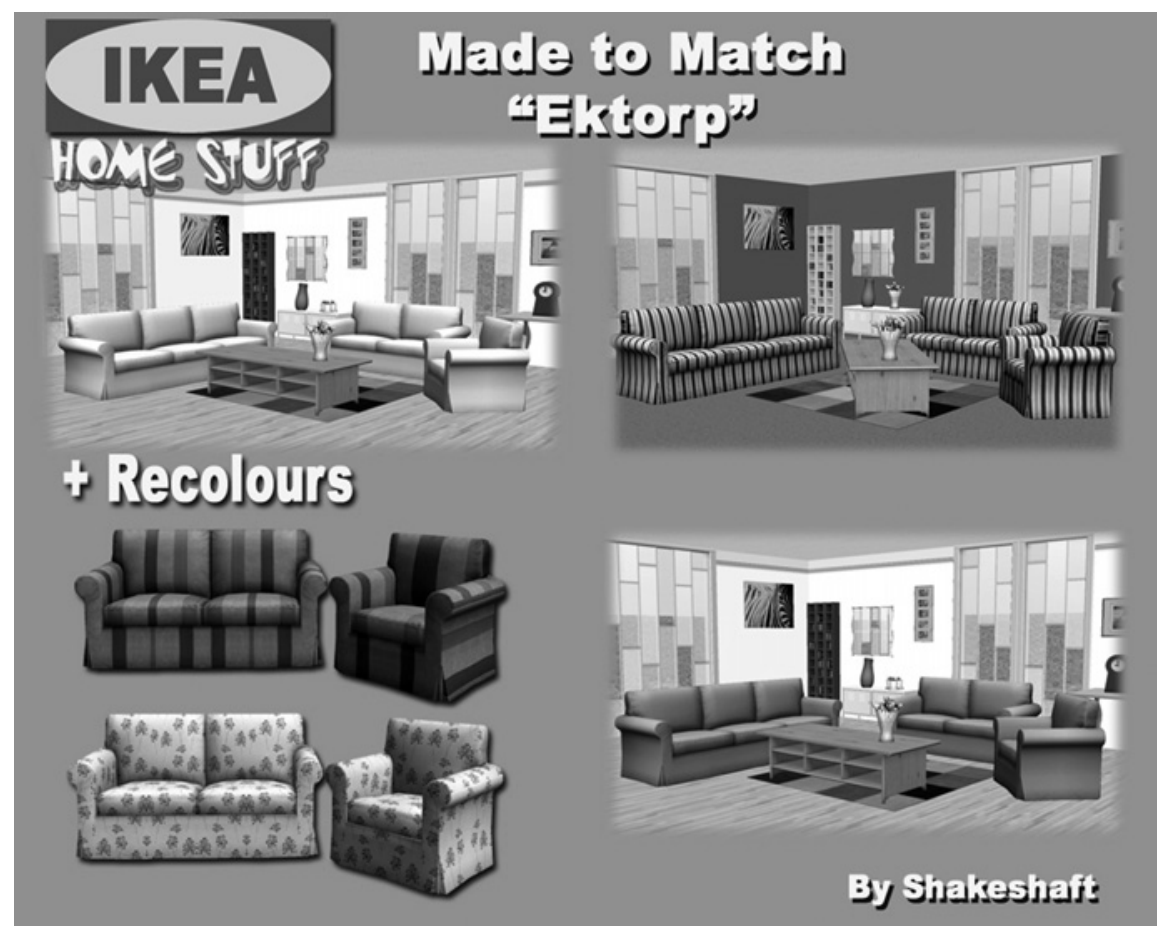

13 User Modifications for The Sims 2

These items were made by gamer Andrea to match the Ektorp collection in the IKEA Home Stuff Pack for The Sims 2. The Ektorp collection is not only a digital collection of furniture to be used in The Sims 2, it is also a real-life IKEA series of sofas. These new designs by Andrea and the re-colorings of the sofas that were already present in the stuff pack are available at The Sims Resource website (image courtesy of Shakeshaft, 2008). These user-generated modifications illustrate that players, in their appropriation of the game, never stray far from the design scripts embedded in the games.

tions and allow for the fast traffic between periphery and core, peripheral play practices are increasingly commodified and seem to be less and less divergent. Players have taken on the role of co-designer, and what they produce is very much in line with the company's discourse. The nude patch is an example of a truly divergent player activity.

In terms of Jenkins' 'jammers' and 'poachers', The Sims poachers are completely legalized, they have become unpaid 'hunters' for EA, and it is their activity that is being poached by EA, although with their consent (2002, p. 167). It is still a 'perruque' but what is being masked is not the penetration of leisure within the work sphere but work in the play sphere (Certeau, 1988, p. 25). Although Herz labels the co-creation of The Sims 1 'bottom-up' and a 'self-organizing process', it was 
EA's decision to release the programming code (2002, p. 3-4). They facilitated this co-creation because this would serve brand, company, user communities and game. As Consalvo stresses, 'Such power systems must be carefully delineated (...) lest this account slide into a false celebration of player agency at the expense of understanding the more complex, dynamic push-pull of industry and player currently at work in the gaming universe' (2007, p. 2).

This is not to say that players are not enjoying the geography of The Sims play. Considering how the game continues to be successful both in terms of sales numbers and positive community activities, this appropriation is not perceived as a threat or a negative development. There is enough content and feedback flowing back into the periphery to keep it 'irrigated' and thus alive and active. If not compromising the geography of play, then what is the effect of this appropriation and commodification of peripheral play activities? For one, it makes questions concerning creative rights and authorship all the more pressing. Moreover, it prompts us to ask what it is that is being played. Playing seems to have transformed from designing with a game or toy to designing for a game or toy. The periphery thereby loses its ludic inconsequentiality and becomes less autonomous while it gains, at the same time, in its importance for and influence over the core.

\section{Unwanted Play Practices in The Sims Online}

In 2002, EA and Wright attempted to recreate the success of The Sims in an online variant: The Sims Online (Maxis, 2002). The Sims Online (or TSO) is a so-called MMOG (Massively Multiplayer Online Game), a game where 'massive' numbers of players gather online to play against or with each other. The game intended to relocate the successful ingredients of the The Sims games within a multi-player online environment. The decision to go into online gaming was a daring endeavor. Online gaming is a difficult, rather closed market with only a few popular games existing side by side. It asks for a different approach to gameplay and facilitated play practices since human players rather than a computer manipulate most or sometimes all onscreen characters. Launching an online variant of The Sims seems to have been based on both Wright's and EA's wishes and visions of the future. EA had been buying numerous companies specializing in online gaming (Origin, AOL and Kesmai, for example) and clearly wanted to tap into the growing and lucrative trend of online gaming: 'EA's (...) chief financial officer, Stan McKee, announced that the company aimed at getting twenty percent of its sales from online revenues within three years' (Kline et al., 2003, p. 272). And who can blame them? The prospect of 250,000 users paying \$9.99 per month in subscription fees would be appealing to every game company.

But it seems that EA was too eager to enter this lucrative market. Probably out of fear of losing potential players to other online games that were being released around the same time, they launched The Sims Online before the beta testers 
thought the game ready. The game never turned into the hoped-for and prophesized success. The game was hyped to such an extent that it would have been very hard to live up to the expectations. In the first few weeks, 80,000 players subscribed to The Sims Online. At its peak, July 2003, The Sims Online had 105,000 subscribers (Woodcock, 2005). The hoped-for 250,000 players never materialized because in a world of active Internet users, bad news travels as fast as good news. And The Sims Online had been surrounded by bad news from the very start. Beta testers announced that the game was not finished and should not have been released. It also became clear that the game world was too big to function as a social space when so 'few' players logged in. The rules of the game further frustrated players rather than motivating them, and soon enough anti-social and criminal behavior became a plague that pestered The Sims Online. Overall, the game did not, as was hoped for, appeal to the large group of devoted SimCity and The Sims players. In 2007 the game was renamed EA-Land, and a new team set about revising the design and code of the game, the gameplay, ways to deal with the bots, and options for players to use user-generated content in the game. However, this rescue plan did not work out, and the game was discontinued on August I, 2008. On the EA.com website the following announcement was published:

It is with mixed emotions that we are announcing the EA-Land experiment will soon draw to a close. Since 2002, EA-Land / TSO has attracted a very special group of players and we certainly appreciate your participation in the community. The lifetime of the game has drawn to an end, and now we will be focusing on new ideas and other innovative concepts in the games arena. We would like to thank everyone who has taken part in this online community as a unique experience in the virtual world (EA.com, 2008b).

During the last couple of years when the game was still online, there were no active, independent user groups where The Sims Online players could find each other. The only meeting place for players was the Stratics website moderated by EA. Some claimed Stratics was a front to pretend that there was still something going on in The Sims Online, and later EA-Land, and to lure new potential players into joining the game. From browsing the Stratics site, you got the feeling that EA was letting the game die a slow and silent death: although many players were announcing on Stratics that they were leaving the game, there were no updates for the game, the installation $\mathrm{CD}$ for the game was no longer on sale, and there were regular reports of criminal activity in the game world. User activity on Stratics was minimal, the most recently uploaded screenshots dated from 2003 for example, and only some 30 pictures had been uploaded in total (Stratics, 2003). This stands in shrill contrast to the continuous stream of user-generated content that is uploaded to SimCity and The Sims websites. A 2006 Stratics polls asked 'How often do 


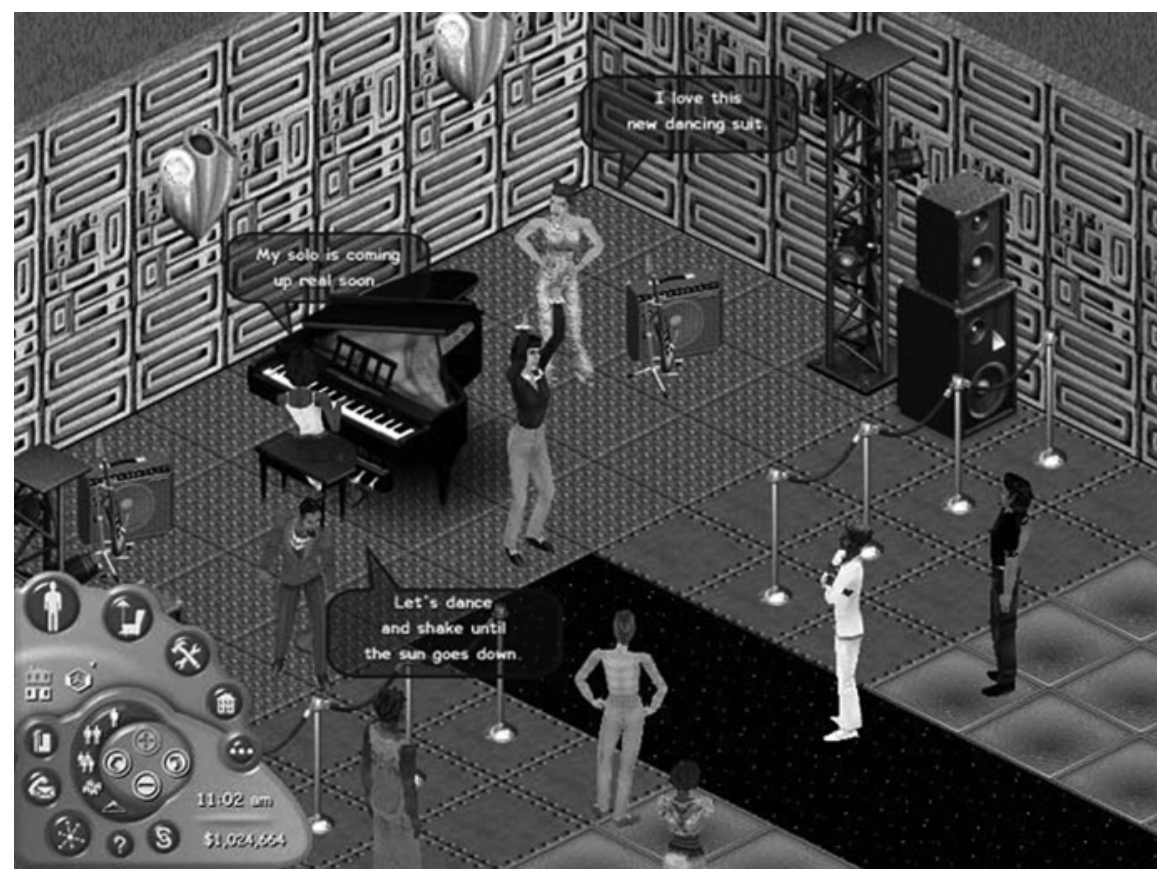

14 Players meeting online in a The Sims Online club

This screenshot from The Sims Online dates from 2003 and was one of the newest screenshots uploaded to the Stratics website dedicated to The Sims Online. Because no player listed his or her name under the picture, it was probably uploaded by one of the people who monitored the website. One of the characters in the club exclaims, 'I love this new dancing suit'. The player at the piano says: 'My solo is coming up real soon'. And the figure at the left shares: 'Let's dance and shake until the sun goes down' (Stratics, 2003).

you log in?', to which 334 people responded, of which 154 replied that they logged into the game daily (Stratics, 2006). Asking players on Stratics why they still played the game or had been playing it, most replied that they played for the people they met up with in the game and not for the game itself (LadyWolf, 2006; QueenFerny, 2006; Steele, 2006).

There are different reasons for the failure of The Sims Online, ranging from a distortion of the symbiotic relationship between players and company to frustrating the design-based play practices that made both SimCity and The Sims so popular, from anti-social players to unfair competition due to cheating bots. From the outside, it looked as if all the elements present in SimCity and The Sims had been incorporated into The Sims Online: one could build houses, cities and communities, had to maintain social relationships and households, and needed to work in order to be able to spend money. However, once inside the game, these construction 
and narrative play elements were compromised. Players who enjoy building and decorating houses would find it easier to do that in SimCity and The Sims games. Both games have more building, decoration and shopping options, and importantly, they allow players to import user-generated content.

Online there were many stories published about mafia gangs in the game who exploited casinos and whorehouses, abused newbies (new players) and long-time players in the form of theft, verbal or 'physical' abuse. Newbies would, for example, report online that their character had been locked in a closet or room and only been set free again after they had handed over their simolean to the abusers. Other players reported racist and sexist remarks, or floods of pestering messages directed at one character/player. Others reported online sexual harassments or the destruction of their property or even game account (Bray, 2004; Ludlow, 2003; Ludlow \& Wallace, 2006). One such story on Stratics reads: 'Today I was scammed of six million, and now I'm [sic] pretty broke. I was buying a rare lot from someone in Blazing Falls. (...) To me, at least, 6 million is alot [sic] of work. I was already on my last leg with this game. (...) So I'm canceling [sic] all three accounts' (LuckyHawk, 2006).

This game differed from SimCity and The Sims because you start with nothing, and it takes many play hours before you have made enough money to build your own house. Diverting from the intended play course, some players would buy simolean (with real money) on websites like eBay in order to build a house without having to actually work a job for many hours. Or players would steal money from other players. But in the 'normal' course of the game, before you reached the state of home owner, you visited other people's houses, and they would most likely welcome you warmly because they got money for every person who entered their home. Houses would typically provide enough sleep, eat, shower, workout and skill-enhancing units (for example, in the form of pianos that enhanced your Sim's creativity or books that enhanced technological or cooking skills) to make a lot of visitors comfortable at the same time. 'Skilling' is important to get a betterpaid job. The owner of the house would cook food and feed the visitors. With friendship being an economy in this game, the idea and intention of this online world as a social meeting place were compromised. Players who enjoy chatting and social interaction will prefer games like There (ThereInc., 2003) or Second Life (LindenLab, 2003) that are considered superior as an online social interaction platform to The Sims Online. Social interaction has been made utilitarian and 'instrumental' in The Sims Online and thus far from social (Steen, Greenfield, Davies, \& Tynes, 2006, p. 320).

Many players inside the game world put their character to work on a skill (e.g. through reading, dancing or playing the piano) while doing something else in the 'real world'. When players needed to do something outside the game, they would type 'AFK', and this would appear in a talk bubble above their Sims's head. Then they left their character alone in the game, and other players knew that this parti- 
cular Sim would not be interacting for a while. This Away From Keyboard or AFK play practice is an unintended play practice, an unexpected and unwanted exploit of the game design, and one of the reasons why The Sims Online did not successfully function as a social interaction space. Too many players simply put their characters at work in the game and left the keyboard.

In terms of the core/periphery model of differentiation, we see that The Sims Online facilitated only a meager set of play options. Although all content in The Sims Online was player-made (houses, parks, cafes, restaurants...) this did not mean that the construction axis of the game was well developed. For one, it would take an average player many hours of working a tedious job to earn enough money to build anything at all. Therefore, the game canvas was rather empty. The answers to a Stratics poll revealed that less than half of the respondents was a home owner (Stratics, 2006). On top of this, the game provided only a meager set of things players could use to build and decorate a home with. This lack of content and consequent craving for content became clear when the Stratics poll question: 'How excited would you be to see new clothes (or clothes from sim page) added to the game' prompted 7256 replies of which $74 \%$ said to be 'Very Excited' about such a prospect (ibid).

The lack of content and building elements in combination with the design scripts of the game diminished not only the construction play elements but also the dollhouse qualities of interior decoration and the pleasures of perfecting a private home. When you finally became the proud owner of a home in The Sims Online, you had to play host to other players in order to earn money. These players could not, as in a dollhouse or in The Sims, be put in certain places or situations, they were not for you to manipulate. Because the characters in The Sims Online were steered by humans rather than a program code, the facilitated narrative play practices and the options for narrative manipulation disappeared: 'The godlike power of The Sims could not be ported to TSO with its many interacting players' (Steen et al., 2006, p. 320). Because the Sims were being played and manipulated by humans rather than a program, the strange behavioral quirks disappeared as well. Much to players' dislike: 'The appeal of The Actual Sims, to me, is that THEY ARE SIMULATED! It's those unknown programmed reactions that are fun to watch and to try to control' (Mike, 2002).

In other words, The Sims Online was a designed object, a programmed and coded artifact that promised the player design possibilities on the level of home building, character development and relationships. However, design possibilities on the level of construction play were reduced because constructing a home was very expensive and the construction options were limited. Designing your onscreen character was equally hard because raising skills was a slow and tedious process. All characters were played by real people who might go offline, go AFK, might only be friendly because that would raise their skills or earn them money, which made designing relationships difficult indeed. 


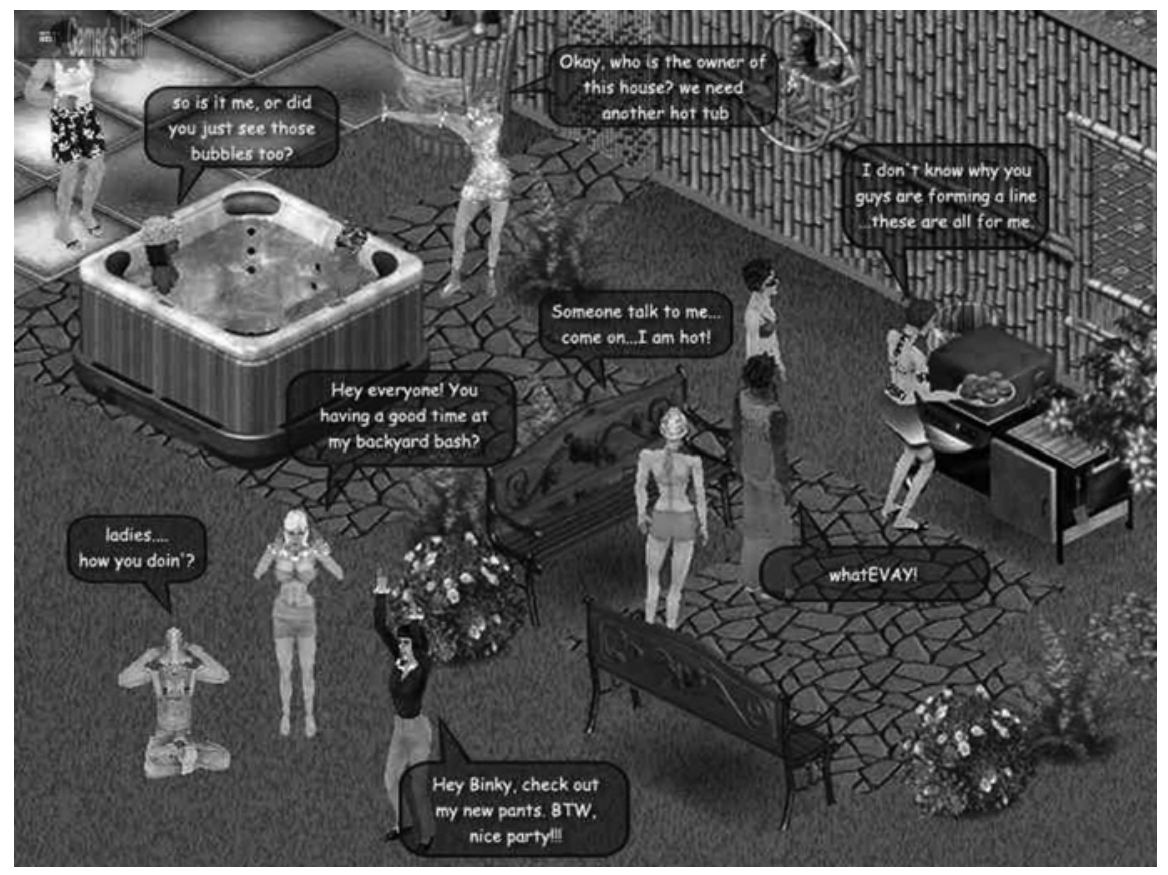

15 Players meeting online in one of the homes in The Sims Online

This screenshot shows different players who are together in a house of one of the hosts in The Sims Online. One of the players asks: 'Okay, who is the owner of this house? We need another hot tub'. Hosts would have to provide enough food, entertainment options and skill enhancing options for the other players so that these players would stay inside the house or come back to it. The hosts would get money for every player who was staying in their house. The character in the center of the picture says: 'Someone talk to me.... Come on... I am hot!' (Gamershell, 2002).

Although the discourse on The Sims Online promised the player a lot of fun, the design of the game, the embedded scripts and the projected uses did not support that discourse. The core of the geography of The Sims Online was characterized by an unfortunate discrepancy between design and discourse. The two elements of the core did not support and reinforce each other and this imbalance frustrated some players who ventured their frustration on other players or on the game company. The stripped-down and unbalanced core of the geography of The Sims Online did not 'tolerate' many divergent play practices either. Both centrifugal and centripetal movements were therefore largely lacking in the geography of The Sims Online.

A good example of the disrupted slower centripetal appropriation of the periphery can be found in EA's dealings with the beta testers. Beta testers are asked by game companies to tinker with games, to be as divergent as possible, find 
bugs and design flaws and come up with suggestions and comments. Normally, beta testers' output is taken seriously and dealt with before the game is officially released.

Beta testing, also known as 'black-box' testing, is part of a larger testing process and is proceeded by an alpha, 'white-box' testing phase. Alpha testing is mostly done indoors by the employees of the game company because white-box testers have access to the source code of the game. In the competitive market of MMORPGs (Massively Multiplayer Online Role Playing Games), the testing phase is likely to be open to the public from the alpha stage onwards because launching a new online game is more difficult than launching an offline game. Most MMORPGs ask a rather heavy investment on the financial level (monthly payments) combined with a heavy time investment (in MMORPGs, players depend on each other to play the game). In most cases, however, large groups of players only become involved in the testing process during the beta, black-box testing phase when the source code is no longer accessible. Beta testers have access to the software through the same user interface that future players will use. During this beta-testing phase, testers will look for bugs and report them and make recommendations for enhancements on all levels of the game.

Reasons for game developers to make use of beta testers are, on the one hand, the prospective loyalty of beta testers to the game they tested, the overall goodwill among user communities that results from game companies using beta testers, and the creation of that symbiotic relationship between player, consumer, product and producer. On the other hand, it would be very expensive and time-consuming to have all the testing done in-house. And of course, players new to a game are likely to find other faults than designers who are already accustomed to the game. Suggestions that do not find their way into the game that is being tested at the time might be incorporated in patches and mods that will be released once the game is already on sale, or they might be used in later installments of the game. The degree to which beta testers can influence the development of a game on the core level differs from one game to the other. But since beta testers are mostly part of a black-box testing phase, their influence is mainly on the 'cosmetic' level of the game.

In relation to The Sims Online the testers themselves perceived their degree of influence on the game as being too low. On the user group alt.games.the-sims beta testers expressed hope during the testing phase that EA would realize the game was not ready for release: 'If it's a good company, they will listen and they will fix the bugs to preserve their good reputation' (AnnieW, 2002). But 'EA failed to listen to the TSO testers' and released the game in 2002 before the testers considered it ready (Squeegee, 2003). Once The Sims Online was released, it soon became apparent to EA and the players that the game was performing poorly. Overall, fans of Wright's games blamed EA rather than Maxis or Wright himself for The Sims Online's failure because 'It's been the history of Maxis to listen to the 
fans' (ibid). The failure to take note of the beta testers' many objections created a negative buzz on the Internet and contributed to the overall negative image that has surrounded The Sims Online since its release.

Besides the discontinuation of the slower centripetal appropriation of the periphery by the core (bridging the beta and official version of the game), the fast centripetal appropriations whereby players can import and employ user-generated content in the game was discontinued as well. Players could not import user-generated content into the game nor could they use the objects they bought for the other The Sims games. This angered many players: 'Not allowing long-time Sims players to import their custom objects seems a slap in the face to all the hard-core people who have their somewhat average game and making it a phenomenon' (Ckought, 2002). As a consequence, the periphery was not characterized by an active many-to-many culture. Both core and periphery were stripped down play areas within a shrinking geography of play. The core neither 'tolerated' user appropriation of the game (centrifugal) nor did it allow the integration of peripheral products into the core (centripetal). In a geography with closed boundaries and minimal traffic between core and periphery, the balance between 'player' and 'game' is askew. There are no tools or means to escape the tyranny of the algorithm, to appropriate the game and its content. Therefore, many players turned to anti-social and criminal behavior in order to avert the tedious working and 'skilling' routines.

There was, in the words of Jenkins, not enough room within the geography of The Sims Online for players as 'poachers' to 'appropriate media content' (2002, p. I67). Therefore, players turned into 'jammers' who jammed the game, the user communities and ultimately the brand. The emptied out play practices of The Sims Online created a breeding ground for unintended and mostly unwanted practices of play that were at odds with the game company's intentions, the game's code of conduct and the overall discourse on The Sims Online. These practices moved away from and took place outside of the circuit of capital, that is to say, the companycircuit of capital. These play activities were not part of what game companies rely on, hope for and can capitalize on and are thus not fed back into the production process. However, these practices might form an independent, anarchistic circle of capital as in the case of the The Sims Online cheating bots.

As already stated, cheats are often used to turn the tables between player and game, to tip the balance and put the player in control of the game rather than the other way around. Players found ways for their unwanted peripheral play activities to enter the core of The Sims Online in the shape of so-called cheating bots (also a form of exploit). A bot is a software programs that performs automated tasks. Since cheating bots are very much unwanted, their intrusion into the core led to a crisis within the geography of The Sims Online. These bots created advantages for the cheating players and introduced a divide between the cheaters and the noncheaters. In a coercive core/periphery model with one sole center of power and 
closed boundaries, as manifested in The Sims Online, conflicts between core and periphery are all the more likely to occur.

In relation to a single-player game such as SimCity or The Sims, leaking and using cheats will not cause any problems because the game has been bought, and players will not 'harm' any other players or the company by using these cheats. Cheats for single-player games are often designed by the companies themselves, incorporated in the games and are as such not unwanted. In relation to online games like The Sims Online, the use of cheats is a totally different story because when you are playing with more than one player, cheats become cheating and cheating devalues the play experience. Many regular players who play according to the facilitated and intended practices of play will leave online games when cheating makes the competition unfair. Game companies will rarely incorporate cheats in their online games because, contrary to single-player games that you purchase with only one transaction, online games ask a monthly subscription fee, and thus the loss of every player means less income. If there are cheats for online games, they will be mostly player-created, unintended and unwanted.

Johan from MySimsOnlineCheats.com was the chief creator and seller of The Sims Online cheating bots. He promoted his bots with the words: 'our bot programs can play the game much faster than you ever can. (...) Playing The Sims Online will become much more fun since you finally don't need to worry about making simoleans any more' (Johan, website). Johan had been programming simolean-generating cheating bots for The Sims Online since 2002 because it was so hard to raise money and skills in the game. On his website there were eight different cheating bots on sale.

The EYE cheating bot was sold for \$12 and acted like a real player. This bot made money in the game without the player having to be present. TSO Guard was only $\$ 9$ and made sure your game did not go offline when you were inactive for too long. It could monitor up to twenty different accounts/games. Both cheating bots catered to the aforementioned AFK play practice. Without using these cheats, the game went inactive when a player was AFK for too long. This rule was installed to counter the unwanted AFK play practice. TSO Auto Code PRO sold for \$2I and had 'been build [sic] with only one idea in mind: to make as many simoleans as possible in the shortest amount of time'. TSO Pizza Bot PRO, TSO Auto Maze PRO and TSO Band Perfect all sold for $\$ 30$ and promised the buyer unlimited simoleans. TSO Pro Bot could be bought in a \$2I or a \$39 edition. This bot had been 'designed for the professional simolean seller' and could handle 'an unlimited amount of games at the same time'. With this bot players could be earning money in different places, in different games and with different onscreen characters from one computer. These bots facilitated practices of play that would normally have been impossible. The Rare Pet Finder sold for \$2I and automated the task of looking for rare pets in the vast world of The Sims Online. Finding these pets would gain the player money (Johan, website). 
Johan promised potential buyers that simolean they could not or did not want to spend in the game could be sold to other players through eBay or comparable websites. However, there seemed to be no potential buyers for these simoleans at the time of conducting this research. Another 2006 Stratics poll asked the players: 'How many Simoleans does your richest Sim have in their account?' Most respondents (26\%) claimed that their richest Sims have 'I billion to max allowed' (Stratics, 2006). This might have meant that players had been playing the game so avidly that they had gained this much money, that they were all using the cheating bots or that they had bought a lot of simolean online. Whatever the case, the market for simolean seemed to be smaller than Johan promised his potential customers. The more cheating bots were used, the more the 'market' was flooded, and the The Sims Online currency became worth less and less. It is unclear how easy or difficult it was to track players using the cheating bots. Players being caught using bots would first get a warning from EA before being banned from the game.

These cheating bots both altered the design of the game and worked against the discourse surrounding the game. Creating, selling, buying, installing and using these cheating bots were all unwanted play practices because they devalued the currency used in the online game world, created a divide between the have's and the have-not's and facilitated 'illegal' play practices such as the AFK practice. Cheating bots (but also the The Sims nude patch) are unauthorized and unendorsed (by the powerful actors, the game companies in the core) boundary crossings between core and periphery.

\section{Commodified Geographies of Play}

A crucial difference between non-digital and digital toys is the fact that the latter are designed, coded software programs. Computer games visualize the world of play and procedural aspects of games to an unprecedented level. The technological object the player plays with or against becomes thus more complex, so do the embedded scripts, the rules and requirements, the projected users and uses.

The results of this digitalization of play are manifold. On the one hand, almost all player-game and player-company interactions are digitalized and take place mainly online. With the advent of private computer ownership and the Internet, the area for digital play increases dramatically. However, the means for companies to tap into the 'can' culture of peripheral play activities increases as well. From SimCity to The Sims, one sees an increase in the traffic between core and periphery, between player and company, until this relationship reaches a symbiotic stage. Within the geography of The Sims play, the core grows and incorporates the periphery in a continuous centripetal movement. Because the periphery is not only appropriated but also continuously 'irrigated' by the core with new opportunities for user appropriation, the geography of The Sims play remains alive and 
'healthy'. The transition between core and periphery in the geography of The Sims is fast, smooth and multiple to the extent that the lines between core and periphery, between player and producer, have almost disappeared, and the geography acquires an organic character. This makes it very difficult indeed to establish the authorship of certain game content and to unravel what is taking place where in the geography of The Sims. With the official LEGO Blacksmith shop, one knows that the product one is buying is a commercialized MOC set because it is advertised as such. With The Sims, one cannot tell whether the objects in the game are user-generated content or manufacturer-generated content.

The LEGO Company occasionally taps into the user-driven 'can' culture of dedicated fans by inviting an elite group of adult LEGO fans to join the designers in Billund, visiting brick festivals and LEGO-dedicated websites. The LEGO Company decides what sort of user-driven innovations, if any, can enter the core of LEGO play. The LEGO Company is thus only partially dependent upon these user-driven innovations and chooses if and when to involve the users within product or brand design. Within this geography, the periphery is only appropriated and commodified by the core in the function of the design and development of new products. With SimCity, EA facilitates a constant and unobstructed flow of user-generated content into the core in fast centripetal movements. However, the functioning and popularity of SimCity are not completely dependent upon these flows. Both the LEGO Company's products and SimCity benefit from a vibrant and active periphery of play without being completely reliant on peripheral activities.

In contrast, The Sims game and brand have, even before its release, been completely dependent on the periphery of play. The Sims development team relied on being able to tap into the periphery, appropriate user-generated content and integrate that content into the game to be released. To draw yet another comparison with LEGO toys, The Sims 1 was presented to the public as an almost empty box with only the basic bricks in it and accompanied by the tools to create your own bricks. The fans were expected to create and add more bricks, detailed particles, in other words content, to the box. Their creations were then returned to the company and incorporated within the launched product. Both fast and slow centripetal appropriations are thus commodified within the The Sims geography of play. As such, the stakeholder positions of player, consumer and producer implode, and a symbiotic relationship between player, product and company is created.

The centripetal and centrifugal movements between core and periphery that have been keeping the Sims brand and the geographies of Sim play vital and dynamic haltered and failed in the process of developing, testing and launching The Sims Online. Both fast and slower traffic between core and periphery came to a standstill, resulting in a shriveling geography of play mainly populated by antisocial players and unwanted play practices. While SimCity and The Sims are both 
characterized by a 'healthy' and active geography of play where movement between the two realms is frequent and fluent, The Sims Online is characterized by a crisis-ridden geography of play. The unwanted peripheral activities in the geography of The Sims Online strayed so far from the discourse and altered the design so drastically that their incorporation in the core resulted in a crisis. Players did not design with the game, nor for the game but against the game.

A geography of play with open boundaries, traffic between core and periphery and dispersed power centers capitalizes on the many-to-many industry, lead userdriven innovations, the 'can' culture of devoted fans. These fans design, co-create and play with or alongside the designers of the game. A geography of play with closed boundaries and one-way traffic between the core and periphery simply cannot capitalize on these user-driven practices of play and thus returns to a oneto-many paradigm. Players will then be enticed to design and play against the designers exactly because they lack the opportunities to co-create. A geography of play that is not a 'can' culture, a 'possibility space' as Wright himself calls it, for interactions between core and periphery but a must culture, a space characterized by restrictions rather than possibilities, cancels out the play potentials of computer games and digital play in general (Wright, 2005b). It is exactly the 'can' aspect of the geography of digital play that makes it the terrain for exciting and innovative play practices - both on the level of the facilitated core and the divergent periphery.

The popularity of both SimCity and The Sims demonstrates the success that can result from using and drawing on the many-to-many model. The Sims Online, on the other hand, illustrated the failure that can result from sidestepping this model. The mechanisms of user involvement within the many-to-many culture are diverse and wide-ranging, from programming software to hosting a website, from posting questions on fansites to downloading new skins for your Sims. With companies' increasing appropriation of this many-to-many culture, both for the design of new products and to keep existing products exciting, players become co-designers to an unprecedented extent. Their divergent play practices enter the core and become part of the design, the embedded scripts and projected uses. When through slow centripetal appropriations user activities are integrated within new product designs, these users and their activities reconfigure the user. The projected use of the documentation tools in The Sims games was reconfigured based on unintended actual uses of the Family Album in The Sims 1. When through fast centripetal appropriations user activities are integrated within existing products, these users and their activities co-configure the user. Through the constant flow of user-generated content into the core, how players actually play the game, the core, the projected user and uses are co-configured. However, considering how true divergent player activities stay to the design and discourse of these technological artifacts, they do not introduce a drastically different user or an antiprogram into the core. 



\section{Part IV: Serious Geographies of Play}

Companies increasingly rely on a vibrant and active periphery of play to keep their brand vital and commercially successful, to maintain a positive relationship between player, consumer, game and company. The many-to-many template is not only becoming common practice among both traditional toy makers and digital game developers, it has also attracted a lot of attention from other companies and organizations as well which are seeking new ways to involve consumers in the world of their brand. The dedication of both LEGO and Sims fans is something most companies dream of. It's not only commercial companies that recognize the potential value of this participative model that can create a symbiotic relationship between different and traditionally remote stakeholders. Notably, the value and appeal of the many-to-many model have not gone unnoticed within the realms of politics and policy-making. One such a policy domain using the many-to-many model is that of urban planning. Through (computer) games, or serious urban games, different stakeholders are given the option to participate in urban planning. ${ }^{17}$

In general, games with a serious purpose, that is, a purpose outside of the domain of entertainment and/or commerce, have found their way into many professional fields and are widely used and experimented with as training and educational devices. Serious games strive to combine the technological possibilities of entertainment computer games with an educational and/or political agenda. Bogost labels games that either support or disrupt social and cultural positions, persuasive games. These games are persuasive because of their 'procedural rhetoric', the 'practice of using processes persuasively' (2007b, p. 28). Bogost considers the procedurality of computer games as an agent for generating political and social change.

One example of a serious urban game that relies on many-to-many mechanisms is Face Your World, initiated by Dutch artist Jeanne van Heeswijk (Heeswijk \& Kaspori, 2002-ongoing).$^{18}$ Face Your World is a mixed media participation process with the Interactor, a photorealistic $3 \mathrm{D}$ design software application, at its core. Face Your World was designed for and played in the Dutch garden city Slotervaart in 2005. It was initiated to deal with the dilapidated garden city, its poor childrelated facilities and lack of social cohesion. Both children and adults participated in the design of a new neighborhood park. The participants worked more than half a year (between January and July 2005) on the design of the park and on March the Ist, 2006, the city council of Amsterdam decided to go through with the project and realize the design as conceived by the children and neighborhood residents. If all goes as planned, the park will be realized by $2010{ }^{19}$ 
The Western garden cities (Westelijke Tuinsteden) in Amsterdam, the Netherlands, were built after the Second World War according to the utopian CIAM (Congrès International d'Architecture Moderne or International Congress of Modern Architecture) tradition. CIAM, a think tank of modern architects such as Le Corbusier and Gerrit Rietveld, was established in 1928 and disbanded in 1959. Dutch architect and urban planner Cornelis van Eesteren (I897-I988) was the CIAM president from 1930 to 1947 . He designed the general expansion plan (AUP, Algemeen Uitbreidingsplan) for Amsterdam in 1934. The Western garden cities were part of this general expansion plan. Air, light and space were leading principles in both the design of the houses and the neighborhoods. The design of the new suburbs of Amsterdam stood in contrast to the overcrowded city center of Amsterdam and the small and dark living spaces of those living in the center of the city. In 1954 the satellite city Slotervaart - where Face Your World took place was built. The lay-out of this suburb is spacious: the streets and boardwalks are broad and the apartment buildings are set apart from each other so that light can enter each apartment. The apartment blocks are laid out in straight lines with green areas in between the blocks or are lined around a central square. These central squares were meant for shops and the green areas between the buildings were meant for recreation and play.

The Western garden cities of Amsterdam have seen a decline in reputation over the last decades. They have gone from utopian and visionary living areas to neighborhoods fraught with social, economic, infrastructural and reputational problems. The city of Amsterdam researches bi-monthly the living quality and safety in the various boroughs of Amsterdam. The results are published online and can be consulted by anyone who is interested. Slotervaart is the suburb with the lowest percentage of what is called 'social quality'. Only $4 \mathrm{r} \%$ of respondents reacted positively on statements concerning the social quality of the borough. Together with two other boroughs, Slotervaart has the highest percentage (22\%) of inhabitants that avoid certain areas of Slotervaart. Also, Slotervaart has the highest percentage $(36 \%)$ of inhabitants who feel unsafe in their neighborhood (Amsterdam, 2008b). These numbers have stayed the same or worsened since 2007.

In 2007, The New York Times ran an article on Slotervaart The End of Tolerance in Amsterdam. The author Erich Wiedemann aptly summarized some of the key issues of this borough:

Crime and unemployment are significantly higher [in Slotervaart] than the national average, and one in three of the neighborhood's young people are highschool dropouts. (...) There is little evidence of Amsterdam's typical charm in Slotervaart, a neighborhood where bleak concrete apartment blocks cluster around a futuristic-looking town hall. Almost half of Slotervaart's 45,000 residents are foreign immigrants, and it is not uncommon to see eight-member 
families living in cramped, 50-square-meter (540-square-foot) apartments (Wiedemann, 2007).

The ward alderman of Slotervaart, Ineke Ketelaar, explained in an interview that the last fifteen years, mainly large families have been appointed apartments in the boroughs of Amsterdam West because these apartments are relatively big, according to Dutch standards. These large families were mainly immigrant families. Because of this policy, many large immigrant families now live in the garden cities. These families have, as Ketelaar tells me, a hard time coping: there is a high percentage of unemployment amongst these families, first generation immigrants feel isolated because they might not be able to speak or write Dutch, and the apartments are often not big enough to give every child a private room. Therefore, many children and teenagers hang around outside (so-called 'hangjongeren', loitering children and teenagers) which adds to the aforementioned feelings of threat (interview with Ketelaar, 2007). Slotervaart is an ethnically mixed neighborhood with $43 \%$ of the 44,185 inhabitants being non-western immigrants, $12 \%$ western immigrants and $44 \%$ non-immigrants. 10\% of the $43 \%$ non-western immigrants are unemployed (Amsterdam, 2008c). The largest community of immigrants consists of Moroccan people ( $17 \%$ of the total population of Slotervaart); Turkish immigrants are the second largest group in Slotervaart (8.5\%) followed by immigrants from Suriname (7.4\%) and the Antilles (0.9\%) (Amsterdam, 2008a).

The end of the I980s saw the initiation of the urban renewal of postwar neighborhoods in The Netherlands. The houses built in the r950s were dilapidating, there was need for more homes to deal with the ever-expanding population of Amsterdam and the boroughs were not a popular destination for those who wanted to leave the city center of Amsterdam. People who could afford it preferred a private, free standing home in a green suburb rather than an apartment in one of the building blocks. On the website of Slotervaart, we read in the historical section that due to the need for new homes in the r95os and 196os, the focus was on fast and large scale production of similar homes. In some of these boroughs, there are only cheaper rental apartments available. Meaning that people who climb up on the social ladder will leave the neighborhood and move to a more upscale area. Those who cannot afford to move out of Slotervaart have no choice but to stay. This means that people do not live by choice in these boroughs but by the lack of options to move out. When those who can afford it move out of these boroughs, only the disadvantaged and underprivileged stay behind (Amsterdam, 2007).

There are two important players in the renewal of the Western garden cities. On the one hand there are the different boroughs or wards (stadsdelen) of Amsterdam West which all have their own ward alderman and legislative council. On the other hand there are the eleven housing corporations who own the houses in 
the garden cities. Based on pilot projects and research conducted in the boroughs (both by the wards and the housing corporations) the report Richting Parkstad 2015 (direction park city 2015) was published in 200r. Richting Parkstad 2015 is the basis of the current plans for renewing the postwar garden cities, although it has been revised, changed, discussed and adapted many times over. The situation is very complex (mainly due to re-housing problems) and there is a general sense of insecurity and confusion among the neighborhood residents concerning the future of their home and neighborhood.

Because of the complex situation in Slotervaart and the long-term renewal process, the ward tries to inform the public as thoroughly as possible, with special websites, publications and newspapers on what is going on where, when and why. There are also a lot of hearings and meetings where the public is invited to reflect on the urban renewal plans, ask questions and object to certain plans. On the Slotervaart website there are, at the time of writing, three different calls for public participation (Amsterdam, 2008d). A 2006 report by the city of Amsterdam showed that mainly younger people and immigrants are less inclined to attend such meetings and hearings (Lindeman, Bicknese, \& Bosveld, 2006, p. 5 \& IoII). Face Your World was an attempt to engage exaclty younger and immigrant inhabitants of Slotervaart in the urban change of their neighborhood.

Given the complex situation in Slotervaart and the many conflicting stakeholders in the urban renewal process, it is surprising that some things, like Face Your World, do in fact happen. Securing the commission to undertake this participation project took considerable time and effort and the word 'coincidence' is often used when people describe how Face Your World became a part of the Slotervaart renewal effort (interview with Engelsman, 2007; Hartoog, 2007; Huisingh, 2007; Wien, 2007). One of the project leaders of the renewal of Slotervaart, Rob van Aarschot, and an area developer for housing corporation De Alliantie, Hanneke Engelsman, were convinced early on of the possible merits of such a participation project (interview with Engelsman, 2007). They had been looking for new ways of organizing public participation because the regular hearings only attracted the same few elderly white men who would always make the same objections or suggestions (ibid).

But the ward council had some reservations. They worried that Face Your World would end in the design of a park that they would not be able to finance. ${ }^{20}$ Designing a park with neighborhood residents that would be too expensive to realize, would damage the image of the ward. Neighborhood residents already have the feeling that the ward does not take their citizen participation seriously. Organizing a large participation process that would result in a park that the ward could not afford to build would only further this feeling and confirm the citizens' skepticism concerning their role in the urban renewal process. Besides budgetary restrictions, another point that was hard to negotiate concerned the pre-set conditions for the park that the ward had assembled (interview with Broekhuizen, 
2007; Hoeve, 2007). The list contained some 25 criteria for the park that ranged from the number of times the results had to be shown to a team of supervisors (minimally twice) to the preservation of old trees in the park, from commonsense elements for a park such as lights and dustbins to specific square meters for certain activities (e.g. $2945 \mathrm{~m}^{2}$ for the playground). Both communication advisor Leta Hoeve and public space designer Joris Broekhuizen from the Slotervaart ward described the negotiations concerning these conditions as difficult. Some of these conditions were met, while others were debated and ultimately changed by Van Heeswijk (e.g. the location of the five entryways into the park). Besides these rather specific conditions, the two main requirements from the Slotervaart ward and De Alliantie were that the participation process would involve neighborhood residents otherwise hard to reach and that the different age and ethnic groups in the neighborhood would support the final design of the park.

\section{Participation Tools}

Public participation in urban planning has a rather short history; it became an important aspect of urban planning processes during the Ig6os. This is not to say that since the rg6os participation has always been exercised. A key text on public participation in urban planning - A Ladder of Citizen Participation by Sherry Arnstein (I969) - stems from this period. Arnstein distinguishes between eight different forms or degrees of public participation to reveal that public participation is all too often used to cover up manipulation. Real participation would only be achieved through the redistribution of power, thus resulting in 'citizen power' (2003, p. 245-246). She writes:

There is a critical difference between going through the empty ritual of participation and having the real power needed to affect the outcome of the process. (...) participation without redistribution of power is an empty and frustrating process for the powerless. It allows the powerholders to claim that all sides were considered, but makes it possible for only some of those sides to benefit. It maintains the status quo (p. 246).

The municipality of Amsterdam also uses a ladder of citizen participation, going from informing citizens to co-production (interview with Hoeve, 2007). The council of Slotervaart strives to reach at least the second or third rung of this ladder, which means that citizens will be able to advise the ward on a certain plan (ibid). The design of the neighborhood park in Slotervaart through the Face Your World process could be considered the result of co-production.

Jim Burns outlines a process of user involvement that goes from awareness to perception to decision-making and finally to implementation or action. Concerning the first step in the process, awareness, Burns writes that this can come about 
in a negative or positive way: 'Negatively, people can be made aware suddenly by a threat to their community and its patterns of life. (...) The usual result is (...) a win-lose situation wherein either the community gets its way or the forces of the other side get to fulfill their plans' (1979, p. 2I). Characteristic of this situation is that 'decisions have been made before people become aware of them' (p. 27). This leaves the people only an antagonistic position, 'either resisting the proposed change or trying to force another change in its place' (ibid.).

The Harbour Game (Kollision, 2002), a serious urban game designed and played in Århus, Denmark, resulted from negative awareness of urban (re)development plans. The Harbour Game concerned the extensive redevelopment plans for the Århus harbor. The Harbour Game was created and played to confront the municipality, to raise awareness among policy-makers concerning the importance of public participation in such large-scale planning processes and to alert the public to the existing plans for the harbor (interview with Delman, Løssing, \& Lykke-Olesen, 2007). As Burns indicates, this is a win/lose situation. In relation to The Harbour Game, the municipality won in the sense that the outcome of playing the game did not affect their redevelopment plans. The plans for the harbor area remain unchanged.

Awareness can also be raised in a positive way and will as such mark the beginning of a 'process of agreed-upon change' (Burns, I979, p. 2I). Positive awareness will lead to perception and understanding (p. 25). The problem is that in reality different actors in a participation process might experience and/or understand things differently or experience and/or understand different things. Although Burns sees a direct connection between and movement from perception to decision-making and ultimately implementation, in reality, it is very difficult in participation trajectories to actually cover these last two steps of decision-making and implementation. During participation processes, numerous things can frustrate these final two steps, ranging from citizens losing interest in a given situation to a new political coalition that decides to do things differently, from running out of money to see the process to the end to the disapproval of the decisions by those higher up. Van Heeswijk and Kaspori made sure that they had the authorization to traverse the whole process described by Burns together with the citizens (interview with Heeswijk, 2007; Kaspori, 2007). Otherwise, participation processes are simply an excuse, a sort of painkiller for difficult urban renewal plans, they state (ibid.).

Besides different levels at which the public can be engaged in urban planning, there are of course many different forms in which participation can be put in practice. Serious urban games are only one means of exercising public participation, and a relatively new one at that. Throughout the decades that citizen participation has been placed on the agenda of planners, architects, municipalities and politicians, it has been put into practice in various ways, with surveys and hearings as the most common strategies to involve or consult the public. Games and 
playing were popular participation tools from the very beginning of public participation in urban planning. Henry Sanoff was an early advocate of games and playful activities as participatory tools in urban planning processes. He designed, for example, the 'Best Fit Slide Rule', a discussion tool to examine alternative street infill solutions and their consequences (1988, p. 35). Sanoff would also organize workshops, such as the 'House Activities' workshop, around rule-based games (p. 36).

Most urban planning projects will use a combination of different participation methods at various stages of the planning process. Face Your World, for example, combined a computer-based public participation game, the Interactor, with surveys, workshops, public meetings and public hearings. These different forms of participation were used for different reasons. The computer game the Interactor was used to design the park. Surveys were used to get an idea of what the neighborhood residents needed, wished and hoped for in relation to the park. Public meetings and public hearings were used to gather more data on the local wishes for the park, to inform people on what to expect from a park or to present ideas and designs for the park that people could then comment on. Through the combination of different forms of participation, different groups of citizens were reached; children would participate in the design process while elderly people were more likely to attend the hearings.

There were basically three groups of participants partaking in the design process: children enrolled in Face Your World as part of their school curriculum, neighborhood children who participated on an individual basis and adult participants. There were roughly two means of participation: computer-based and non-computer-based. Both groups of children participated mainly through the use of the Interactor. This was complemented with lessons, excursions and real-life drawing and modeling. The adults participated almost exclusively through workshops, meetings and surveys. Over the course of the seven months when Face Your World Slotervaart took place, 49 different events - workshops and meetings mainly were organized. These 49 events, except for one workshop for teenage girls, were targeted at the adult participants. The meetings and workshops each addressed a specific group of stakeholders: elderly neighborhood residents, Turkish and Moroccan women or teenage girls. During these events, an illustrator visualized all the ideas and wishes of the neighborhood residents to guide the discussions and make suggestions more 'tangible'.

The central location for all activities was an old sporting hall - renamed Stedelijk Lab (urban lab) - that was destined for demolition and stood on the very grounds where the park would be developed. The Lab was open to the public on Tuesday, Wednesday and Thursday afternoons (from 2 to $6 \mathrm{pm}$ ). During these public hours neighborhood residents were free to walk in and make suggestions for the park (these were all noted down in a logbook) and children could come in and join in the design process. The interns managing the Lab - Irene den Har- 
toog and Nienke van Ankeren - guided children working on the design of the park during public hours. The popularity of the Lab increased immensely among neighborhood children during the Face Your World project. Not all of the children intended to work on the design of the park. Since it was the first time that the Face Your World team was involved in such an extensive participation project, they had to learn how to deal with these problems along the way (interview with Hartoog, 2007; Heeswijk, 2007; Kaspori, 2007). Over the 26 weeks of the Face Your World process, hundreds of people and children visited the Lab during public hours. The Lab was further used on Tuesday mornings between 9:30 am and 12:30 pm and on Wednesdays between II:30 am and 2 pm by the children enrolled in Face Your World as part of their school curriculum.

The Interactor software application was created for children aged 8 to I2. The Interactor is a game-like environment that guides the players through the different stages of a design process: exploring, sketching, discussing and designing. Throughout the process of playing with the Interactor, the participating children were 'guided by a group of experts in the fields of urban planning, design and landscape architecture' (Heeswijk, Kaspori, \& Mosterd, 2005-2006 weblog).

During the first phase of the Interactor, children entered their digitalized neighborhood and started exploring the controls of the game. They were represented in the game by a standard onscreen character. A picture of the player's face could be mounted on this standard onscreen character. When the participants had familiarized themselves with the workings of the Interactor, they were asked to take a picture in the game of the area they would like to work on. This picture served as their canvas on which they could experiment, explore their ideas and try out different solutions. In this second stage of the game - the sketching phase children would work individually. They could draw on their picture and add objects from the library to this sketch.

The image library of the game consisted of more than 400 digital pictures categorized into nature, people, animals, buildings, vehicles, street furniture, logos, ground and miscellaneous. A very important aspect is that the children could also add elements to this library. They could take pictures of real-life objects they found important and add them to the library. They could design objects themselves within the game or alter existing objects from the library. During the Face Your World particpation process in Slotervaart, 1207 objects were added to the standard library consisting of original drawings, adaptations of existing objects and pictures taken by the children of their neighborhood. Through this feature, children could add to the facilitated core of the geography of serious play to a certain extent. In adding items to the library, children effectively expanded the tools with which they could design the park. This form of fast centripetal appropriation in which objects made in the periphery become part of the core is a way in which the participants can co-configure the user and can co-determine the designed artifact and their own tools for participation and design. The children par- 


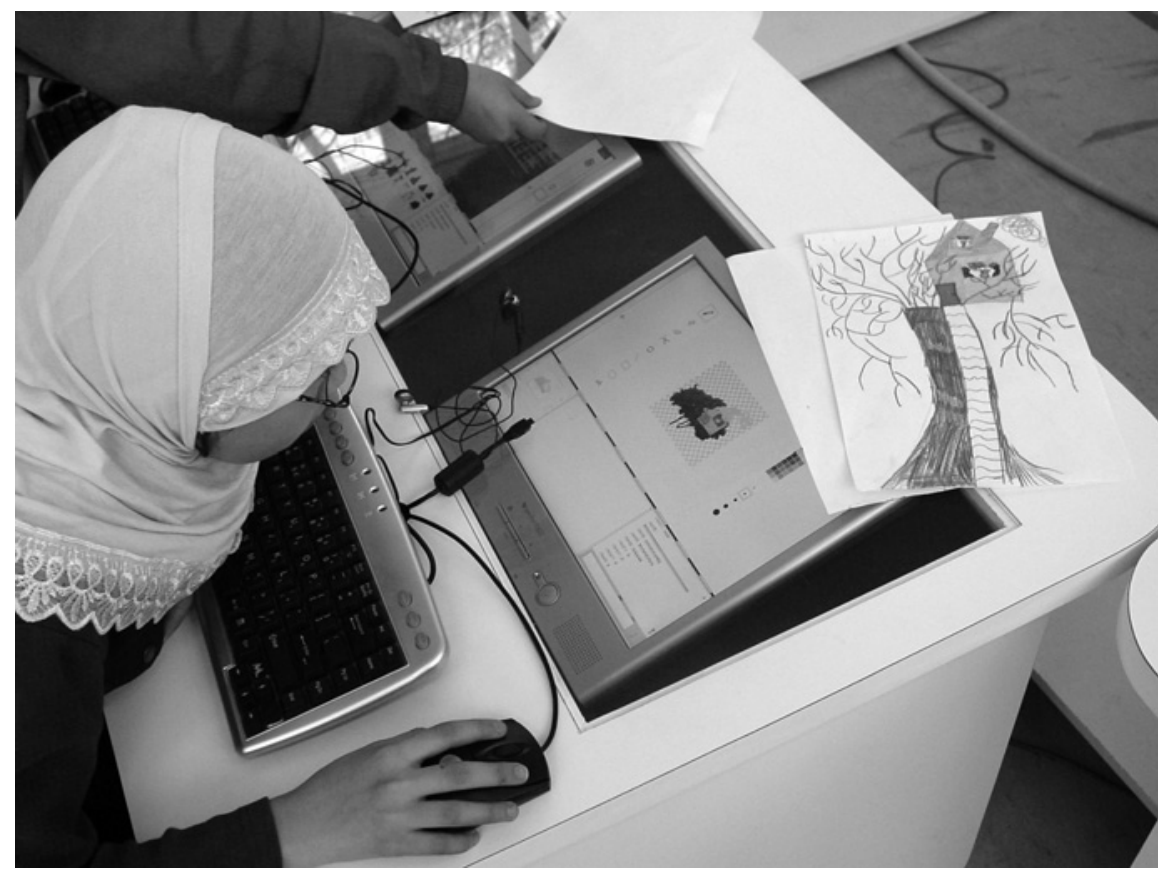

16 Face Your World

A girl at work with the Interactor during the Face Your World participation process (image courtesy of Van Heeswijk). On top of the workstation we see the drawing the girl made in an earlier stage of the process. The drawing depicts a large tree with a little house inside the tree and a rope ladder leading up to the little house. On the screen we see the girl working on a new object for the library. She is digitally redrawing her design for a tree house. Once this drawing is finished, she can save it to the library of the Interactor and use it when designing the park.

ticipating in Face Your World Slotervaart made a total of I2I6 sketches in this phase of the planning project and Kaspori considered this the most creative part of the process (interview with Kaspori, 2007). In the third phase of the game, children would discuss each other's sketches, vote for the best sketch and write down why they had voted for that particular sketch. In the final stage, children entered the multi-player mode and had to start designing the park together. This final designing phase was directed at cooperation between the children: they had to agree on how to design the park and work together in order to be able to realize their ideas (interview with Heeswijk, 2007). To realize their ideas, players thus needed to communicate and cooperate. The discussion option of the game was facilitated through a chat function. This chat function was one of the few aspects of the game that did not work as it had been intended and projected by the designers. Children working with the Interactor did not use the chat function for communi- 
cation about the game. They simply shouted things at each other and used the chat function for nonsense or verbal abuse.

Games used as participation tools have changed considerably over the last decades. The paper toys used by Sanoff between the I960s and I980s have been replaced by high-end computer games. There are, needless to say, both advantages and disadvantages to this change in participatory gaming from non-digital to digital. One advantage, identified by Kheir Al-Kodmany, professor in urban design and planning, is the possibility to represent contextual data: 'Computerized tools can illustrate abstract concepts, such as environmental impacts, in a way that would be impossible with traditional tools' and these tools 'provide so much more specific information that can be provided on the spot, thus enabling the public to explore alternatives quickly and with more competence' (2006, p. 63). The Interactor used in the Face Your World participation process also makes abstract concepts that are related to the ins and outs of designing a public park 'tangible' and visible. In a digital environment such as the Interactor, one can indeed explore alternatives quickly and without lasting consequences.

Another advantage of digital participation tools is the possibility to display information selectively: 'When working on paper, even a relatively small amount of information can quickly become overwhelming and appear cluttered' (ibid.). The library of the Interactor contains a standard set of 400 images from which players can pick and choose. To these standard images, the participating children added another 1207 images and objects. If you were to make a non-digital version of Face Your World, those r607 objects would indeed appear 'overwhelming' and 'cluttered' and browsing through them, picking an object, deleting it again and choosing an altogether different object would be more difficult.

Third, the ability to navigate the geographical scale is considered an advantage. 'With traditional tools, multiple maps are needed for each geographic scale: region, city, community, neighborhood, and individual lots. Computerized mapping allows for zooming in on a region, city, neighborhood, or even a specific house on a single map' (ibid.). In the Interactor, players navigate between a 'micro' level view during the sketch phase (where they work on a single picture of the neighborhood) and a more 'macro' level view of the whole park during the design phase.

Concerns Al-Kodmany raises have to do with the relation between realistic computer-generated images and reality:

One drawback of computerized tools is that the images can be so realistic and persuasive that they mislead people. It has been found that computer visualization can lead to false conclusions by the public. (...) there is the danger that audiences may see a generated image as constituting reality. (...) Just as these tools can be used to create compelling representations of future urban development, they can create compelling misrepresentations as well (ibid.). 
Serious urban games are rarely so realistic that they become misleading. It remains generally clear that what the player is dealing with is a ludic, artistic or architectural vision on a planning project. As Syb Groeneveld from Digitale Pioniers (digital pioneers), one of the sponsors of Face Your World, told me: 'SimCity is a realistic environment in terms of design but not in terms of interaction. Face Your World is realistic in terms of interaction but not of design' (interview with Groeneveld, 2007). The sort of overtly realistic computer generated images Al-Kodmany talks about are often used to make a visual representation of urban renewal plans so that these plans can be presented to the public in a visually convincing manner. Serious urban games have a different purpose, they are used to actively engage people in urban renewal rather than convince them about a certain plan.

Second, the considerable costs involved in using these computerized visualization and simulation techniques are considered a problem (Al-Kodmany, 2006, p. 63). The costs of the long and intensive participation process of Face Your World are indeed high: the software development amounted to a total of $€ 180,000$ and the management of the Lab to $€ 80,000$. Different stakeholders financed Face Your World. The high costs, the efforts involved in finding so many different financial investors, communicating with them and delivering a product that all can agree upon make these large-scale participation trajectories unfeasible for many cities.

Third, Al-Kodmany criticizes the participants' limited options for social interaction when computer-based tools are used: 'traditional non-computerized public participation methods are more participatory, experiential, and interactive' (ibid.). $\mathrm{He}$ is in favor of combining 'the social benefits of low-tech methods and the efficiency and power of high-tech methods' (p. 64). Face Your World makes this combination between the Interactor on the one hand and meetings, workshops and social events on the other hand. The Face Your World project consisted of more than a computer-based participation tool. Real-time social interaction and experimenting were amply facilitated as well. Combining both low- and high-tech, nondigital and digital participation tools has the advantage of including different users. Serious urban games appeal especially to younger people already familiar with gaming and not put off by the technology they need to work with in order to participate. Serious urban games exclude mainly older people without PC or gaming experience. However, when serious urban games are used in combination with non-digital forms of public participation, the group of possible participants diversifies. Children and teenagers have largely been excluded from participation in urban planning and are a group hard to reach by the municipality. Game-based participatory tools can enable them to become part of participation processes as well. Mainly children aged 8 to I4 visited the Lab and participated in Face Your World through the use of the Interactor. But adults were present in large numbers during those 49 activities that were organized and during the public presentations of the design. The progress made on the design of the park was presented half- 
way through the process during a public event that attracted 600 visitors and the presentation of the final design attracted Iooo visitors.

To be sure, the digital divide is not simply a generational divide separating parents/grandparents and children. Among children, boys are often more knowledgeable about and familiar with computer use in general and gaming in particular. When I asked two participants what aspect of their days spent at the Lab they liked best, the girl Khadya (I4 years old) told me she did not particularly like working on the computer while the boy Hicham (12 years old) liked working with the computers best (interview with Hicham, 2007; Khadya, 2007). Abdi did not like working with the computer because she has to work a lot with computers at home to do her homework. More importantly, she found the game difficult at first, especially placing objects from the library in the game. Once she mastered the workings of the game it became more fun to use the Interactor. According to her, using the Interactor did not determine the design of the park but it did make it easier to see what you were doing and what you were creating (interview with Khadya, 2007). Hicham did not experience the Interactor as difficult. He had fun creating his own world and collaborating with other players to get new ideas. According to him, the Interactor was an essential addition to the design process because it allowed the players to shape their ideas. Playing with the game also generated new ideas because abstract things would take a concrete shape: 'When someone would put, for example, a McDonald's in the game, then I would think: 'a terrace in front of the McDonald's restaurant would be nice so that people can sit outside while eating' (interview with Hicham, 2007). According to him, the computer game made things easy. You could simply click on an object and place it in the game world. With clay you had to first make the objects (ibid). Khadya's lack of computer game experience made it hard for her to master the working of the game. Hicham plays a lot of games at home (mostly racing games) and had an easier time learning how to play and design with the Interactor.

Al-Kodmany ends his article by stating: 'these tools often fall short in allowing the participants to design and alter the representation' (2006, p. 64). In other words, players are not granted access to the design of the design tool itself. This critique is very much in line with Cascio (2004) and Turkle's (1996) comments on the black-box nature of simulations such as SimCity. Communication professor Paul Starr argues likewise:

The critical problem raised by simulation is the black-box nature of the models. (...) to most participants in policy debates as well as the public at large, the models are opaque. Only a few can penetrate the black box and understand what is inside (1994, p. 28).

This is true in relation to the Interactor as well. The designed core of the game and the embedded scripts were not open for redesign, centrifugal appropriation, 
meddling or altering. Children designed the park with the tools provided. They could add objects and images to the library of the game but they could not redesign or alter the game itself.

\section{Participation Processes}

Measuring the effectiveness of participation efforts is a difficult task, as risk analysts Gene Rowe and Lynn Frewer state in Evaluating Public-Participation Exercises. They describe an agenda of sequential steps to evaluate effectiveness in a structured rather than a subjective manner. First of all, effectiveness needs to be defined in terms of process or outcome effectiveness (pp. 517-522). In relation to Face Your World, both process and outcome effectiveness were intended. The process had to involve neighborhood groups that were otherwise hard to engage and the ultimate design of the park had to be supported by the different age and ethnic groups in the neighborhood.

The explicit aim of Face Your World was to go beyond those participants, the lead users so to speak, who have the time and interest to attend meetings and hearings and dare to speak up for themselves. Face Your World did indeed succeed in involving neighborhood residents that would rarely be seen in the town hall during conventional meetings or hearings.

However, there were some problems as well. For example, to involve both Turkish and Moroccan women, individual meetings and workshops needed to be organized because they would not attend activities together with men. Some meetings or workshops would start with a two-hour women-only session after which men were welcome as well. This offended some men who felt discriminated against and refused to participate further in Face Your World (interview with Gerard, 2007). Both those working at the ward and the city council questioned this measure (interview with Hoeve, 2007). Gerard told me that many senior white neighborhood residents felt left out from the participation process in general because they thought it was targeted mainly at immigrant neighborhood residents (interview with Gerard, 2007). Consequently, the design of the park does not very much appeal to him. From his point of view, the preset goal to engage those otherwise excluded from participation processes was too successful and the intent to design a park that would be supported by the whole neighborhood not successful enough (ibid). Van Heeswijk explains that such a radical participation project as Face Your World, which gives a voice to those otherwise unheard, is a learning process for all those involved (interview with Heeswijk, 2007). She understands that it must have been difficult for people who are used to be the norm to become, in such a process, one of many voices (ibid).

There are two sides to the outcome effectiveness of Face Your World: the design of the park and the actual construction of the park. The park of 13.500 square meters is designed to appeal to different projected users. There is a sports field 
that can be used for football, basketball, theatre plays and markets, a play area for little children with a slide and swings, a secluded area for teenage girls and benches for elderly people or parents accompanying their children. The ultimate design tries to cater to as many wishes of the park's future users as possible. One of the critiques of the design of the park is that it is too conventional (interview with Broekhuizen, 2007; Hoogeveen, 2007; Lentz, 2007). It is a design based on compromises, and as such the design is not innovative. Compromise-based and co-designed plans will easily turn into detail-based designs because that is a practical way to tackle and integrate various and diverging wishes into one and the same design. Moreover, the working of the Interactor as a participation and design tool was detail-based. One cannot have 50 or even more different children working on the same canvas, deleting each other's work and overwriting it with their own ideas. In order to steer the participation between the children and at the same time guide the design of the park, the children focused on details and certain parts of the park rather than the overall design.

The construction of the park should have started in 2006 and been finished in 2007. However, construction has been postponed till 2010. Wien explains that a school from the region was looking for housing. The school building that had to be demolished in order to build the park was suited for this school. 'It is impossible to deny a request from a school to be temporally housed in a building that is still useable' (interview with Wien, 2007). For the neighborhood children and citizens who contributed to the design of the park, the gap between participation and realization is rather long. What Wien and his team at the ward feared, that this intensive participation project would widen the gap between ward and citizens instead of closing it, became reality in part, although in a different way than could have been foreseen. Many neighborhood citizens feel let down by the ward and the Face Your World team that after all this energy they put into the park, there is still no sign of it.

The postponed realization of the park illustrates Anique Hommels' theory concerning the obduracy of cities. Slotervaart fits Hommels' description of 'disputed' and 'contested' areas that are 'subjected to 'unbuilding activities" (2005, p. II). Often, in urban renewal processes, the "stakes are so high that years of planning, debate, and controversy may result in no changes at all' (p. 7).

Returning to Rowe \& Frewer, they further argue that effectiveness needs to be operationalized (for example through participant interviews and questionnaires) so that the extent to which the effectiveness is achieved can be measured (2004, pp. 542-548). At the presentation of the design of the park, people could fill in a questionnaire about it. Also, the participating children were asked to write about their experiences with Face Your World at the end of the process. The results of this evaluation then need to be interpreted state Rowe and Frewer (pp. 548-552). Although some data has been accumulated on the process and outcome effective- 


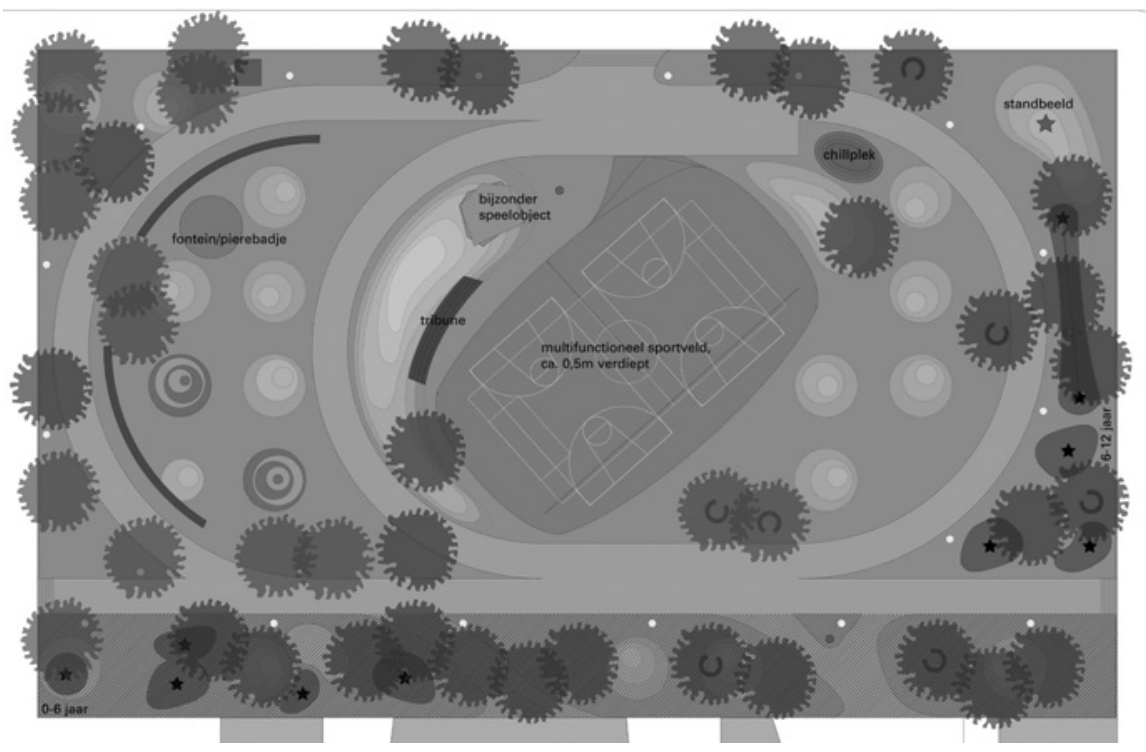

17 A new Neighborhood Park for Slotervaart

This is the final design for the park that resulted from the Face Your World participation process (image courtesy of Van Heeswijk). The park is divided into different areas for children of different ages. In the area for children aged between 0-6 years old, there will be a sand garden and some playground tools. The area for the 6-12-year-old children will also consist of playground tools. The middle area of the park contains the multi-functional sports field and a separate area for teenage girls.

ness of Face Your World, this has not led to a structured assessment of the successes and failures of the project.

Besides questions on the effectiveness of citizen participation in urban planning, there is also the issue of democracy and empowerment. Certain participatory tools are therapeutic rather than empowering, others might, albeit unintentionally, create a divide between those having access to the participation tool and those not, or the tool itself might be ingrained with specific biases that will exclude certain users from taking part in the participatory project. And there are of course always people who cannot or will not participate: the non-users or nonparticipants. Hans Harbers argues, for example, in Politics of Technology that not everyone wants to participate in direct democracy exercises (I996, p. 313). In a representational democracy people have voted for professional representatives and should thus be exempted from having to spend time and energy on familiarizing themselves with the issues at stake (ibid.). Harbers argues that consulting the public is not necessarily a sign of democracy, it might just as well be a sign of political incompetence (p. 3I4). Whatever the case, non-users - either by choice 
or by other forms of exclusion - should be taken seriously in public participation efforts. As Sally Wyatt ascertains, not only 'the powerful actors' should be followed but the non-actors as well (2003, p. 78). She distinguishes between four different forms of non-users, two of which (excluded and expelled) indicate the 'have nots' while the other two (resisters and rejecters) indicate the 'want nots'. Wyatt has pointed out how non-users of technological artifacts (the car or the Internet, for example) are generally framed in policy discussions as deprived of something or subject to inequality and therefore in need of remedies that will promote non-users to users. This has also been the case in relation to Face Your World. This participation process was targeted at young people and immigrants who were not taking part in participation projects related to the urban renewal of Slotervaart. Instead of thinking of non-users as a problem waiting to be solved, Wyatt proposes considering them as 'relevant social groups who might influence the shape of the world' (pp. 68, 76 \& 78).

\section{Purposeful Play}

When many-to-many activities are taken to the streets and used outside of the realm of entertainment, the geography of play changes from ludic to serious. Serious games, persuasive games or serious urban games might stretch an essentialist's definition of 'play' or 'game'. There are, for example, no winners or losers amongst the users of the Interactor, no handbook explaining complex rules, no increasing levels of difficulty and no 'boss fights'. ${ }^{21}$ However, some distinctive game-like features characterize the Interactor. Within a rule-based, programmed and designed environment, players are represented by an onscreen character and encouraged to explore, build and construct. They can 'drag and drop', 'pick and choose' from the extensive library and add their user-generated content to this library. The basic rule of the Interactor is that players have to participate, communicate, cooperate and collaborate if they want to make progress. The four phases of the game (exploring, sketching, discussing and designing) do represent levels to a certain extent, although these levels do not demand an ever-increasing finger-twitching and button-pressing capacity of the player but accumulating insight into urban planning and design. Although not all the mechanisms or ingredients of an essentialist definition of entertainment games are present in the Interactor, the software is built upon a game-like engine and looks and operates like many entertainment games. Furthermore, it knows implicit (e.g. courtesy towards other players) and explicit (e.g. design a park that is supported by the whole neighborhood, cooperate with other participants) rules, it involves different players, it is progressive and invites the children, to a certain extent, to role-play.

The core of the Interactor is shaped by the design of the game in combination with the discourse on the game. The Interactor facilitates experimenting with design options for a public park. This experimentation is guided by elements such 
as the size of the game canvas, the objects in the library, the embedded tools for manipulation and design, the municipal restrictions and requirements for the park. Besides these design characteristics of the Interactor, the discourse surrounding Face Your World influenced how the children would use the Interactor. The meetings, workshops, excursions, specialists and experts who guided the children in the design process shaped this discourse.

The important question is what happens with or to the periphery of a geography of serious play. When a game becomes serious and its aim lies outside the realm of entertainment, the periphery becomes highly important and loses part of its autonomy and inconsequentiality. The Face Your World team was relying heavily on divergent activities, on unforeseen design solutions and creative input from the participating children. Kaspori considers Face Your World Slotervaart a success because he could never have come up with this particular park design himself (interview with Kaspori, 2007). Designing a park was the ultimate goal of Face Your World, and deviating from that goal was therefore not an option. The Sims fans might come up with outrageous and unforeseen additions to the game, and as long as they are commercially feasible, sustain the brand and work with and not against the user communities, they are applauded and welcomed. Participants of Face Your World see these freedoms restricted by the goal of designing a park that will have to be supported by the various age and ethnic groups in the community, the preset conditions of the municipality and the design tools they are offered to work with. Much of the basic layout, such as entryways and pathways of the park were already determined in the municipal list of requirements for the park. Inside these predetermined parameters the area for both facilitated and peripheral play activities and traffic between core and periphery was limited.

With serious urban games, participation between the players, the many-tomany culture, is not an anticipated and hoped for or carefully orchestrated and sustained effect of a successful game, as in entertainment computer games for example, but the very raison d'être of these games. As such, it moves from the periphery to the core. Participation and 'by us for us' activities change from being divergent player behavior in the periphery of a 'healthy' geography of play to being an embedded and facilitated core activity. The Interactor is about creating and designing a park together - for 'us' and by 'us'. While both toy and computer game companies increasingly tap into the many-to-many community and commodify divergent player activities, in serious geographies of play, the many-tomany culture and its activities are not so much commodified as they are instrumentalized: the many-to-many paradigm is facilitated in the core, and its results are put to use.

Because of this purposefulness of serious urban games, their instrumental character and nature, the periphery shrinks, and the core is relatively large and takes up most of the geography. The shrinking periphery in the geography of serious play loses both its ludic inconsequentiality and autonomy and its relative 
power over the core. The outcome of public participation projects is of such importance to so many different stakeholders that there is little room for divergent play activities. Peripheral activities will only be incorporated within the core when useful to the projected outcome of serious play. As such, the core of the geography of serious play is a strong and coercive one and takes up most of the geography. The geography of serious play is compact and confined because the outcome of play is anything but trivial or ludic; it is highly significant and serious in terms of individual careers, financial commitments and stakeholder relationships. Within the geography of serious play, both core and peripheral play practices are closely monitored and studied.

Serious urban games are created and used for public participation and public co-design in urban planning. Therefore, the stakes are high, and the outcome of the interplay between core and periphery loses its ludic inconsequentiality. The nature and goal of traffic between core and periphery change from commercial success, strong brand image and vital user communities in entertainment games to trust- and community building, education and design in serious urban games. Serious urban games push the masking of work as play (De Certeau's upended perruque) further because play becomes utilitarian, purposeful and outcomeoriented. Serious urban games take the many-to-many model to the streets and maximize the tapping into the 'can culture' of users.

This brings about changes for both players (who are now playing 'for real' and involved in serious play) and professional designers (who need to examine play practices in order to generate useful content). Both these stakeholder positions change within a serious geography, and both parties will need to readjust to these changes. Broekhuizen, for example, had a hard time adjusting to the fact that his role and function changed from the one designing the park to the one monitoring children designing the park (interview with Broekhuizen, 2007; Hoeve, 2007).

In the shrinking periphery of serious play, the space for playing against the design or designers decreases. The game facilitates the playing with the design. Anarchistic play practices are not facilitated (although this might sound like an oxymoron, computer game companies will often facilitate anarchistic play as was the case with the hacking function that was programmed in the Enter the Matrix (Shiny Entertainment, 2003) game), nor does the periphery provide enough space for players to manifest such practices of play. The option to add objects to the library of the Interactor is the only way in which users can appropriate this designed artifact.

\section{Serious Geographies of Play}

Face Your World mediated between the city and the child, as did the construction toy towns and SimCity. Through participating in Face Your World by means of the Interactor, the city or outside world was presented to the children in a containable 
version emptied of the real life problems pestering the neighborhood. For once, their neighborhood was tamed and domesticated and could be manipulated. More specifically, serious urban games mediate between urban change or unbuilding practices and the public. Serious urban games are aimed at generating discussion, (re-)creating relationships, generating a common purpose amongst neighborhood inhabitants and re-establishing some of the social glue that has been lost in ever-expanding urban areas.

With serious urban games, crucial aspects of a 'healthy' geography of play are compromised, such as a vibrant and expansive periphery for divergent play, easy transfer between core and periphery of play, a certain amount of influence of the periphery over the core, the triviality or purposelessness of the ludic. With the increasing commodification of the many-to-many model within the toy and game industry, we have seen how the periphery gains influence over the core and loses autonomy. The fact that serious urban games are serious, meaning that their goal and function are not to amuse but to achieve something within the 'real world', further erodes the autonomy of the periphery without increasing its influence over the core. The core takes up most of the space within the geography of serious play because the outcome of playing these games will be put to use. The many-to-many culture is not commodified so much as instrumentalized in this serious context.

Public participation in urban planning through game-based new media applications intends to maximize the many-to-many approach. LEGO toys and Sim games illustrated how players increasingly become (co-)producers and (co-) designers of the next consumer product, thereby partaking in the cycle of production>marketing >consumption on various levels and at different stages. With serious urban games, players become (co-)producers and (co-)designers of their neighborhood and built environment. Through serious urban games, players can enter the cycle of policy-making>design >implementation. Serious urban games are intended to open not only the black-box, obdurate city but also the equally black-box processes of policy-making. However, as we have seen, serious urban games are themselves black-box systems in that they do not facilitate the participating public to design their own tools for urban (re-)design.

Assessing Face Your World along the lines of the media and tools used for public participation and the participation process as a whole brought to the forefront what made this project successful. Both the intended process (involving remote stakeholders) and outcome (community-supported park design) effectiveness were realized to the extent they were under the control of the Face Your World team. The participation process was designed to involve different ethnic communities and different age groups, to go beyond tapping into lead user knowledge. Indeed, many people participated who would never have been found in the city hall during a conventional meeting or hearing on urban renewal plans for Slotervaart. The outcome is the design of a neighborhood park supported by the ethni- 
cally diverse residents of Slotervaart that contains their wishes and requests (e.g. a fence around the park, benches, a picnic area). The different forms of participation and media (non-digital and digital) that were used explain, in part, this success.

In considering a participation project such as Face Your World in the context of democratizing participation and policy-making, it is important to keep the intended effectiveness in mind. The process and outcome effectiveness of Face Your World were decided before the neighborhood residents became involved. Participation thus fell within these parameters or boundaries. The suggestion of many teenage girls to build a shopping mall on the piece of land that would become available for the park, was therefore not a feasible option nor a suggestion the Face Your World team could act upon (interview with Hartoog, 2007; Heeswijk, 2007). Nevertheless, within the given parameters of participation and the intended process and outcome effectiveness, Face Your World can be considered to effectively democratize a particular aspect of the design phase of an urban renewal plan. Remote stakeholders in general and children in particular were given the chance to become part of urban redevelopment plans. Kaspori made the final drawing of the park, but he did not alter or translate the design made by the children with the Interactor (interview with Kaspori, 2007).

In the same sense that the many-to-many approach within consumerist practices is not the ultimate empowerment of the consumer because power is in the hands of the companies who choose to blur the lines between player, consumer and producer and to tap into the user-driven 'can culture', the many-to-many approach within policy-making is not the ultimate form of democracy. The largest chunk of power is in the hands of those designing policies and tools for exercising democracy and deciding when, under what terms and conditions and in which format to involve the public. However, in consumerist practices and participation processes, a window of opportunity opens when stakeholder positions implode and users are invited to partake in the design of consumer goods or urban renewal plans. 


\section{Conclusion}

\section{Changing Geographies of Play}

This book deals with the ways in which the many-to-many model produces changes within the world of toys and playing. The nature, characteristics, mechanisms and problems of the many-to-many model are acutely visible and manifested within the world of toys and playing but are by no means restricted to this domain.

The historiographical perspective on the complex interplay between societal processes, technological innovations, toys and players shows the many-to-many model at work and on the move, its rise, manifestations and ways of involving users. In the context of commodification, domestication and urbanization, new technological artifacts are introduced, consumed, domesticated, modified, appropriated and resisted.

Toys and playing are taken to be central forces in bridging societal processes on the one hand and the individual on the other hand. Toys are considered to function as mediators, mirrors and promoters. In their role and function as intermediaries, toys are often at the heart of anxieties, fears, longings and battles. Toys are sites where crucial battles concerning a changing society and the changing place of children within that society are being fought. Toys are not only intermediaries but also 'generation-shapers'. They can create connections as well as disconnections between different generations.

The first part of this book laid the historical groundwork for the notion of toys as mediators, mirrors and promoters. From the mid-rgth century onwards, the way toys are produced and consumed, the scale and variety of this production and consumption, the way in which society looks upon children and the function of toys in the lives of these children transform drastically. The processes of commodification, domestication and urbanization are exemplary processes illustrating how societal shifts and the changing world of toys co-evolve, mirror each other and/or resist one another. We have seen how toys mirror and stimulate the up and coming consumerist society, how toys answer to the need for domestication of the child and play while reinforcing it at the same time, how they distance children from the urbanized landscape while mimicking it in their designs. The interplay between societal processes, toys and children in the second half of the Igth and first decades of the 2oth century is understood within the framework of the construction of the Innocent Child and the increasingly diverging (play) paths of boys and girls. 
From the mid-Igth to the early 2oth century, Western consumer culture facilitated the design, development, marketing and selling of diverse toys on a larger scale than witnessed ever before. Toys mirrored the changing industrial world and brought these changes into the private home and into the lives of children. The family home was the new prime location for the wealthier children to play. The outdoors was no longer considered to be a safe playground. Domestication of children and play necessitated indoor toys, toys that would keep children occupied safely indoors. However, many of the children living in the Igth-century industrialized cities did not enjoy such upper- and middle-class privileges. Children from the working and lower classes would often work in the factories producing the new commodities. Living in small quarters and sharing the available space with family and lodgers, they would turn to the streets. Saving these children became a late I9th-, early 2oth-century effort that crystallized in, among many things, the building of playgrounds in urban and industrial areas.

The postwar period saw the maturation of commercialism, the suburban obsession with the private sphere and the increasing fear of the world outside that private (suburban) home. The Igth-century department stores were classconscious, but with the Americanization of consumption and the economic growth after the Second World War, Western countries witnessed an unknown prosperity down to the working classes. Part and parcel of the postwar maturing consumerism was a strong emphasis on the domestic realm. The mid-rgth- and early 2oth-century guidebooks on housekeeping called for the separation of child and adult in both the architectural layout of the private home and the upbringing of children. The postwar family home put the child and play (for children as well as for adults) front center in the recreation area and the open plan living room.

The relatively cheap, easy to clean, durable, colorful and standardized plastic LEGO bricks epitomized the postwar vogue of indoor plastic products. The (sub-)urban and domestic designs of the early LEGO sets reflected the sanctity of the private suburban home of the I950s nuclear family. LEGO toys answered to and reinforced the increasing domestication of child and play and the angst-ridden relationship between the child and the 'mean world' outside the private suburban home. More recent developments within the LEGO Company bring us into the 2Ist century and signal a change in the relationship between players, consumers and producers in which players increasingly become co-designers and coproducers of their own commodities. The SimCity and The Sims series of games take the serial- and expansion-pack economy to an unprecedented level, prompting players to keep on buying additions to the games and leaving no one an excuse for not buying the game with its all-round compatibility, from PC to Playstation, from Game Boy to cell phone. Moreover, capitalist principles that amount to what one could call a consumerist ideology drive the The Sims series. The Sims game further mediates, mirrors and reinforces domestication by taking this 2Istcentury domesticated family as its subject, by situating play in the domesticated 
indoors. The SimCity games on the other hand mediate, mirror and simulate an increasingly complex urban environment and bring it in a containable format inside the family home. The participation project Face Your World took children out of their private rooms and private homes to engage them in the design of a neighborhood park, the domestication of their own neighborhood. The game, the Interactor, presented the city and outside world to the children in a containable version emptied of all the real-life problems pestering the neighborhood. Face Your World mediates between city and citizen in general and between urban change and the public specifically.

The focus of this book has been on construction toys, from non-digital LEGO toys to digital construction and simulation games likes SimCity, The Sims and the Interactor. Construction toys, popularized during the igth century, deal with urban and domestic design, reflect technological innovations - from wood and steel to plastic and digital technologies - and are indoor toys pur sang. Construction toys have proven to be an outstanding example to illustrate how toys mediate between the societal processes of commodification, domestication and urbanization and the player because these toys exemplify and embody these societal processes. The history of construction toys is closely linked to the coming into being of consumerism. Construction toys were mass produced from the materials of the Industrial Revolution (steel and iron) and thus relatively cheap, which allowed for mass consumption. The toys had to be assembled with care and patience on a flat surface, meaning that they facilitated long and quiet hours of indoor play. Although construction toys catered to the reluctance to let children play outside unsupervised, they would center on urban design and the successes of the industrial engineer.

Since the igth-century heyday of the construction toy, the materials used for producing this type of toys has changed: from wood, stone and steel in the rigth century, to various plastics in the postwar period, to digital technologies from the I980s onwards. The porté of construction play has changed as well. While early construction toys can be best characterized as building toys, the second-generation construction sets are designed to be about design. The first-generation construction toys are generally wooden blocks without an interlocking mechanism that facilitated the building of abstract and architectural constructions. The second-generation construction toys are characterized by interlocking mechanisms, more diverse shapes and materials, and allow for the design and construction of more complex objects. Digital (construction) toys add an extra layer to this designed-to-be-about-design characteristic. Computer games are designed objects, coded and programmed computer applications. The rules and interactions with the game are inscribed within that programmed code. Digital construction toys are designed-to-be-about-design and procedural, meaning that the constructions evolve visually over space and time. The actualization of designed objects through 
their use is turned into a procedural activity, a string of actualizations of design potentials.

The more or less solitary and individual geographies of Igth-century play practices have been largely replaced by densely populated and heavily networked geographies through the incorporation of the Internet within the geography of play. The igth-century geographies of play were characterized by contact with peers, siblings and adults through and about play. From the 2oth century onwards, toys are increasingly linked to clubs and magazines, radio programs and contests, special days and festivities. Today, these peripheral, social and participatory activities have increased immensely due to new media technologies. Innovations such as the Internet have knitted players together within the geography of digital play in an unprecedented interconnectedness. In this, players increasingly become (co-)designers and (co-)producers within 2Ist-century geographies of play. The stakeholder positions of player, consumer and producer are increasingly entangled up to a point where the differences implode and many players embody all three positions.

These transformations also bring about the redistribution of power on different levels. While it would be correct to situate the company in the core and the user in the periphery of a one-to-many geography, this situation becomes more complex in largely digital geographies wherein the core splinters and disperses, companies increasingly enter the periphery, and users shape and control the core to a large extent. In the one-to-many geography, the periphery is of less importance to the companies and thus more autonomous than in the many-to-many geography. The result is less movement between core and periphery and thus a more static geography. Access to the core is company-controlled, and fast centripetal appropriations are not manifested. In the many-to-many geography, the periphery gains in importance for the companies, has therefore more influence over the core but loses some of its autonomy. There is more movement between the core and the periphery, making the many-to-many geography almost an organic system.

There are different reasons for the transformation from one-to-many to manyto-many geographies and the increased importance, relevance and power of the periphery. For one, the Internet has made peripheral play activities highly visible and thus important. Within an increasingly competitive toy market, the many-tomany model is a means to create loyalty amongst one's customers, to bring them into the universe of a brand. And the increased cost of generating new content for computer games has made it all the more attractive to rely on peripheral play activities that might result in the creation of content for computer games.

From the different case studies - LEGO toys, Wright's Sim games and serious urban games - we have seen how the core/periphery relations evolve from relative independence in pre-I9gos LEGO toys to symbiotic dependence with The Sims, from an autonomous periphery of play in the one-to-many geography to an instrumental, appropriated and far less autonomous periphery in the many-to- 
many geography, from an expansive periphery and a splintered core in contemporary entertainment geographies to a shrinking periphery and an outsized core in serious geographies.

One of the key characteristics of the geography of digital play is the increasing and far-reaching appropriation and commodification of the periphery through both slow and fast forces. New media technologies generate an expansive periphery of play that is appropriated by the core to an unprecedented extent. The splintered and dispersed cores of the geography of digital play spread across and absorb the periphery, traffic between the two areas is frequent and fluent, and the digital geography acquires organic and symbiotic qualities. In the largely nondigital geography of LEGO play, we can often still trace and mark the point where, when and why the LEGO Company taps into the user-driven 'can culture' of dedicated fans. In the digitalized geography of Sims play, EA facilitates and counts on a constant and unobstructed flow of user-generated content into the core. The Sims was completely dependent on the periphery of play, even before its release. Because the periphery is not only appropriated but also continuously 'irrigated' by the core with new opportunities for user appropriation, the geography of The Sims play remains alive and 'healthy'.

With the advent of digital technologies in general and the Internet in particular, the periphery of play has expanded considerably and gained in importance as a source for new input and ideas. With the core increasingly tapping into and appropriating the periphery, the boundaries between the two areas are blurred. Because of this boundary blurring, players might feel in command, empowered and thus inclined to be loyal to a brand. And players are to a certain extent in command: their products and practices of play all too often become part of the facilitated core. In the contemporary geography of play, the grassroots character of the many-to-many approach has been successfully commodified.

The implosion of the different stakeholder positions of player, consumer and producer signals the loss of a certain triviality and inconsequentiality of play. The periphery becomes more important but less autonomous. When games are instrumentalized as planning tools, participation tools, simulation models or policy devices, the loss of triviality and inconsequentiality amplifies and intensifies. Both the core and the periphery in the geography of serious play gain in importance because the outcome of play will be put to use. Because of this instrumentalization and the projected outcome of play, the periphery of the geography of serious play shrinks while the core takes up the greater part of the geography. Players have to perform within strict parameters and boundaries. As such, serious games lack certain aspects of digital geographies of play such as a vibrant and expansive periphery for divergent play, easy transfer between core and periphery of play, a certain amount of influence of players within the periphery on the core, the triviality or purposelessness of the ludic. 
The increasing use and importance of both the many-to-many model and serious games signal a shift in the context and meaning of play. Not only the practices of play and the sites for play are changing, the very context of and reasons for play are, too. Both the many-to-many model and serious (urban) games undo playing of its triviality and inconsequentiality and turn it into an instrumental, productive, outcome-oriented activity, either for commercial or policy-related ends.

\section{Making Do}

The many-to-many model, originally stemming from Internet use and software applications, indicates a shift from the domination of expert knowledge and content to an increase in end-user knowledge and content. Technological innovations and Internet applications such as file sharing, blogging, tagging and Wikiing have created platforms for end-users to meet, exchange, comment, learn and help each other. The dynamics of the many-to-many model, and then especially the bond it can create between traditionally remote stakeholders, have been experimented with by diverse and wide-ranging industries - from politics to journalism, from art practices to marketing, from education to policy-making. The popularity of the many-to-many phenomenon has reached an unprecedented height as we witness today an almost ubiquitous search for user-involvement. The attractions of the many-to-many model are the wish to establish a faithful, positive, constructive relationship between, for example, brand and consumer, politician and voter, city council and citizen.

Needless to say, the situation is less utopian and egalitarian than the diverse users of this model will often proclaim. To become part of this many-to-many culture, people need a computer, Internet access and technological skills, they need time and interest and the willingness to enter this paradigm. Moreover, many of these platforms and social networks have become walled gardens that exclude as much as they include. Besides problems of access, there are also technological aspects of new media that pose serious questions about the democratic or empowering potential of these participatory cultures, such as the black-box nature of many computer games and the fact that users are expected to participate according to scripted roles. Also, the question of non-users (either by choice or circumstances beyond their control) becomes more pressing when a model that proclaims to be many-to-many gains in popularity and importance. What if you do not care about MySpace and being LinkedIn? What if you do not want to post your every thought to a personal blog nor feel the need to leave your ramblings as tags over the Internet? What if you have nothing to share or nothing that you want to share? What if you do not see the purpose of chatting with political wannabes or voting for this statement or against that one? What if you do not want to film your friends acting weird and post it on YouTube or find your old classmates 
again and chat with them? Tracing and following not only the powerful actors but also the non-users (who can be equally powerful) within a many-to-many culture deserve further research.

Adding to the issues of non-users are the increasing commodification and instrumentalization of the many-to-many model. Although it has always been instrumental to certain users, the many-to-many model is now increasingly put to use for purposes lying outside of the 'original' function of this model, namely personal expression, user-to-user assistance, free end-user advice and the like. The 'by us for us' activities are tapped into, commodified and used. The 'us' in this 'by us for us' model now contains various industries and non-profit organizations as well. Companies and industries can profit from the many-to-many culture in terms of financial gains, brand strength and marketing. In some cases, this has led to 'controversies' or has prompted angry reactions from users who feel used. For example, the prosumers of YouTube.com, who have turned it into a phenomenal success through their avid use of the video-sharing website, were affronted when Chad and Steve sold their YouTube.com website to Google for $\$ 1.65$ billion in 2006. Some 6o video responses to the sale, which Chad and Steve happily announced on YouTube, appeared on YouTube itself, ridiculing Chad and Steve and demanding a share of the money (YouTube, 2006).

The blurring and mingling of different stakeholder positions within the manyto-many paradigm might be perceived as the ultimate empowerment of consumers and citizens now that they are consulted, tapped into or asked to (co-)design new commodities or policies. However, the power holders are unmistakably those deciding to consent to this boundary blurring for the sake of a healthy brand, prosperous company or positive community relationships. The many-to-many approach is not, as is often assumed, the ultimate empowerment of the consumer or citizen. As Jenkins puts it: "The interactive audience is more than a marketing concept and less than "semiotic democracy" (2002, p. 158). He finds consumer power in the current era of expanded corporate reach (as demonstrated, the corporate reach has extended well into the periphery of play) within the culture of blogging and poaching rather than jamming (p. r68).

In relation to play, however, blogging does not create an 'antidiscipline' within the geography of play because it does not directly pertain to playing but might reflect on it (Certeau, I988, p. xv). Poaching is a strategy of 'making do' within geographies of play, of 'trailblazing in the jungle of functionalist rationality' (p. 29 \& 34). Unfortunately, as we have seen, within a commodified geography wherein players become producers, players are more 'company hunters' than poachers, and their activities are very much in line with and affirmative of this corporate reach. The project Velvet Strike. Counter-military graffiti for Counter Strike by Anne-Marie Schleiner is an example of user-generated content created in the periphery of play, used in the core of the game and very much designed against the 
discourse of the existing Counter Strike game. Schleiner explains her project and motivation as follows:

Velvet-Strike is a collection of spray paints to use as graffiti on the walls, ceiling, and floor of the popular network shooter terrorism game 'Counter-Strike'. Velvet-Strike was conceptualized during the beginning of Bush's 'War on Terrorism.' We invite others to submit their own 'spray-paints' relating to this theme (Schleiner, 2002).

Graffiti that players can spray paint in Counter Strike varies from peace messages to embracing soldiers, from the Counter Strike soldiers arranged in a heart shape to a cat licking her dead kitten. The reactions to the graffiti have been rather hostile. Some players accused the creators and users of the graffiti of disturbing the game experience. These acts of graffiti, user-generated content created in the periphery and used in the core, are a good example of one and the same product being wanted by one group of users and being unwanted by another group. The graffiti successfully establishes an antiprogram or an antidiscourse within the game. However, such examples are exceptions, and generally speaking, the blurring of boundaries between players, consumers and producers makes the activities of poaching and trailblazing very difficult to sustain.

Areas for making do should then mainly be sought outside of existing geographies of play and, for example, within the area of low-budget, 'home-made' computer games. Players, and then mainly adult players, are increasingly using game-design itself as a tool and vehicle for making do. The website watercoolergames.com, for example, provides a platform for such user-generated games targeted at creating political or social changes (Bogost \& Frasca, 2007). These games seek to raise awareness concerning issues the users-as-game designers find important. For example in relation to the bad working conditions in FedEx Kinko's stores (Disaffected! by Bogost, 2006), the fraudulent cycles of food production in McDonald's (McDonald's Videogame by Molleindustria, 2006) or the relationship between obesity and the politics of nutrition (Fatworld by Bogost, 2007a).

Users-as-game designers do not simply appropriate content for or of existing games, they use the tools for game design itself to appropriate content and to establish an antidiscipline or antiprogram to counter corporate reach. Although such persuasive games might not provide the most heterogeneous, active or expansive geographies of play (these games have a clear purpose and goal after all), they do provide players-as-game designers with expressive tools for their visions and ideas. De Certeau stresses that tactics and practices of making do are to be sought within the manipulation of products by 'users who are not its makers' (p. xiii). However, in an era of expanded corporate reach users do have to become the makers of alternative products and games to make do. Knowing how to create your own game (or your own website or mashup for that matter) grants you cer- 
tain knowledge and insight into the workings of these technological systems, these black boxes or walled gardens. ${ }^{22}$ This knowledge and insight is essential if you want to create something yourself or appropriate an existing tool so that it might better fit your personal needs. More importantly, this knowledge also enables you to 'read', assess and analyze existing technological tools and mechanisms more thoroughly and critically. 



\section{Notes}

I. I use the terms 'toy' and 'computer game' in referring to designed, commercial artifacts with which one engages in play. Computer games have brought about a terminological shift: from toys to computer games (often referred to as simply 'games') and from playing to gaming. Toys are generally considered to be non rule-based play objects that induce open-ended play, while computer games are commonly understood as rulebased play objects that facilitate rule-based forms of play.

2. See: The Savage Mind (Levi-Strauss, I966).

3. For a more detailed comparison of fears and expectations involved in the introduction of new media, see Computerspellen en de Geschiedenis van Angst (Lauwaert, Wachelder, \& Walle, 2004). For a more detailed analysis of the historical roots of current debates on the playing of computer see Get Up \& Play (Lauwaert, 2006).

4. A shorter version of these chapters on LEGO toys has been published in History and Technology (Lauwaert, 2008).

5. The LEGO Group owns the copyrights to the images of LEGO products used in this book.

6. From 1965 onwards, LEGO had been producing toys that were gender- and age-specific. Before 1965 , LEGO products were not targeted at specific age or gender groups. The first LEGO sub-brand was LEGO Duplo for younger children followed by LEGO Technic for older boys.

7. Bug, one of the characters in Canadian writer and artist Douglas Coupland's novel Microserfs, voices his annoyance at this change: "You know what really depresses the hell out of me? The way that kids nowadays don't have to use their imagination when they play with Lego. Say they buy a Lego car kit-in the old days you'd open the box and out tumbled sixty pieces you had to assemble to make the car. Nowadays, you open the box and a whole car, pre-fucking-built, pops out-the car itself is all one piece. Big woo. Some imagination-challenger that is. It's total cheating" (I996, p. 76).

8. Mitchel Resnick became the LEGO Papert Professor of Learning Research in I999. Resnick's MIT research group Lifelong Kindergarten has launched the PICO Cricket Kit, financially backed by the LEGO Company, which is not so much about robot building but about creating computerized designs going from signing birthday cakes to meowing cats (PICO, 2006).

9. Lurkers are people who read discussions on fansites, chatsites and the likes without actively participating in these discussions. Most forms of lurking are considered bad netiquette (contraction of 'network' and 'etiquette'), and lurkers or non-participants are therefore not popular.

I0. A previous and slightly different version of the analysis of SimCity was published in Games and Culture (Lauwaert, 2007).

II. See also: Frustrating Desire on continuous loops between player and game (Lauwaert, Wachelder, \& Walle, 2007).

12. A few years ago I happened to witness a very different SimCity being played by my youngest brother and two of my nephews. Their ages at that time varied between 6 and 9 years old. The three boys were playing in my brother's room and when I went to say hello I asked them what they were playing. They told me they were playing simcity. But 
there was no computer running the game. The three of them were in different corners of the room surrounded by different types of toys: Warhammer, LEGO, Kapla, toy cars. When I asked them what simcity was they told me it was a game about cities and defending them. I then asked whether they knew the computer game that goes by that same name and, rolling their eyes, responded 'of course'. They explained that the copy of SimCity 3000 my brother owns did not work on his hand-me-down computer and that therefore they decided to play the game without a computer. Their simcity involved a complex and ad hoc trading system whereby little scraps of paper were being tucked under the mattress. By doing this they could acquire things (cars, bricks, soldiers, ...) that would help them defend their city.

I3. Stephen Kline suggested using the phrase 'tyranny of the algorithm' in relation to my work on Wright's games after he read this chapter during an expert meeting that took place in Amsterdam on March 30, 2007.

I4. The exception being the expansion pack Open for Business that has you simulating exactly the work sphere of your Sims (Maxis, 2006b).

15. For a discussion of the use and abuse of irony in computer games, see Een constante, duizelingwekkende omkering (Lauwaert \& Hendriks, 2006).

I6. This game is very much in tune with what Elliott and Lemert label 'new individualism'. With this term they want to indicate that individualism as it 'was coined by Alexis de Tocqueville in the early I $\mathrm{gth}$ century to describe an emerging sense of social isolation in American society' has undergone a crucial shift under the influence of 'globalization, new information technologies and multinational capitalism' (2006, p. 3 \& 7). They describe three changes in individualism - expansion of 'the range of personal choice and opportunity', increase in 'privatization' and a shift from individualism as an upper-class affair to a more widely available or longed for privilege - all of these very much visible and playable in The Sims games (p. 7-II).

17. Urban games commonly refer to entertainment or artistic games that take place in urban places and typically combine a screen-based game world with the 'real world'. These games strive to merge physical and virtual game worlds whereby handheld technology (GPS, digital camera, cell phones) will link players in the real world with those onscreen. Well-known examples come from the London-based group Blast Theory. This group has staged many urban games around the globe such as Can You See me Now? (200I) and Uncle Roy All Around You (2003). In contrast, serious urban games have a goal outside of the domain of entertainment.

I8. Van Heeswijk developed the first version of Face Your World in 2002 for the Wexner Centre of the Arts, Columbus, USA.

19. Research for this case study is also based on interviews with stakeholders of the Face Your World participation process. Individuals are referred to only by their first name while professional stakeholders are referred to by their first and last name and their role in the participation project. All interviews were held in Dutch and have been translated by the author. A slightly different analysis of Face Your World was published as Playing the City in The Journal of Urban Technologies (Lauwaert, 2009).

20. The specified budget for the park remains undisclosed until the park is realized.

2I. A boss fight is a type of battle in a computer game against a powerful enemy. Typically, boss fights take place at the end of a game level, and the player needs to win this battle in order to move on to the next level. Boss fights are generally difficult fights that need many retries.

22. In mashups, data from different sources is combined in one tool. A lot of user-generated mashups overlay certain data with Google Maps. For example, one user-generated mashup combines data on free museums in Paris with Google Maps (patroc.com, 2008). 


\section{Bibliography}

Addams, J. (I92I [Igog]). The Spirit of Youth and the City Streets. New York: The Macmillan Company.

Akrich, M. (1992). 'The De-Scription of Technical Objects'. In W. E. Bijker \& J. Law (Eds.), Shaping technology/building society: studies in sociotechnical change (pp. 205-224). Cambridge, Mass.: MIT Press.

Akrich, M., \& Latour, B. (I992). 'A Summary of a Convenient Vocabulary for the Semiotics of Human and Nonhuman Assemblies'. In W.E. Bijker \& J. Law (Eds.), Shaping technology/building society: studies in sociotechnical change (pp. 259-264). Cambridge, Mass.: MIT Press.

Al-Kodmany, K. (2006). 'Computer-Based Public Participation'. In E. Sendich (Ed.), Planning and urban design standards (pp. 63-64). Hoboken: John Wiley \& Sons.

Alcorn, A. (2006). 'The Modern Boy is Air-Minded': Boy Consumers and the Model Airplane League of America. Paper presented at the Society for the History Of Technology (SHOT) Annual Meeting.

Alexander, C., Ishikawa, S., \& Silverstein, M. (1977). A pattern language: towns, buildings, construction. New York: Oxford University Press.

Amsterdam, Gemeente. (200I). Richting Parkstad 2015 - ontwikkelingsplan voor de vernieuwing. Amsterdam: Gemeente Amsterdam Bureau Parkstad.

Amsterdam, Gemeente. (2007). 'Geschiedenis'. Retrieved November 24, 2008, from http:// www.slotervaart.amsterdam.nl/stadsdeel_in_beeld/geschiedenis

Amsterdam, Gemeente. (2008a). 'Bevolking stadsdeel Slotervaart naar buurten en herkomstgroepering, I januari 2008'. Kerncijfers Retrieved November 24, 2008, from http:// www.os.amsterdam.nl/tabel/9778/

Amsterdam, Gemeente. (2008b). 'Cijfers bevolkingsonderzoek'. Cijfers Leefbaarheid en Veiligheid Amsterdam Retrieved November 24, 2008, from http://buurtcijfers.eenveiligamsterdam.nl/

Amsterdam, Gemeente. (2008c). 'Kerncijfers Stadsdeel Slotervaart, 2004-2008'. Kerncijfers Retrieved November 24, 2008, from http://www.os.amsterdam.nl/tabel/8220/

Amsterdam, Gemeente. (2008d). 'Slotervaart Actueel'. Retrieved November 24, 2008, from http://www.slotervaart.amsterdam.nl/

AnnieW. (2002). 'Re: Anyone play the TSO Play-Test and decided not to buy the official game?' Retrieved August 2I, 2007, from http:/groups.google.com/group/alt.games. the-sims/browse_frm/thread/4c8gef7839II5c3o/2e32a83d93a7oc6e?q=TSO\&rnu$\mathrm{m}=94 \# 2 \mathrm{e} 32 \mathrm{a} 83 \mathrm{~d} 93 \mathrm{a} 70 \mathrm{c} 6 \mathrm{e}$

Anonymous. (1900). How Department Stores are Carried on in America: The Business Man's Publishing Company.

Anonymous. (I9I4). 'Constructional Toys of Merit'. Games \& Toys. The Leading Trade Journal, 1 (2). 
Anonymous. (I9I5). 'Transfers for the Toy Trade. Wood for the Toy Trade'. Games \& Toys. The Leading Trade Journal, 1(7).

Anonymous. (I9I9). 'Toy Industry in Germany'. Games \& Toys. The Leading Trade Journal, V (LIV).

Anonymous. (1923, March 17). 'Health Preferred'. Time.

Arendt, H. (1998 [1958]). The Human Condition. Chicago: University of Chicago Press.

Ariès, P. (I962). Centuries of childhood: a social history of family life (R. Baldick, Trans.). New York: Random House.

Arnstein, S. R. (1969). 'A Ladder of Citizen Participation'. Journal of the American Institute of Planners, 35(4), 216-224.

Arnstein, S. R. (2003). 'A Ladder of Citizen Participation'. In R. T. LeGates \& F. Stout (Eds.), The City Reader (3rd ed., pp. 244-255). London: New York: Routledge.

Auerbach, S. (1999). Toys for a Lifetime. Enhancing Childhood Through Play. New York: Byron Preiss

Barthes, R. (1993 [1957]). Mythologies. London: Vintage.

Baum, D. 'Dave's LEGO site'. Retrieved August 22, 2007, from http://www.baumfamily. org/dave/lego/index.html

Beckett, A. (1996). 'Revenge of the town planners'. The London Independent.

Beets, P., \& Sandwijk, G. v. (ca. 1865). Spelen in de vrije lucht en in de speelkamer. Leiden: Noothoven van Goor.

Bisset, K. (2006). 'Meccano in the United States'. Retrieved August I3, 2007, from http:// www.usmeccano.com/

Blast Theory. (200I). 'Can You See me Now?' Retrieved August 23, 2007, from http://www. blasttheory.co.uk/bt/work_cysmn.html

Blast Theory. (2003). 'Uncle Roy All Around You'. Retrieved August 23, 2007, from http:// www.blasttheory.co.uk/bt/work_uncleroy.html

Bogost, I. (2006). 'Disaffected!' [Computer Game]: Persuasive Games.

Bogost, I. (2007a). 'Fatworld' [Computer Game]: Persuasive Games.

Bogost, I. (2007b). Persuasive games: the expressive power of videogames. Cambridge, Mass.: MIT Press.

Bogost, I., \& Frasca, G. (2007). 'watercoolergames'. Retrieved August 2I, 2007, from http://www.watercoolergames.com/

Boon, M. (1935). 'Speeltuinen'. Rotterdam: Nijgh \& Van Ditmar.

Bowlby, R. (1985). Just Looking. Consumer culture in Dreiser, Gissing and Zola. New York, London: Methuen.

Brandweek. (2006). 'Dove Joins DIY Ad Creative Marketplace'. Retrieved September I2, 2007, from http://www.brandweek.com/bw/news/recent_display.jsp?vnu_content_i$\mathrm{d}=\mathrm{I00352226}$ I\&imw $=\mathrm{Y}$

Bray, H. (2004). 'Justice has its price in Sim world'. The Boston Globe Retrieved August I7, 2007, from http://www.boston.com/news/globe/living/articles/2004/or/I4/justice_has_its_price_in_sim_world

Brett, A., Moore, R., \& Provenzo, E. (1993). The Complete Playground Book. Syracuse: Syracuse University Press.

Broekhuizen, J. (2007). Interview (public space designer at the Slotervaart ward). 
Burns, J. (I979). Connections: ways to discover and realize community potentials. Stroudsberg; New York ; London: Dowden Hutchinson and Ross : McGraw-Hill.

Calvert, K. L. F. (1992). Children in the house: the material culture of early childhood, 1600-1900. Boston, MA: Northeastern University Press.

Captain Syrup. (2002). 'SimCity: The Syrup FAQ'. Retrieved August 23, 2007, from http:/l faqs.ign.com/articles/369/369282pr.html

Carter, R. B. (Ed.). (1883). Our Homes and How to Make them Healthy. London: Clearing House.

Cascio, J. (2004). 'The map is not the Terrain; the sim is not the City. To Know It for the First Time - Place, Environment and Ecology'. Retrieved December 15, 2006, from http://www.worldchanging.com/archives/oor622.html

Cavallo, D. (I98I). Muscles and Morals. Organized Playgrounds and Urban Reform, 1880-1920. Philadelphia: University of Pennsylvania Press.

Certeau, M. d. (I988). The practice of everyday life. Berkeley, Calif. ; London: University of California Press.

Ckought. (2002). 'Sims Online (maybe Maxis will read and rethink)'. Retrieved August 2I, 2007, from http://groups.google.com/group/alt.games.the-sims/browse_frm/thread/ 395c96e2b438r63e/3fcr44f65orb5567?q=TSO\&rnum=393\# 3 fcr $44 f_{6} 6_{50}$ Ib $_{55} 6_{7}$

Consalvo, M. (2007). Cheating: gaining advantage in videogames. Cambridge, Mass.: MIT Press.

Console Cheat Codes. 'The Sims Cheats'. Retrieved December I2, 2006, from http://www. consolecheatcodes.com/pc/thesimscheats.html

Coolidge, [pseud.]. (1873). What Katy did. A story. London: Ward Lock \& Tyler.

Coupland, D. (1996). Microserfs. London: Flamingo.

Cross, G. (I997). Kids' stuff: toys and the changing world of American childhood. Cambridge, Mass: Harvard University Press.

Dale, T. (I98I). Harrods. The Store and the Legend. London: Pan Books.

Dan, H. (I907). English shop-fronts old and new: a series of exemples by leading architects. London: Batsford.

Dargahi, N., \& Bremer, M. (I996). Spelen met SimCity 2000: Macht, Politiek en Strategie (L. Vissers, Trans. 2nd ed.). Schoonhoven: Academic Service informatica.

Davidson, R., \& Vine, S. (2007). The Great Big Glorious Book for Girls. New York, N.Y.: Viking.

Delman, T. F., Lфssing, T., \& Lykke-Olesen, A. (2007). Interview (Designers of The Harbour Game).

Donath, J. S. (1998). 'Identity and Deception in the Virtual Community'. In M. Smith \& P. Kollock (Eds.), Communities in Cyberspace (pp. 29-59). London: Routledge.

Dorst, J. v. (2007). Interview (Retired carpenter and construction toy fan).

EA.com. 'About The Sims 2'. Retrieved September 24, 2006, from http://thesims2.ea.com/ about/index_ts2.php

EA.com. 'SimCity 4 Experience'. Retrieved December 12, 2006, from http://simcity.ea.com/

EA.com. 'What is SimCity.com?' Retrieved December 15, 2006, from http://simcity.ea.com/ about/simcityweb/simcityweb.php

EA.com. (2007). 'Sim Exchange'. Retrieved August 20, 2007, from http://thesims2.ea.com/ exchange/search.php?view=new\&search=I\&asset_type=story\%22.

EA.com. (2008a). 'Must-Have Stuff for Your Sims' Home from IKEA!' Retrieved September 30, 2008, from http://thesims2.ea.com/about/sp8_order.php 
EA.com. (2008b). 'What are the details of EA-Land's Sunset?' Retrieved October I, 2008, from http://support.ea.com/cgi-bin/ea.cfg/php/enduser/std_adp.php?p_faqid=19639\#sunset

Edgeworth, M., \& Edgeworth, R. L. (I8or [I798]). Practical Education (Vol. I). London: J. Johnson.

Ekman, I. (2005, July 2-3). 'Lego braces for big changes'. International Herald Tribune, p. 9 \& II.

Elliott, A., \& Lemert, C. C. (2006). The new individualism: the emotional costs of globalization. London: Routledge.

Engelsman, H. (2007). Interview (Area Developer at housing corporation De Alliantie).

Fisher-Price. (2007). 'Smart Cycle TM Physical Learning Arcade System'. Retrieved April 26, 2007, from http://www.fisher-price.com/fp.aspx?st=5450\&e=mainproduct

Flynn, B. (2003). 'Geography of the Digital Hearth'. Information, Communication \& Society, 6 (4), $55^{\mathrm{I}-576 .}$

Frasca, G. (200I). 'The Sims: Grandmothers are cooler than trolls'. Game Studies Retrieved February 24, 2005, from http://www.gamestudies.org/

Frasca, G. (2006). 'Videogames of the Oppressed: Critical Thinking, Education, Tolerance, and Other Trivial Issues' In N. Wardrip-Fruin \& P. Harrigan (Eds.), First person: new media as story, performance, and game (pp. 85-94). Cambridge, Mass.: MIT Press.

Friedberg, A. (1993). Window Shopping. Cinema and the Postmodern. California: University of California Press.

Friedman, A. (1995). 'Model Homes and Dream Houses'. In C. Dufresne (Ed.), Dream Houses, Toy Homes (pp. 7-27). Montreal: Centre Canadien d'Architecture/Canadian Centre for Architecture.

Friedman, T. (1995). 'Making Sense of Software: Computer Games and Interactive Textuality'. In S. G. Jones (Ed.), Cybersociety: Computer-mediated communication and community (pp. 73-89): Sage Publications.

Fröbel, F. (1887). The Education of Man (W. N. Hailmann, Trans. Vol. I). New York: Appleton and Company.

Furnée, J. H. (2003). 'Winkeletalages als Moderne Massamedia. Visuele Cultuur en Sociale Verhoudingen in Den Haag, I850-I890'. De negentiende eeuw: documentatieblad Werkgroep 19e eeuw, 27(2), 74 - ro6.

Gamershell. (2002). 'Sims Online Gallery'. Retrieved October 2, 2008, from http://www. gamershell.com/pc/sims_online/screenshots.html?id=51073

Gamespot. 'SimCity 4: Deluxe Edition'. Retrieved December 15, 2006, from http://www. gamespot.com/pc/strategy/simcity4deluxeedition/hints.html

Genette, G. (1997). Paratexts: thresholds of interpretation. Cambridge: Cambridge University Press.

Gerard. (2007). Interview (Face Your World participant).

Gesell, A. L. (I906). 'The Psychology of Human Jealousy'. The American Journal of Psychology, XVII(4), 452-48o.

Gillin, J. L. (1918). Wholesome Citizens and Spare Time. Cleveland: Cleveland Foundation.

Gjols-Andersen, P. (200I). The Internal Dimensions of Branding. A Case Study of the Change on Brand Strategy in Lego from a Focus on the Famous Building Brick to Introducing a Broad Variety of Lego Products in the Children's Universe. Copenhagen Business School, Copenhagen. 
Gjфls-Andersen, P., \& Karmark, E. (2005). 'Corporate Brand Stretch - Brand Extension in a Corporate Branding Perspective'. In M. Schultz, M. A. Yun \& F. F. Csaba (Eds.), Corporate branding: purpose/people/process : towards the second wave of corporate branding (pp. I5I179). Copenhagen: Copenhagen Business School Press.

Gottmann, J. (I980). 'Preface'. In J. Gottmann (Ed.), Centre and periphery: spatial variation in politics Beverly Hills; London: Sage.

Green, P. (1899). A History of Nursery Rhymes. London: Greening.

Greenberg, J. (2006). 'Interview with Soren Lund, Lego Mindstorms and Product \& Marketing Development Director' Friends Talking Retrieved June 2I, 2007, from http://friendstalking.joelandkaren.com/?p=23

Groeneveld, S. (2007). Interview (Digitale Pioniers, Kennisland - Financial supporter Face Your World).

Grossman, L. (2006). 'Time's Person of the Year: You'. Time, 168, 28-29.

H\&M. (2007). 'H\&M IN COOPERATION WITH THE SIMS 2'. Retrieved September II, 2007, from http://www.hm.com/nl/press/pressreleases/_prfashion.nhtml?pressreleaseid $=922$

Hall, P. G. (2002). Cities of tomorrow: an intellectual history of urban planning and design in the twentieth century (3rd ed.). Oxford: Basil Blackwell.

Hall, S., \& Smith, T. (1903). 'Showing off and Bashfulness as Phases of Self-Consciousness'. The pedagogical seminary: international record of educational literature, institutions and progress, 10, I59-I99.

Hansen, J. (2007). 'Not Quite C'. Retrieved August 20, 2007, from http://bricxcc.sourceforge.net/nqcl

Hansen, O. S. (1997). Grote zakensuccessen. Godtfred Kirk Christiansen en Lego (M. C. Solleveld, Trans.). Gilze: Dahlgaard Media B.V.

Hanson, M. (1993). Minibrix - The Unique Rubber Building Toy. Henley on Thames: MW Models.

Harbers, H. (1996). 'Politiek van de technologie'. Kennis en Methode, 3, 308-315.

Hardyment, C. (1984). Dream Babies. Child Care from Locke to Spock. Oxford: Oxford University Press.

Hartoog, I. d. (2007). Interview (Face Your World project supporter).

Heeswijk, J. v. (2007). Interview (Initiator Face Your World).

Heeswijk, J. v., \& Kaspori, D. (2002-ongoing). 'Face Your World' [Public Participation Tool].

Heeswijk, J. v., Kaspori, D., \& Mosterd, R. (2005-2006). 'Face Your World 2.0 (Slotervaart)'. Retrieved September 28, 2007, from http://www.faceyourworld.nl/slotervaart

Hendricks, B. (200I). Designing for Play. Aldershot: Ashgate.

Herz, J. C. (2000, February 10). 'The Sims Who Die With the Most Toys Win'. The New Yrok Times.

Herz, J. C., \& Macedonia, M. R. (2002). 'Computer games and the military: two views'. Retrieved February I4, 2006, from http://purl.access.gpo.gov/GPO/LPS23406

Hicham. (2007). Interview (Face Your World participant).

Hippel, E. v. (2005). Democratizing innovation. Cambridge, Mass.: MIT Press.

Hjarvard, S. (2004a). Brand new toys. Paper presented at the International Colloquium 'Pluridisciplinary Perspectives on Child and Teen Consumption'. 
Hjarvard, S. (2004b). 'From Bricks to Bytes: The Mediatization of a Global Toy Industry'. In I. G. Bondeberg, Peter (Ed.), European Culture and the Media (Vol. I, pp. 43-63). Bristol: Intellect Books.

Hoeve, L. (2007). Interview (Communication advisor at the Slotervaart ward).

Hommels, A. (2005). Unbuilding cities: obduracy in urban socio-technical change. Cambridge, Mass.: MIT Press.

Hoogeveen, R. (2007). Interview (Area developer at housing corporation De Alliantie - Financial supporter Face Your World).

Howard, E. (1965). Garden Cities of To-Morrow. Cambridge, Mass.: MIT Press.

Hughes, J. (2007). 'Brick Fetish'. Retrieved June I6, 2007, from http://www.brickfetish. com/

Huhtamo, E. (2005). 'Slots of Fun, Slots of Trouble: an Archeology of Arcade Gaming'. In J. Raessens \& J. H. Goldstein (Eds.), Handbook of computer game studies (pp. 3-2I). Cambridge, Mass.: MIT Press.

Huisingh, A. (2007). Interview (Former head of Culture and Education at AFK, Amsterdam Fonds voor de Kunst - Financial supporter Face Your World).

Iggulden, C., \& Iggulden, H. (2006). The dangerous book for boys. London: HarperCollins.

Ingham, A. (1928). Gamage's Children's Annual. London: Gamage Book Department.

Jacobson, M. A. (1994). Being a boy again: autobiography and the American boy book. Tuscaloosa: University of Alabama Press.

Jenkins, H. (1992). Textual Poachers: Television Fans and Participatory Culture: New York: Routledge.

Jenkins, H. (2000). 'Complete Freedom of Movement: Video Games as Gendered Play Spaces'. In J. Cassell \& H. Jenkins (Eds.), From Barbie to Mortal Kombat gender and computer games (pp. 262-297). Cambridge, Mass.: MIT Press.

Jenkins, H. (2002). 'Interactive Audiences?' In D. Harries (Ed.), The new media book (pp. I57170). London: British Film Institute.

Jenkins, H. (2006a). Convergence Culture: Where Old and New Media Collide. New York: New York University Press.

Jenkins, H. (2006b). Fans, Bloggers, and Gamers: Exploring Participatory Culture. New York: New York University Press.

Jenkins, H. (2006c). 'From a "Must Culture" to a "Can Culture": Legos and Lead Users'. Retrieved June 2I, 2007, from http://www.henryjenkins.org/2006/Io/from_a_must_culture_to_a_can_c.html

Jenkins, H., \& Thorburn, D. (2003). 'Introduction: The Digital Revolution, the Informed Citizen, and the Culture of Democracy'. In H. Jenkins, D. Thorburn \& B. Seawell (Eds.), Democracy and new media (pp. I-17). Cambridge, Mass.: MIT Press.

Johan. 'The Sims Online Cheats - Bots, Automation Tools, and Codes'. Retrieved December I5, 2006, from http://www.mysimsonlinecheats.com/

JonhB. (2006). 'Cactus Flora Mod' [Computer Game Modification]: www.simtropolis.com.

Jorgensen, U. (I998). The LEGO brick system under reconstruction - an era of constructional toys challenged by the information age. Paper presented at the Path Creation and Dependency Conference.

Jung, J. (2003). 'SimCity FAQ Ver 0.03'. Retrieved December 15, 2006, from http://faqs.ign. com/articles/387/3879Iopr.html 
Kaspori, D. (2007). Interview (Architect on Face Your World team).

Keen, A. (2007). The Cult of the Amateur: How Today's Internet is Killing our Culture and Assaulting our Economy. London: Nicholas Brealey.

Kerstens, M. (1997). 'It's all in the game!' Rooilijn: mededelingen van het planologisch en demografisch instituut, I5-I9.

Ketelaar, I. (2007). Interview (Ward alderman Slotervaart ed.).

Key, E. (Ig09). The Century of the Child. New York: Putnam; The Knickerbocker Press.

Khadya. (2007). Interview (Face Your World participant).

Kline, S. (1993). Out of the Garden: toys, TV and children's culture in the age of marketing. London: Verso.

Kline, S., Dyer-Witheford, N., \& De Peuter, G. (2003). Digital play: the interaction of technology, culture, and marketing. Montreal: McGill-Queen's University Press.

Koerner, B. I. (2006). 'Geeks in Toyland'. Wired, 14.

Kollision. (2002). 'The Harbour Game' [Public Participation Tool]. Denmark: Projektgruppen Havnen På Spil.

LadyWolf. (2006). 'Re: Question for Research Purpose'. Retrieved September 25, 2006, from http://boards.stratics.com/php-bin/sims/showflat.php?Cat=\&Number=629976\&page $=I \& v i e w=$ collapsed $\&$ sb $=5 \& 0=\&$ fpart $=I$

Lane, A. (1998). 'The Joy of Bricks'. Retrieved January 2I, 2005, from http://www.randomhouse.com/boldtype/0802/lane/excerpt_bricks.html

Lauwaert, M. (2006). 'Get Up \& Play'. In B. Neitzel \& R. F. Nohr (Eds.), Das Spiel mit dem Medium. Partizipation - Immersion - Interaktion Zur Teilhabe an den Medien von Kunst bis Computerspiel (pp. 48-63): Schüren Presseverlag.

Lauwaert, M. (2007). 'Challenge Everything? Construction Play in Will Wright's SIMCITY'. Games and Culture, 2(3), 194-212.

Lauwaert, M. (2008). 'Playing Outside the Box - On LEGO Toys and the Changing World of Construction Play'. History and Technology, 24(3), 22I-237.

Lauwaert, M. (2009). 'Playing the City - Public Participation in a Contested Suburban Area'. The Journal of Urban Technologies r6(2).

Lauwaert, M., \& Hendriks, M. (2006). 'Een constante, duizelingwekkende omkering'. DWB, 5-6, 75I-758.

Lauwaert, M., Wachelder, J., \& Walle, J. v. d. (2004). 'Computerspellen en de Geschiedenis van Angst. Het Gebruik en Misbruik van Historische Vergelijkingen'. Tijdschrift voor Mediageschiedenis, 2, 3I-52.

Lauwaert, M., Wachelder, J., \& Walle, J. v. d. (2007). 'Frustrating Desire. On Repens and Repositio, or the Attractions and Distractions of Digital games'. Theory, Culture \& Society, 24(I), 89-Io8.

LEGO. 'Fan Designs His Own LEGO Set! The 'My Own Creation' Series'. Brick Street Journal Retrieved April, I8, 2007, from http://club.lego.com/eng/newsandfeatures/story.asp? contentid $=313$

LEGO. 'LEGO Certified Professionals'. Retrieved June 20, 2007, from http://www.lego. com/eng/info/default.asp?page=affiliates

LEGO. 'LEGO Factory Fan Designed Exclusives'. Retrieved April I8, 2007, from http:// shop.lego.com/product/Factory/Default.aspx?cn=I57

LEGO. 'LEGO Factory'. Retrieved April I8, 2007, from http://factory.lego.com/ 
LEGO. (I975). A Brick - and the story behind it: LEGO Company.

LEGO. (1979). Heden en verleden. Denmark: LEGO Company.

LEGO. (I982). 50 years of play. Billund: LEGO Group.

LEGO. (1997). Developing a Product. Billund: LEGO Group.

LEGO. (2004). 'Annual Report 2004 LEGO Group'. Retrieved August 17, 2007, from http:// www.lego.com/eng/info/default.asp?page=annualreport

LEGO. (2005). 'Annual Report 2005 LEGO Group'. Retrieved August 17, 2007, from http:// www.lego.com/eng/info/default.asp?page=annualreport

LEGO. (2006). 'Annual Report 2006 LEGO Group'. Retrieved August 17, 2007, from http:// cache.lego.com/downloads/aboutus/annualreport2006UK.pdf

LEGO. (2007a). 'Annual Report 2007 LEGO Group'. Retrieved October 18, 2008, from http://cache.lego.com/downloads/aboutus/annualreport2007UK.pdf

LEGO. (2007b). 'Legoland Discovery Centre Berlin'. Retrieved July 3I, 2007, from http:// www.legolanddiscoverycentre.com/

Lentz, W. (2007). Interview (Director of SKOR, Stichting Kunst en Openbare Ruimte Financial supporter and original commissioner of Face Your World).

Levi-Strauss, C. (I966). The savage mind (La pensee sauvage). London: Weidenfeld \& Nicolson.

Lie, M., \& S申rensen, K. H. (I996). 'Making technology our own? Domesticating technology into everyday life'. In M. Lie \& K. H. S申rensen (Eds.), Making technology our own? Domesticating technology into everyday life (pp. I-30). Oslo: Scandinavian University Press.

Lieshout, M. v., Bijker, W. E., \& Egyedi, T. M. (200I). 'Social Learning'. In M. v. Lieshout, T. M. Egyedi \& W. E. Bijker (Eds.), Social learning technologies: the introduction of multimedia in education (pp. 37-59). Aldershot: Ashgate.

Lim, K. (2006). 'Why Time Magazine's Person of the Year isn't exactly 'You'...'. Retrieved November 8, 2008, from http://theory.isthereason.com/?cat=25\&paged=8

Lindeman, E., Bicknese, L., \& Bosveld, W. (2006). 'De Amsterdamse Burgermonitor 2006'. Amsterdam: Gemeenste Amsterdam Dienst Onderzoek en Statistiek.

Linden Lab. (2003). 'Second Life' [Online computer game]. San Francisco: Linden Lab.

Lithgow, A. (1987). 'Analysis: Astonishing secret behind the world's most famous toy. The ghost that is haunting LEGO land'. Retrieved September I6, 2007, from http://www. best-lock.com/new/page.html

Lobo, D. G. (2004). 'Playing with Urban Life: How SimCity Influences Planning Culture'. Technology \& Cities(6).

Loudon, J. C., \& Loudon, J. W. ([I838] I982). The suburban gardener, and villa companion. New York: Garland Pub.

Lovink, G. (2008). Zero comments: blogging and critical Internet culture. New York: Routledge.

LuckyHawk. (2006). 'Scammers \& Me'. Retrieved September Io, 2006, from http://boards. stratics.com/php-bin/sims/showflat.php?Cat=\&Number=628202\&page=2\&view=collapsed $\& \mathrm{sb}=5 \& \mathrm{o}=\&$ fpart $=\mathrm{I}$

Ludlow, P. (2003). 'Evangeline: Interview with a child cyber-prostitute in TSO'. Retrieved November I5, 2005, from http://www.alphavilleherald.com/archives/000049.html

Ludlow, P., \& Wallace, M. (2006). Only a Game: Online Worlds and the Virtual Journalist Who Knew Too Much: O'Reilly.

Lugnet. 'MOC' Blacksmith Shop on lego.com'. Retrieved April I8, 2007, from http://news. lugnet.com/castle/?n=II209\& $\mathrm{t}=\mathrm{i} \& \mathrm{~V}=\mathrm{a}$ 
Lury, C. (2004). Brands: the logos of the global economy. London ; New York: Routledge.

Manzini, E., \& Cau, P. (1989). The material of invention. Cambridge, Mass: MIT Press.

Matt, S. J. (2002). 'Children's Envy and the Emergence of the Modern Consumer Ethic, I89o-I930'. Journal of Social History, 36(2), 283-302.

Maxis. (1989). 'SimCity Classic' [Computer Game]: Maxis.

Maxis. (1992). 'SimCity 2000' [Computer Game]: Maxis.

Maxis. (I999). 'SimCity 3000' [Computer Game]: Electronic Arts.

Maxis. (2000a). 'Livin' Large' [Computer Game Expansion Pack]: Electronic Arts.

Maxis. (200ob). 'The Sims' [Computer Game]: Electronic Arts.

Maxis. (200I). 'Hot Date' [Computer Game Expansion Pack]: Electronic Arts.

Maxis. (2002). 'The Sims Online' [Online Computer Game]: Electronic Arts.

Maxis. (2003). 'SimCity 4' [Computer Game]: Electronic Arts.

Maxis. (2004). 'The Sims 2' [Computer Game ]: Electronic Arts.

Maxis. (2006a). 'The Sims 2: Glamour Life Stuff' [Computer Game Stuff Pack]: Electronic Arts.

Maxis. (2006b). 'The Sims 2: Open for Business' [Computer Game Expansion Pack]: Electronic Arts.

Maxis. (2007). 'The Sims 2 H\&M Fashion Stuff' [Computer Game Stuff Pack]: Electronic Arts.

McAtee, C. (I997). 'The Elements of Toy Towns'. In E. Tingley (Ed.), La ville en jeux: du 22 octobre 1997 au 31 mai 1998 = Toy town: from 22 October 1997 to 31 May 1998. Montreal: Centre Canadien d'Architecture.

McClary, A. (1997). Toys with nine lives: a social history of American toys. North Haven, Connecticut: Linnet Books.

McKee, J. (2005). 'Announcing LEGO Ambassadors'. Retrieved April I8, 2007, from http:// news.lugnet.com/lego/?n=3116

Mey, T. (1999). 'Baukästen vom Biedermeier bis zur Jahrhundertwende. Das Spiel mit Holzbaukästen'. In U. Leinweber (Ed.), Baukästen. Technisches Spielzeug vom Biedermeier bis zur Jahrtausendwende. Ausstellungskatalog (Vol. 7, pp. 34-47). Wiesbaden: VMA Verlag Drei Lilien Edition.

Mike. (2002). 'I'm disappointed...' Retrieved August 17, 2007, from http://groups.google. com/group/alt.games.the-sims/browse_thread/thread/83f92730feofoo59/ 7705 b8big92eb2db?tvc $=2 \& q$

Miklaucic, S. (2003). 'God Games and Governmentality. Civilization II and Hypermediated Knowledge' In J. Z. Bratich, J. Packer \& C. McCarthy (Eds.), Foucault, cultural studies and governmentality (pp. 317-335). Albany: State University of New York Press.

Molleindustria. (2006). 'McDonald's Videogame' [Computer Game]: Molleindustria.

Mumford, L. (I96I). The city in history: its origins, its transformations, and its prospects ([Ist ed.). New York,: Harcourt Brace \& World.

Nasaw, D. (1985). Children of the city: at work and at play (Ist ed.). Garden City, N.Y.: Anchor Press/Doubleday.

Nintendo. (2007). 'Wii'. Retrieved August 21, 2007, from http://wii.nintendo.com/

Oudshoorn, N., \& Pinch, T. J. (2003). 'Introduction: How Users and Non-Users Matter'. In N. Oudshoorn \& T. J. Pinch (Eds.), How users matter: the co-construction of users and technologies (pp. I-25). Cambridge, Mass.: MIT Press. 
Page, H. (1938). Playtime in the first five years. Croydon: Surrey, Watson \& Crossland.

Pandora Sims. 'Pandora Sims'. Retrieved August 20, 2007, from http://www.pandorasims. net/

Papert, S. (I99I). 'Situating Constructionism'. In S. Papert \& I. Harel (Eds.), Constructionism. Research Reports and Essays, 1985-1990 by the Epistemology \& Learning Research Group (pp. III). New Jersey: Ablex Publishing Corporation.

Papert, S. (1993). Mindstorms: children, computers, and powerful ideas (2nd ed.). New York: Basic Books.

Patroc.com. (2008). 'Museums in Paris with Free Admission'. Retrieved November 24, 2008, from http://www.patroc.com/paris/map_museums.html

Paulk, C. (2006). 'Signifying Play: The Sims and the Sociology of Interior Design'. Game Studies: the international journal of computer game research, 6(I).

Pearce, C. (2002). 'Story as Play Space'. In L. King (Ed.), Game on: the history and culture of videogames (pp. II2-IIg). London: Laurence King Pub.

Pearce, C. (2004). 'Towards a Game Theory of Game'. In N. Wardrip-Fruin \& P. Harrigan (Eds.), First person: new media as story, performance, and game (pp. I43-153). Cambridge, Mass.: MIT Press.

PenguinWiki. (2007). 'A Million Penguins'. Retrieved September 12, 2007, from http:// www.amillionpenguins.com/wiki/index.php/About

PICO. (2006). 'PICO Cricket Kit'. Retrieved January I8, 2006, from http://www.playfulinvention.com

Pollock, L. A. (I983). Forgotten children: parent-child relations from 1500 to 1900. Cambridge: Cambridge University Press.

QueenFerny. (2006). 'Re: Question for Research Purpose'. Retrieved September 25, 2006, from http://boards.stratics.com/php-bin/sims/showflat.php?Cat=\&Number=629976\&page $=\mathrm{I} \&$ view $=$ collapsed $\& \mathrm{sb}=5 \& \mathrm{o}=\& \mathrm{fpart}=\mathrm{I}$

Raessens, J. (2005). 'Computer Games as Participatory Media Culture'. In J. Raessens \& J. H. Goldstein (Eds.), Handbook of computer game studies (pp. 373-389). Cambridge, Mass.: MIT Press.

Richtel, M., \& Stone, B. (2007, June 6). 'Doll Web Sites Drive Girls to Stay Home and Play'. The New York Times

Rideout, V.J., \& Hamel, E. (2006). 'The Media Family: Electronic Media in the Lives of Infants, Toddlers, Preschoolers and their Parents'. Retrieved August 17, 2007, from http://www.kff.org/entmedia/upload/7500.pdf

Rideout, V.J., Vandewater, E. A., \& Wartella, E. A. (2003). 'Zero to Six. Electronic Media in the Lives of Infants, Toddlers and Preschoolers'. Retrieved August 17, 2007, from http:// www.kff.org/entmedia/upload/Zero-to-Six-Electronic-Media-in-the-Lives-of-InfantsToddlers-and-Preschoolers-PDF.pdf

Riffel, R. J. (2008). 'Revelstoke'. Retrieved October 2, 2008, from http://www.simtropolis. $\mathrm{com} /$ forum/messageview.cfm?catid $=36 \&$ threadid=I00755\&STARTPAGE $=\mathrm{I}$

Riis, J. A. (I894). 'Playgrounds for City Schools'. The Century (48).

Roberts, D. F., Foehr, U. G., \& Rideout, V. J. (2005). 'Generation M: Media in the Lives of 8-I8 Year-olds'. Retrieved August 17, 2007, from http://www.kff.org/entmedia/725I.cfm 
Roberts, D. F., Foehr, U. G., Rideout, V. J., \& Brodie, M. (I999). 'Kids \& Media @ the New Millennium'. Retrieved August 17, 2007, from http://www.kff.org/entmedia/loader.cfm? url=/commonspot/security/getfile.cfm\&PageID $=13267$

Rosenzweig, R., \& Blackmar, E. (I992). The park and the people: a history of Central Park. Ithaca, N.Y.: Cornell University Press.

Rowe, G., \& Frewer, L. J. (2004). 'Evaluating Public-Participation Exercises: A Research Agenda'. Science, technology, \& human values, 29(4), 512-557.

Rybczynski, W. (1995). City life: urban expectations in a new world. New York; London: Scribner.

Salen, K., \& Zimmerman, E. (2004). Rules of play: game design fundamentals. Cambridge, Mass.: MIT Press.

Salmon, E. G. (I886). 'What Girls Read'. Nineteenth Century, 20, 515-529.

Sanoff, H. (I988). 'Participatory Design in Focus'. Arch. \& Comport. / Arch. Behav., 4(I), 2742.

Schiesel, S. (2006). 'Welcome to the New Dollhouse'. Retrieved May 7, 2006, from http:/l www.nytimes.com/2006/05/07/arts/o7schi.html?ei=5088\&en=68a3d7baf996ora$\mathrm{d} \& \mathrm{ex}=\mathrm{I} 304654400 \& \mathrm{adxnnl}=\mathrm{I} \&$ partner $=$ rssnyt\&emc=rss\&pagewanted=print\&adxnnlx=II49591792-dBs5fP7ryNfR7dMlPoGb+Q

Schleiner, A.-M. (2002). 'Velvet-Strike: War Times and Reality Games'. Retrieved November 7, 2008, from http://www.opensorcery.net/velvet-strike/about.html

Schmiedeler, E. (1927). The industrial revolution and the home: a comparative study of family life in country, town and city (PhD Thesis). Washington: Washington Catholic University of America.

Schönberg, E. (1908). Wat kan en moet de winkelier van het warenhuis leeren? Rotterdam: W.L. \& J. Brusse.

Schrijver, J. (1907). 'Van Kinderen en Speelgoed'. De Vriend des Huizes. Tijdschrift voor het Huisgezin, IIg-I24.

Segel, E. (1986). 'As the Twig Is Bent...' In E. Flynn \& P. Schweickart (Eds.), Gender and reading: essays on readers, texts, and contexts. Baltimore: Johns Hopkins University Press.

Selten, P., Adriaanse, C., \& Becker, B. (I996). Af en toe met pa en moe... : de speeltuinbeweging in Nederland 1900-1995. Utrecht: De Tijdstroom.

Shakeshaft, A. (2008). 'Shakeshaft's Blog'. Retrieved October I, 2008, from http://www. thesimsresource.com/artists/Shakeshaft/blog/

Shiny Entertainment. (2003). 'Enter the Matrix': Atari/Warner Brothers Interactive.

Silverstone, R., \& Haddon, L. (1996). 'Design and the Domestication of Information and Communication Technologies: Technical Change and Everyday Life'. In R. E. Mansell \& R. Silverstone (Eds.), Communication by design: the politics of communication and information technologies (pp. 44-74). Oxford: Oxford University Press.

Silverstone, R., \& Hirsch, E. (I992). 'Introduction'. In R. Silverstone \& E. Hirsch (Eds.), Consuming technologies: media and information in domestic spaces (pp. xiii, 24I). New York: Routledge.

Simmons, D. (2007). 'Re: Its starting to happen...' Retrieved April 25, 2007, from http:// news.lugnet.com/color $/$ n $=\mathrm{I} 333 \& \mathrm{t}=\mathrm{i} \& \mathrm{v}=\mathrm{a}$ 
Simonsen, C. (2006). 'LEGO Press Release'. Retrieved June 20, 2007, from http://www. lego.com/eng/info/default.asp?page=pressdetail\&contentid=21555\&countrycode $=2057$ \&yearcode $=2006 \&$ archive $=$ true

Singer, D. (2005). 'Personal Communication'.

Siskind, D. (2000-ongoing). 'Brickmania'. Retrieved April 18, 2007, from www.brickmania. com

Smallbone, F., \& Hanson, M. (2007). 'Minibrix'. Retrieved September I8, 2007, from http:// www.minibrix.com/

Smith, D. B. (I980). Inside the great house: planter family life in eighteenth-century Chesapeake Society. Ithaca, N.Y.: Cornell University Press.

SmokeD. (2006). 'Funny Events?' Retrieved June 15, 2006, from http://groups.google.com/ group/alt.games.the-sims-2/browse_frm/thread/c550775c892505aa/coba49adoada2933? Ink=gst\&q=funny\&rnum=2\# coba49adoada2933

Snyder, D. (2004). 'Playroom'. In B. Colomina, A. Brennan \& J. Kim (Eds.), Cold war hothouses: inventing postwar culture, from cockpit to playboy (pp. I24-I42). New York, NY: Princeton Architectural Press.

Sony. (2005). 'EyeToy'. Retrieved August 2I, 2007, from http://www.eyetoy.com/

Squeegee. (2003). 'Something Fishy TSO Comes Part II'. Retrieved August 2I, 2007, from http://groups.google.com/group/alt.games.the-sims/browse_frm/thread/ cce63ed539oc9ood/4Idddi2ac5ea6b3c?q=TSO\&rnum=4\#4Idddi2ac5ea6b3c

Starr, P. (1994). 'Seductions of Sim. Policy as a Simulation Game'. The American Prospect, 17, I9-29.

Steele, J. (2006). 'Re: Question for Research Purpose'. Retrieved September 25, 2006, from http://boards.stratics.com/php-bin/sims/showflat.php?Cat=\&Number=629976\&page $=\mathrm{I} \&$ view $=$ collapsed $\& \mathrm{sb}=5 \& \mathrm{o}=\& \mathrm{fpart}=\mathrm{I}$

Steen, F., Greenfield, P., Davies, M. S., \& Tynes, B. (2006). 'What Went Wrong With The Sims Online: Cultural Learning and Barriers to Identification in a Massively Multiplayer Online Role-Playing Game' In P. Vorderer \& J. Bryant (Eds.), Playing video games: motives, responses, and consequences (pp. 307-323). Mahwah, N.J.: Lawrence Erlbaum Associates.

Stephens, C. (2005). 'Marking the difference in Lego ${ }^{\text {TM }}$ parts'. Retrieved September I6, 2007, from http://isodomos.com/

Stevenson, R. L. (I883). Treasure Island. London: Cassell \& Co.

Stewart, S. (1993). On longing: narratives of the miniature, the gigantic, the souvenir, the collection. Baltimore ; London: Johns Hopkins University Press.

Sticht, W. (2002-ongoing). 'Walther's STABIL Metallbaukästen'. Retrieved May 9, 2007, from http://home.arcor.de/stabil_baukasten_modelle/walther/sinhalt.html

Stratics. (2003). 'The Sims Online Stratics. Community Corner. Image Gallery'. Retrieved July 5, 2007, from http://sims.stratics.com/content/gallery/sod/archives.php

Stratics. (2006). 'Poll Archive'. Retrieved July 5, 2007, from http://sims.stratics.com/content/community/pollarchive.php

Sumner, W. G. (I877). 'What Our Boys Are Reading'. Scribner's Monthly: an Illustrated Magazine for the People, 15, 68I-685.

Sutton-Smith, B. (I986). Toys as culture. New York: Gardner Press.

Tapscott, D., \& Williams, A. D. (2007). Wikinomics: how mass collaboration changes everything. New York: Portfolio. 
There Inc. (2003). 'There' [Online computer game]. Silicon Valley, CA: Makena Technologies.

Thurston, H. W. (1918). Delinquency and Spare Time. Cleveland: Cleveland Foundation.

Trease, G. (1975). 'The Revolution in Children's Literature'. In E. Blishen (Ed.), The thorny paradise: writers on writing for children. Harmondsworth: Kestrel Books.

Turkle, S. (1996). Life on the screen: identity in the age of the Internet. London: Weidenfeld \& Nicolson.

Walters, W. (2004). 'Color change: Let's go straight to the CEO!' Retrieved April 25, 2007, from http://news.lugnet.com/color/?n=625

White, B. D. (2007). 'Its starting to happen...' Retrieved April 25, 2007, from http://news. lugnet.com/color $/ ? \mathrm{n}=\mathrm{I} 333 \& \mathrm{t}=\mathrm{i} \& \mathrm{v}=\mathrm{a}$

Whitehead, I. (2000). 'Will Wright wants you to rule your own urban empire'. Architectural Record, 188, 246.

Wiedemann, E. (August 2, 2007 ). 'The End of Tolerance in Amsterdam'. New York Times.

Wien, H. (2007). Interview (Project leader at the Slotervaart ward - Financial supporter Face Your World).

Wiencek, H. (I987). The World of LEGO Toys. New York: Abrams.

Williams, R. H. (I99I). Dream worlds: mass consumption in late nineteenth-century France. Berkeley: University of California Press.

Woodcock, B. S. (2005). 'MMOG Active Subscriptions 21.0. Subscribers: O - I20,000'. Retrieved August 24, 2007, from http://www.mmogchart.com/

Wright, W. (2005a). The Future of Content. Paper presented at the Game Developers Conference Europe. Retrieved December 15, 2006, from http://www.gdceurope.com/.

Wright, W. (2005b). Time and simulation. Paper presented at the When 2.0: Time and Timing Conference. Retrieved December 15, 2006, from http://www.releaser-o.com/events/ When 2 index.php.

Wuyts, T. (I999). 'SIMCITY 3000 - Guide (version I.II)'. Retrieved December 15, 2006, from http://www.the-spoiler.com/STRATEGY/Maxis/simcity3000.2.html

Wyatt, S. (2003). 'Non-Users Also Matter: The Construction of Users and Non-Users of the Internet'. In N. Oudshoorn \& T. J. Pinch (Eds.), How users matter: the co-construction of users and technologies (pp. 67-79). Cambridge, Mass.: MIT Press.

XMAT. (2007). 'Introducing the all new GamerCycleTM fitness system!!!' Retrieved April 26, 2007, from http://www.gamercycle.com/

YouTube. (2006). 'RE: A Message From Chad and Steve'. Retrieved October II, 2007, from http://www.youtube.com/video_response_view_all?v=QCVxQ_3Ejkg

Zola, É. (I883). Au bonheur des dames. Paris: G. Charpentier. 



\section{Index}

A

actors I5-I6, I8, 66, 69, 9I, I03, II2, I22, I33

adaptation (by users) I8, 64, 76, 9I, II4

amateur 9

Americanization 37,57, I28

anarchy (of players) 73, IOI, I24

antidiscipline I9, 73, I33-I34

antidiscourse $92, \mathrm{I} 34$

antiprogram 73, I05, I34

appropriation I6-I9, 57, 63-64, 67,

73, 76-77, 9I-94, 99, I0I, I03-105,

I24, I30-I3I, I34

centrifugal appropriation I6, I8-

I9, 43, 64, 69, 76, 78, 99, IоI, I04, II8

centripetal appropriation I6, I8-

I9, 43, 64-65, 67-69, 76-78, 89-

9I, 99, IOI, I03-I05, II4

reappropriation 19,73

architect Io, 30, 39, 58, 80, I08, II2

architecture 49, 80, II4

authorship 94, I04

\section{B}

beta testers $64,75,94-95,99$-IOI

beta testing Ioo

black box 9, 8I, I00, II8, I25, I32, I35

blog 8-9, I0, I32

blogging 8-9, I32-I33

boss fight $122,{ }_{13} 8$

boundary blurring (between core and

periphery) I3I, I33 boundary blurring (between player and company) 69, I04, I26, I30, I33-I34

boundary crossing (between core and periphery) I03

brand II, I5, 58-6I, 65-68, 7I, 9I, 94, IOI, I04, I07, I23-I24, I3I-I33, I37

The Sims brand 89, I04

Brand Asset Valuator (BAV) 58-59

brand design 104

brand extension 58-6r, 66

brand image 6o, 7I, I24

brand strength 67,133

brand universe II, I3O

branded 65-66

healthy brand $\mathrm{I} 33$

LEGO brand 58-59

the Sims brand I04

bricolage I9, 73

bricoleur $\mathrm{I} 8$

building toys $34,46-47$, I29

building blocks $34,46-47,53,57$, 72

building kits 46

building sets $39,47-48$

Kapla I4, 138

wooden blocks I29

C

can culture 68, I24, I26, I3I, I46

capitalism

capitalist principles $\quad$ I28

circuit of capital 9 , IOI

hyper capitalism 87

late-capitalism 22

chatsites I37 
chatting $42,74,83,97$, II5-II6, I32I33

cheating I4, I6, I8, 8I-82, 96, IOII03, I37

cheats $74,8 \mathrm{I}-82,92$, IOI-IO2

cheating bots I4, I6, I8, 95-96, IOI-IO3

exploits 8I, 97-98, IoI

child culture 22-23

code (software, program, game) $6_{3}$, 72, 82, 89, 94-95, 98, І0о-Iог, I29

coded 72-73, 8I-82, 98, I03, I29

commodification I2, 2I-22, 26, 39-

4I, 45-46, 69, 86, 89, 94, I25, I27,

I29, I3I, I33

commodified Io, 64, 69, 7I, 77,

89-9o, 93, I04, I23, I25, I3I,

I33

commodities 40, I28, I33

computer games 8 , II, I3-I4, 2I, 4I-

$42,60,64,7 I, 73,8 I-82,85-86$, 9I-

93, І03, I05, І07, II6, I23, І29-Ізо,

I32, I34, I37-I3 8

digital toys 2I, 72, 103

configuring the user I3, I6, 64, 87

co-configuring the user 64, I05,

II4

reconfiguring the user 67, I0 5

construction play $49,58-6$ I, 83,88 ,

92, 98, I 29

construction toys $40,45-49,56,5^{8-}$

$59,6 \mathrm{I}-62,72, \mathrm{I} 24, \mathrm{I} 29$

Bild-O-Brik 52

construction sets $40,47-49,56$,

$$
\text { 6o, } 129
$$

digital construction toys 72, I29

Erector Sets 47

Kiddicraft $\quad 5^{\mathrm{I}-52}$

Lincoln Logs 47

Meccano I4, 30, 47-48, 6o

Minibrix 52

Stabila 49,5 I constructionism 62

consumer culture $22,39,60,71,87$, I 28

consumerist ideology $8 \mathrm{I}, 87$, I28

consumerist society $39, \mathrm{I} 27$

consumerism 22, 28-29, 39, 45, 57,

86-87, I28-I29

consumers 8-II, I9-20, 29-30, 39, 52, $58,60-6$ I, 63, 65, 68-69, 7I, 73, 86-

87,91, I00, I04, I07, I25-I26, I28,

I30-I34

customers 26, I03, I30

passive consumers II, I8-I9

consumption $9,22,28,4 \mathrm{I}, 45,63$,

$68,79,87$, I25, I27-I29

over-consumption 87

core/periphery model of differentia-

tion I2, 57, 69, 74, 98, IOI, I30

Counter Strike I33-I34

crowdsourcing Io

D

democratization 9,68, I26, I32

democracy I2I, I26, I33

department stores $26-30,45,128$

design 7-8, I2-I6, I8-I9, 23, 3І, 34, $3^{8-4 I}, 45-48,5 \mathrm{I}-53,56-60,62-63$, $65,67-68,7 \mathrm{I}-74,76-78,80-84,86-$ 87, 89-92, 96, 98--100, I02-I05, I07Io8, IIO-I20, I22-I26, I28-I29, I33I34, I37

designing $7,15,46-48,53,60-61$, 72, 94, 98, II3-II6, I23-I24, I26 designer 8, I3, I8-I9, 68, 80, 90, 92, I00, I04-I05, I24, I34

co-designers 8, I8, 68, 7I, 93, I05, I25, I28, I30, I33

digital technologies $42,46,64, \mathrm{I} 29$, I3I

digitalization $8,64,74,8$ I, I03

digitalized 74, 78, I03, II4, I3I 
discourse (on toy, computer game) I2-I4, I6, I8-I9, 27, 56, 59-6I, 69, 78-79, 8I, 83-84, 88, 9I, 93, 99, IOI, I03, I05, I22-I23, I34

discussion boards $16,78,90$ divide (digital, generational, playstyle, gender) 39,82 , IOI, IO3, II 8 , I2I dollhouse $72,84,87-88,98$ dolls 23, 28, 34, 39, 72, 87-88

Barbie 88

domestication I2, I7, 2I-22, 24, 26, $32,35,38-42,45,58,7 \mathrm{I}, 84,86$, 88 , I27-I 29

domesticated I9, 4I, 85-86, I25, I27-I 28

high chairs $33-34$

household 23, 30, 34, 39, 4I, 7I, $83-84,86-87$ over-domestication $4 \mathrm{I}-42$

\section{E}

education 22-23, 30, 33, 36-38, 40, I24, I32

egalitarian $9, \mathrm{I} 32$

elite (in terms of access and activities)

$52,64,68,74$, I04

empowerment 9, 80-8I, I2I, I26, I32-

I33

end-user knowledge 9, I32

engineer (play) I4, 39, 57, 60, 89, I29

expansion pack 4I, 84, 90, 138

expansion-pack economy $\quad$ I2 8

expert knowledge 9, I32

expert $9,63,132, I_{3} 8$

\section{$\mathbf{F}$}

fan culture 63,67

fans 8-II, I5-I6, 48, 59, 62-68, 75,

88-90, 100, I04-105, I07, I23, I3I

fansites $67,77,90,105,137$

female gamers $7 \mathrm{I}$

forums 65,78
Fröbel 46, 48

G

game console $42-43,86$

game content 89

game studies 2I

game world 74, 76-77, 95, 97, I03, II 8, I 38

gameplay I4, 74, 83, 86, 91, 94-95

gamers $71,76,92$

gaming I4, 2I, 42-43, 71, 73, 82, 86,

94, II7-II8, I37

garden city 36, I07-IIO

geography of play I2-I4, I6, I8-I9, 66-67, 69, 74, 76, 94, I0I, I04-105, I22-I23, I25, I30-I3I, I33-I34

core (of the geography of play) I2I6, I8-I9, 57-6I, 64, 66-69, 72, 74, 76-78, 82-83, 88-94, 98-105, I07, II4, II 8 , I22-I25, I30-I3I

geography of SimCity play 74 geography of The Sims Online play IOI, I05

geography of The Sims play 92 geography of digital play 69,72 , 74, I05, I30-I3I geography of LEGO play I5-I6, 57, 6o-6I, 64, 68-69, 7I geography of Serious play I23I25, I3I

many-to-many geography 67,69 , I3O-I3I

non-digital geography of play $13 \mathrm{I}$ one-to-many geography 67,69 , I30

periphery (of the geography of play) I2-I4, I6-I9, 64, 66-69, 74, 76-78, 89-94, 99, I0I-I05, I07, II4, I23-I25, I3O-I3I, I33

Google I33

Google Maps I38 


\section{$\mathrm{H}$}

H\&M $\quad 84,87$

hackers 64,82

hacking $63-64,68,124$

hand-held gaming devices $\quad 42-43$

cell phone $58, \mathrm{I} 28$

Game Boy I28

\section{I}

IKEA 7I, 86, 93

indoor toys $33-34,39-40,57$, I28-I29

indoors entertainment 42

indoors play $35,4 \mathrm{I}, \mathrm{I} 29$

Industrial Revolution $23,36,40,58$, I28-I29

Innocent Child I4-I5, 22, 28, 39, 9I, I27

interlocking mechanism (of construction toys) $47,52-53,56,129$

Internet 8-10, 22, 4I-43, 65, 69, 7I,

74, 88, 95, I0I, I03, I22, I30-I32

Invention of Childhood 23

J

jammers 63, 93, IOI, I33

K

KGOY (Kids Growing Older Younger) 58,68

Kindergarten 46,137

$\mathbf{L}$

la perruque I9, 69, I24

lead users 63-65, 68, I05, II9, I25

lead players $82-83$

LEGO 65,138

Clikits 60

Creator 6I

Digital Designer 6r

Harry Potter 6o, 84

LEGO Ambassadors Program 65, 68
LEGO Automatic Binding Bricks $50,52-53,56$

LEGO bricks 7, 53, 56-57, 62, 66, I28

LEGO Certified Professionals Program 65

LEGO communities 65

LEGO Company 7-8, I0, 15, 50$53,56-69$, I04, I28, I3I, I37

LEGO designers 8

LEGO employees 59,67

LEGO Factory 8, Io, 6I, 65

LEGO fans 7-8, I6, 63, 65, I04

LEGO game 92

LEGO Master Builders 7

LEGO pieces 7,57

LEGO products $59-62,65-66$, I 37

LEGO sets 7-8, I6, 56-59, 6I, I28

LEGO System of Play 56-57, 6r, 66

LEGO toys 52-53, 56-6o, 66, 77, 84, I04, I28-130

LEGO website 7-8

Mindstorms 2.0 62-63

Mindstorms NXT 62, 65, 68

Star Wars 84

LinkedIn $\quad$ I32

ludic 94, II7, I23-I25, I3I

lurking 33, 42, 68, 90, I37

M

making do I2, I9, 73, I33-I34

male gamers $7 \mathrm{I}$

male gaming market 72

masculine game $7 \mathrm{I}$

manuals (for play) $7,12,57,64,78$ -

$79,82-83$

many-to-many 8-Io

by us for us I4, 67, I23, I33

many-to-many activities I8, 69, 7I, I 22

many-to-many approach 8-10, I25-I26, I3I, I33 
many-to-many communities 64 ,

$67-68, \mathrm{I} 23$

many-to-many culture 64, 67-69,

76,90, IOI, I05, I23, I25, I32-

I33

many-to-many industry 105

many-to-many model 8 , IO-I2, I9-

22, 67, 69, 72, I05, I07, I24-

I25, I27, I30, I32-I33

many-to-many paradigm $9, \mathrm{I} 4,62$,

68, I23, I32-I33

many-to-many phenomenon II, I32

many-to-many practices of play 77

many-to-many template 107

marketing I0, 39, 65, 91, I25, I28, I33

mashup I34, I39

MOC (My Own Creation) 7, 9, I4-I6, $63,68,104$

modernism 80

mods (modifications) 75-76, 100

modular (toy or game) 57, 6I, 8I, 89

must culture 68, 105

MySpace 132

\section{N}

narrative 59-6I, 83-84, 87-89, 92, 9798

netiquette 137

new media $4 \mathrm{I}-42,60,69,8 \mathrm{I}-82$, I25,

I3O-I3I

New Urbanism 80-8I

non-digital toys 20-2I, 34, 72, 86,

I03, I29

non-participants I2I, I37

non-users I6, 7I, I2I-I22, I32-I33

obduracy (technological artefacts, cities) 120,125

off-the-couch-games 4I one-to-many 8 , Io, I9, 66-67

one-to-many approach 8

one-to-many paradigm 8,105

one-to-one Io one-to-one paradigm 8

online communities 68, 95

online games 94, 102

MMOG 94

MMORPG IOO

online gaming 94

open source Io, 64, 76

outdoors play $35-38,40,58$

$\mathbf{P}$

participation $8,63,92$

participatory cultures 8-II, 65, 69,

I30, I32

participatory games II6

participatory tools II3, II7, I2I

pastoral 22, 24, 36, 79

patch 75-76, 90-93, 100, 103

pedagogy 22, 46

personal computer $42-43,58,76,86$ plastic $46-47,50-53,57-58,66$, I28I29

plastic molding machine $50,53,56$ playability 92

players 8 , I4-I6, I8, 2I, 42-43, 58, 63$64,66-67,69,71-78,80-83,85-92$,

94-I05, IO9, II4-II6, II8, I22-I25,

I27-I28, I30-I3I, I33-I34, I38

playground 24, 27, 36-4I, 66, 69, 78, 86, III, I28

playworlds $8 \mathrm{I}$

poachers I9, 63-64, 73, 93, IOI, I33-

I34

policy-making I07, I25-126, I32

politics of search engines 9

postwar 22, 3I, 46, 58, 86, I09, I28-

I29

power 52, 56, 67, 80, 82-83, 94, 98,

IOI, I05, III, II7, I24, I26, I30, I33 
practices of play $13,72,74,78,84$, $87,92,96$, IOI, I05, I24, I30, I32 digital practices of play 73

divergent practices of play $\mathrm{I} 2-\mathrm{I} 3$, I5, I8, 6I, 67-69, 74-75, 89, 9I94, 99, I03-105, I23-I24, I30 facilitated practices of play $\mathrm{I} 2-\mathrm{I} 3$,

69, 73, 8I, 94, I02

LEGO practices of play $56-57,6 \mathrm{I}$, $67-68$, 104, I3I unwanted practices of play I4-I6, $77,82,91$, IOI-IO4 wanted practices of play I4-I6, 94 private home 22, 30, 39-40, 43, 57$58,69,84-86,98$, г2 8

private room 30, 33, 4I-42, 69 bedroom $3 \mathrm{I}-32,42-43,86$ nursery 24, 3I-32, 34-35 playroom $3 \mathrm{I}-32,34,42,45,58$ procedural (play, rhetorics) $72,8 \mathrm{I}$, 92, I03, I07, I29-I3O producers 8, II, I5, I9-20, 63, 68-69, 89 , I00, I04, I26, I28, I30-I3I, I33I34

co-producers I8, 68, I25, I28, I30 product differentiation $59-6 \mathrm{I}$ prosumers 8,133 public participation I07, IIO-II4, II7, II9-I 25

\section{$\mathbf{R}$}

Realpolitik 79, 8I reform movement $24,36-38$ role-playing 59-6o, 84 rules (of a game, of playing) $\mathrm{I} 2-\mathrm{I} 3$, I6, 2I, 38, 72, 78, 80-83, 95, I02I03, II3, I22, I29, I37

rural $23,35,79,8 \mathrm{I}$

\section{$\mathbf{S}$}

scripts I3, I6, I8, 57, 64, 67, 7I, 76, 8o-82, 87, 9I, 93, 99, I03, I05, II 8
Serious Games I07, I22, I3I-I32

Serious Urban Games II2, II7, I22I25, I3O, I38

Face Your World I07-108, IIO-III, II3-II7, II9-I2I, I23-I26, I29, I3 8

The Harbour Game II2

SimCity 7I-74, 76, 78-83, 88, 92, 9596, I02-I04, II7, I28, I37

simulation $73,79,8 \mathrm{I}-83,88$, II7-II8, I29, I3I

simulation games $73,83,129$

social media II

social technologies II

software $8,60,62-64,74,76,82-83$, IOO-IOI, I03, I05, I07, II4, II7, I22, I32

stakeholders Iо, 62, 67, 69, I04, I07, IIO, II3, I24-I26, I30-I33

suburb 3I, 58, 80, 84 suburban 22, 3I, 58, 83, 85, 87, 9I, I28

suburbanites 3I

suburbanization 35

symbiotic relationship (between

player, product and company) 96 , IOO, I03-IO4, I07, I30-I3I

T

tagging 8,132

technological artifacts 86, 9I, 105, I22, 127

technological innovations 2I-22, 57, $67,86, \mathrm{I} 27, \mathrm{I} 29$

technological skills and know-how 9, $68,74,132$ technologization 8 television Io, I9, 4I-43, 60, 86, 88 The Sims 72, 78, 80-81, 83-84, 86-94, 97-98, I0I-I05, I07, I23, I28-I3I, I38 
The Sims Online I6, I8, 7I-72, 78, 94I05

toy homes $72,84,88$

toy towns $78-79,8 \mathrm{I}, 84, \mathrm{I} 24$

toy villages $72,78-79,84$

trolling $77-78$

tyranny of the algorithm 8I, 92, IoI, I3 8

\section{U}

urban areas $23-24,35,38$, I25

urban planner 73 , 108

urban planning 7I, 79-8I, I07, III-

II4, II7, I2I-I22, I24-I 25

urban redevelopment $\quad$ 26

gentrification 8I

unbuilding cities $\mathrm{I} 2 \mathrm{O}$

urban renewal Iog-IIO, II2, I25-I26

urbanization I2, 2I, 26, 3I, 39-4I, 45,

I27, I29

user communities $\mathrm{I5}, 65,68,7 \mathrm{I}, 77$,

82, 90-9I, 94, IOO-IOI, I23-I 24

user groups $67,77-78,88,95$, Ioo

User-Generated Content 8 , Io-II, 63-

64, 74-78, 80-8I, 83, 89, 9I, 95, 97,

IOI, I04-I05, I22, I3I, I33-I34

users 7-I0, I3, I6-20, 22, 40, 6I-68,

7I, 74, 76, 78, 9I, 94-95, I03-I05,
II7, II9, I2I-I22, I24, I26-I27, I32-

I34

user-driven Io, 65, 67-68, 89, 92, I04-I05, I26, I3I

user-driven innovation 65, 67-68, 89,93, ro4

user-involvement I0, I05, I32

user-to-user assistance I33

utopian 9, 36, Io8, I32

V

Velvet-Strike I33-I34

virtual world 2I, 95

W

walkthrough $75,80,82-83$

walled gardens 9, I 32

Web 2.08

Wiki 8-ıo, I32

Will Wright $7 \mathrm{I}-72,74,76-77,80-8 \mathrm{I}$, 84, 91, 94, I00, I05, I30, I38

wooden toys 50,52

Y

YouTube I32-I33 